\title{
Chapter 10. The Calibration and Characterization of Earth Remote Sensing and Environmental Monitoring Instruments
}

James J. Butler

NASA's Goddard Space Flight Center, Greenbelt, MD USA

\author{
B. Carol Johnson \\ National Institute of Standards and Technology, Gaithersburg, MD USA
}

Robert A. Barnes

Science Applications International Corporation, Beltsville, MD USA

\subsection{Introduction}

\subsubsection{The Use of Satellite Instruments in Earth Remote Sensing and Environmental Monitoring}

The use of remote sensing instruments on orbiting satellite platforms in the study of Earth Science and environmental monitoring was officially inaugurated with the April 1, 1960 launch of the Television Infrared Observation Satellite (TIROS) [1]. The first TIROS accommodated two television cameras and operated for only 78 days. However, the TIROS program, in providing in excess of 22,000 pictures of the Earth, achieved its primary goal of providing Earth images from a satellite platform to aid in identifying and monitoring meteorological processes. This marked the beginning of what is now over four decades of Earth observations from satellite platforms.

Satellite-based Earth remote sensing can be defined as the measurement of reflected and emitted radiation from the Earth using instruments on satellite platforms. These measurements are input to climate models, and the model results are analyzed in an effort to detect short and long-term changes and trends in the Earth's climate and environment, to identify the cause of those changes, and to predict or influence future changes. Examples of short-term climate change events include the periodic appearance of the El Nino-Southern Oscillation (ENSO) in the tropical Pacific Ocean [2] and the spectacular eruption of Mount Pinatubo on the Philippine island of Luzon in 1991. Examples of long term climate change events, which are more subtle to detect, include the destruction of coral reefs, the disappearance of glaciers, and global warming. Climatic variability can be both large and small scale and can be caused by natural or anthropogenic processes. The periodic El Nino event is an example of a natural process which induces significant climatic variability over a wide range of the Earth. A classic example of a large scale anthropogenic influence on climate is the well-documented rapid increase of atmospheric carbon dioxide occurring since the beginning of the Industrial Revolution [3]. An example of the study of a small-scale anthropogenic influence in climate variability is the Atlanta Land-use Analysis Temperature and Air-quality (ATLANTA) project [4]. This project has found that the replacement of trees and vegetation with concrete and asphalt in Atlanta, Georgia, and its environs has created a microclimate capable of producing wind and thunderstorms. A key objective of climate research is to be able to distinguish the natural versus human roles in climate change and 
to clearly communicate those findings to those who shape and direct environmental policy.

The advantages of using satellite platforms in Earth remote sensing and environmental monitoring are made clear when one considers the challenging nature of the measurement problem. The Earth is a complex, integrated, changing physical system driven by a principle energy source, the Sun, which interacts with the components of the Earth system, namely the land, oceans, atmosphere, and cryosphere. From a remote sensing perspective, the Earth appears as a temporally variable, spatially and spectrally variegated object. Earth climate and environmental studies, therefore, require the acquisition of large numbers of observations to be properly understood. Instruments placed on satellites in Earth orbit satisfy temporal Earth remote sensing requirements in that they are capable of performing frequent observations. They also satisfy spatial remote sensing requirements in that they monitor areas of the Earth larger than those capable of being monitored by ground-based, airborne, or balloon-borne instruments.

$<$ Figure 10.1>

On-orbit measurements made by Earth remote sensing instruments are exoatmospheric radiances, irradiances, or reflectances measured at the remote sensing instruments' apertures. The Earth's atmosphere, through the processes of absorption, reemission, reflectance, and scattering, plays a significant role in the amount of solar energy impinging on the Earth surface. Figure 10.1 shows the solar irradiance at the top of the atmosphere and through the atmosphere at an altitude $2 \mathrm{~km}$ above mean sea level. Figure 10.1 also shows the irradiance produced by a blackbody at $5870 \mathrm{~K}$, the approximate equivalent radiance temperature of the Sun. Absorption features seen in the irradiance data obtained by looking through the atmosphere are attributed primarily to the following gaseous molecules: $\mathrm{O}_{3}$ below $360 \mathrm{~nm}, \mathrm{O}_{2}$ centered at $762.1 \mathrm{~nm}, \mathrm{H}_{2} \mathrm{O}$ centered at $720 \mathrm{~nm}, 810 \mathrm{~nm}, 940 \mathrm{~nm}, 1100 \mathrm{~nm}, 1400 \mathrm{~nm}$, and $1900 \mathrm{~nm}$, and $\mathrm{CO}_{2}$ centered at 1400 $\mathrm{nm}$ and $2000 \mathrm{~nm}$. In Fig. 10.1, the absorption feature beginning near $2500 \mathrm{~nm}$ extends to $3300 \mathrm{~nm}$ and is attributed primarily to $\mathrm{H}_{2} \mathrm{O}$ and $\mathrm{CO}_{2}$. Also visible in this figure are the atmospheric window bands centered at $1050 \mathrm{~nm}, 1250 \mathrm{~nm}, 1650 \mathrm{~nm}$, and $2300 \mathrm{~nm}$. An example of the complexity of the interaction of incident solar flux with the Earth's atmosphere and surface is shown in Fig. 10.2 which shows the typical radiation budget of the Earth [5]. Since Earth scientists are typically interested in processes occurring at the Earth's surface, at-satellite measurements must be transferred to the Earth's surface. This involves correcting the at-satellite measurements for the presence of the Earth's atmosphere using an atmospheric model, inputs to which include temperature, pressure, concentrations of absorbing and scattering atmospheric molecular species, aerosol optical depth, and water vapor content for the region of interest. Inputs to atmospheric correction models are obtained from a variety of ground-based, air-borne, balloon-borne, and satellite-based instruments.

$<$ Figure 10.2>

\subsubsection{Launch and Space Environmental Effects on Remote Sensing Instruments}

In addition to the spatial, spectral, and temporal complexities of remotely sensing the Earth system, the on-orbit deployment and operation of satellite instruments presents a unique set of additional challenges. Remote sensing instruments and their spacecraft must first survive the vibrational and acoustic stresses of the launch process and entry 
into the vacuum of space. Once on-orbit, the instruments are exposed to ionizing radiation and coronal mass ejection (CME) protons produced by the Sun. On-orbit instruments are also exposed to impacts by orbital debris, oxidizing chemical species, such as atomic oxygen, and high energy electrons and protons, heavy ions, and cosmic ray flux which can cause instrument on-orbit Single Event Upsets (SEUs) and Single Event Latchups (SELs). Instruments operating in the vacuum environment of space are subject to outgassing of various molecular species which, in the presence of solar radiation, can be baked or "solarized" onto exposed instrument optical components and surfaces. The on-orbit operation of remote sensing instruments occurs in a zero gravitational, continuously changing thermal environment. While the effects of the latter are extensively modeled and tested pre-launch, the effects of the former cannot be tested. The net effect on the orbiting instrument is usually a degradation of the overall system radiometric responsivity. A key aspect in the use of satellite remote sensing data in the study of the Earth is the ability to distinguish between those on-orbit instrument changes and actual Earth geophysical changes.

\subsubsection{Target Calibration Uncertainties, Measurement Stability and Continuity in Climatic Remote Sensing and Environmental Monitoring}

The ability to monitor, understand, and subsequently predict short and long-term climate and environmental processes is related to the quality of the data produced by the remote sensing instrument or instruments used to measure those processes. While it is possible to study short-term processes using a single generation of a remote sensing satellite instrument, long-term, decadal processes require measurements from successive generations of instruments, which are often non-identical and potentially operate in different on-orbit environments. The global nature of the study of climate and environmental processes requires consistent calibration of successive generations of remote sensing instruments against a common scale and the careful characterization of those instruments. Calibration is defined as the process of quantitatively defining an instrument's system response to known, controlled signal inputs. Characterization is defined as the set of operations or processes used to quantitatively understand the operation of an instrument. For a satellite instrument, characterization involves determination of the instrument's response as a function of the gamut of operating and viewing conditions experienced by that instrument on-orbit. Instrument measurement accuracy, precision, and stability requirements are directly derived from Earth science and environmental monitoring requirements and differ depending on the particular geophysical process being studied. The study of geophysical processes using instruments on satellite platforms often requires the measurement of small-scale signals and signal changes superimposed upon larger signals. For this reason, the accuracy, precision, and stability requirements imposed upon satellite remote sensing instruments and, logically, upon the instrumentation used in their calibration and characterization are, from purely a metrological standpoint, often state-of-the-art. Table 10.1 presents the accuracies and stabilities of remote sensing satellite instrument measurements required in the study of the listed geophysical parameters [6].

$<$ Table 10.1> 


\subsubsection{The Importance of Traceability in Earth Remote Sensing}

The study of climate and environmental change is global in nature and involves measurements made by remote sensing instruments from a number of countries. The ability to relate and compare instrument measurements depends on the pre-launch and onorbit calibration of those instruments against a common, internationally-recognized physical scale. The remote sensing goals of acquiring high-quality, global remote sensing data over a time period of decades requires that the calibration of these instruments be traceable to metrological physical scales maintained by national measurement institutes (NMIs) such as the National Institute of Standards and Technology (NIST) and the National Physical Laboratory (NPL). NMIs realize the physical quantities which define the International System of Units (SI) and, as such, represent the expertise in fundamental metrology. Interactions between NMIs through the Treaty of the Meter and related key measurement intercomparisons ensure a global consistency in measurement science. The level of interaction of NMIs with remote sensing calibration facilities occurs on several levels. Traceability of remote sensing instrument calibration to the SI is accomplished at the first level through the use of reference information, special publications, databases, calibration services, and standard reference materials readily available from NMIs. The state-of-the-art metrological requirements on remotely sensed data have prompted some remote sensing programs and instrument calibration facilities to invite greater involvement by NMIs in their remote sensing instrument calibration efforts. This level of involvement by NMIs includes coordinating training courses, workshops, and conferences and direct participation in and coordination of radiometric measurement campaigns and artifact measurement round-robins [7]. The advantages of these programs include direct validation of instrument calibration methods through NMI measurements (i.e. shorter traceability chains and lower calibration uncertainties) and access to NMI metrology programs which are permanent across multiple remote sensing mission lifetimes. The NMIs also benefit from close interaction with remote sensing calibration programs in that the state-of-the-art calibration requirements of the instruments often lead to the incorporation of improved measurement technologies by the NMIs which are then made available to the larger international remote sensing measurement community.

\subsubsection{The Measurement Equation Approach in Earth Remote Sensing}

Characterization procedures are not limited to the radiometric sources used to calibrate satellite instruments. For accurate results and proper assessment of measurement uncertainties, the flight instrument must also be characterized. A systematic, proven approach to the characterization of remote sensing instruments is to first determine the instrument's measurement equation. The measurement equation of an instrument is a mathematical expression that describes the roles and effects of all influencing parameters. Table 10.2 lists a number of influencing parameters which must be measured in the process of instrument characterization. In addition to the parameters listed in Table 2, time is an essential variable, as it relates to both the measurement precision (i.e. short term stability) and drift or degradation (i.e. long term stability). Temperature of the surrounding environment, intervening medium, or instrument components is also a significant influencing parameter. Certain parameters influence the measurement process more than others. 
As a first approximation in the measurement equation approach, influencing parameters can be treated independently, allowing for separate characterizations to be made for each. This assumption must be confirmed in an effort to identify and test crossparameter dependencies, and experiments must be designed to minimize possible systematic effects. Examples of these tests include measurements that determine the degree to which a satellite sensor's output is independent of integration time or temperature. An example of reducing sensitivity to systematic effects would be to fully characterize the response of an instrument over its entire field-of-view, which means to approximately $\pm 55^{\circ}$ for nadir observations from a typical low Earth orbit to the Earth's limb. The measurement equation ultimately forms the basis of a satellite instrument's radiometric mathematical model. The instrument mathematical model is used pre-launch to validate that an instrument design will meet specifications and on-orbit to assist in understanding instrument operation.

<Table 10.2>

In the case of remote sensing instruments, the response of an instrument to incoming photon flux is usually expressed in digital numbers (DNs). For the measurement of radiance, this response in general can be described mathematically by the measurement equation

$$
D N_{i, j}=G \iiint \int L(x, y, \lambda, t) R(x, y, \lambda, t) d x d y d \lambda d t
$$

where $D N_{i, j}$ is the digital number output by instrument detector $i$ in band $j, G$ is the instrument detector plus digitization gain, $L(x, y, \lambda, t)$ is the spectral radiance at the instrument entrance aperture, and $R(x, y, \lambda, t)$ is the instrument spectral responsivity. For simplicity and completeness, the limits of integration for each variable in Eq. (10.1) and for variables in the equations which follow are assumed to be $+\infty$ to $-\infty$. For an instrument with narrow bandwidth channels, the assumption can be made that the variables in Eq. (10.1) do not have a strong wavelength dependence. In addition, the time and spatial variables in Eq. (10.1) can be ignored if the scene radiance and detector uniformity are spectrally uniform and temporally invariant. These assumptions lead to the following simplified equation describing an instrument's digital output

$$
D N_{i, j}=G \cdot A_{i, j} \cdot \Omega \cdot L(\lambda) \cdot \Delta \lambda \cdot \eta \cdot t \cdot \tau \cdot \rho,
$$

where $A_{i, j}$ is the area of detector $i$ in band j, $\Omega$ is the instrument acceptance solid angle, $\Delta \lambda$ is the bandwidth, $\eta$ is the detector quantum efficiency in electrons per incident photon, $t$ is the integration time, $\tau$ is the instrument optical transmission, and $\rho$ is the instrument optical reflectance. For optical systems employing refractive and reflective optics, the instrument optical transmission and reflection can be represented by

$$
\tau=\prod_{1}^{N} \tau_{i}
$$

and

$$
\rho=\prod_{1}^{M} \rho_{i},
$$

where $\tau_{i}$ and $\rho_{i}$ are the transmission and reflection of the $i^{\text {th }}$ of $N$ transmissive and $M$ reflective optical elements, respectively. Instrument response non-linearity, zero radiance response (i.e. background), focal plane temperature effects, or response versus scan angle effects are not shown in Eq. (10.2). These quantities are determined in pre-launch 
instrument characterization tests and are incorporated in instrument radiometric math models and in the production of measured radiances.

Equation (10.2) can be re-written as

$$
L(\lambda)=D N_{i, j} \cdot m
$$

where

$$
m=\frac{1}{G \cdot A_{i, j} \cdot \Omega \cdot \Delta \lambda \cdot \eta \cdot t \cdot \tau \cdot \rho}
$$

is the inverse of the product of the instrument responsivity and gain. It is determined prelaunch for an end-to-end remote sensing instrument by viewing uniform sources of known radiance, such as well-characterized and calibrated integrating sphere sources and blackbodies. It is also determined pre-launch through remote sensing subsystem characterization measurements of quantities such as mirror reflectance, polarization responsivity, spectral radiance responsivity. These subsystem level characterization measurements are used as input to instrument radiometric mathematical models used to validate the system level pre-launch calibration and in the calculation of instrument measurement uncertainty. The quantity, $m$, in equation 5 is monitored on-orbit using stable, uniform on-board sources of known radiance.

Equation (10.1) is written for the detection of radiance. For remote sensing measurements in the reflective solar wavelength region (i.e. $200 \mathrm{~nm}$ to $2500 \mathrm{~nm}$ ), Eq. (10.1) can also be written in terms of the relative quantity of reflectance,

$$
D N_{i, j}=G \iiint \int E_{s u n}(x, y, \lambda) B R D F\left(\theta_{i}, \varphi_{i}, \theta_{r}, \varphi_{r}, \lambda, t\right) R(x, y, \lambda, t) d x d y d \lambda d t,(
$$

where $E_{\text {sun }}$ is the solar spectral irradiance, $B R D F$ is the bidirectional reflectance distribution function of either the Earth scene or a reflectance standard, $\theta_{\mathrm{i}}, \varphi_{\mathrm{i}}$, and $\theta_{\mathrm{r}}, \varphi_{\mathrm{r}}$ are the elevation and azimuthal angles for incident and reflected solar flux, respectively. In reflectance-based Earth remote sensing measurements, the instrument is used as a transfer radiometer between two diffuse surfaces both illuminated by the Sun, namely, the Earth scene and an optically diffuse reflectance standard. Assuming narrow bandwidth channels and spectrally and spatially uniform and temporally invariant detectors, instrument measurements of an Earth scene and a diffuser can be described by

$$
D N_{i, j, E S}=G \cdot B R D F_{E S}\left(\theta_{i}, \varphi_{i}, \theta_{r}, \varphi_{r}, \lambda, t\right) \cdot E_{s u n}(\lambda) \cdot A_{i, j} \cdot \Omega \cdot \Delta \lambda \cdot \eta \cdot t \cdot \tau \cdot \rho
$$

and

$$
D N_{i, j, S D}=G \cdot B R D F_{S D}\left(\theta_{i}, \varphi_{i}, \theta_{r}, \varphi_{r}, \lambda, t\right) \cdot E_{s u n}(\lambda) \cdot A_{i, j} \cdot \Omega \cdot \Delta \lambda \cdot \eta \cdot t \cdot \tau \cdot \rho \cdot \Gamma,
$$

where $D N_{i, j, E S}$ and $D N_{i, j, S D}$ are the digital numbers output by instrument detector $i$ in band $j$ for the Earth scene, $E S$, and solar diffuser, $S D$, respectively; $B R D F_{E S}$ and $B R D F_{S D}$ are the bidirectional reflectance distribution functions for Earth scene and solar diffuser views, and $\Gamma$ accounts for on-orbit degradation of the solar diffuser BRDF. Taking the ratio of Eqs. (10.8) and (10.9),

$$
B R D F_{E S}=\frac{D N_{E S}}{D N_{S D}} \cdot B R D F_{S D} \cdot \Gamma .
$$

On-orbit degradation of the solar diffuser, $\Gamma$, is determined using dedicated on-board detector-based monitor hardware, multiple diffuser surfaces exposed to the sun for variable duty cycles, or repeated views of stable or well-characterized celestial and ground-based targets, such as the Moon or desert playas. 
Feb 212005

For remote sensing in the thermal infrared region beyond $2500 \mathrm{~nm}$, the brightness temperature of an Earth scene is determined relative to the brightness temperature of an on-board, well-characterized blackbody source. Assuming a simple infrared remote sensing instrument comprised of a scan mirror, transmissive optics, an on-board blackbody located in the instrument scan cavity, and a filtered infrared detector, the infrared detection of Earth scenes can be mathematically described by

$$
\begin{aligned}
& D N_{i, j, E S} \\
& G\left\{\left[\rho_{M}\left(\theta_{i}\right) \cdot L\left(T_{E S}\right)+\rho_{M}\left(\theta_{i}\right) \cdot \varepsilon_{C A V}\left(\varphi_{i}\right) \cdot L\left(T_{C A V}\right)+\varepsilon_{M}\left(\theta_{i}\right) \cdot L\left(T_{M}\right)\right] \cdot \tau_{O P T},\right. \\
& \left.+\varepsilon_{O P T} \cdot L\left(T_{O P T}\right)\right\}+D N_{\text {offset }}
\end{aligned}
$$

where $D N_{i, j, E S}$ is the digital signal from instrument detector $i$ in band $j$ while viewing an Earth scene; $G$ is the instrument gain; $\rho_{M}\left(\theta_{i}\right)$ is the reflectance of the instrument scan mirror in the direction $\theta_{i} ; L\left(T_{E S}\right)$ is the radiance of the Earth scene at temperature $T_{E S}$; $\varepsilon_{C A V}\left(\varphi_{i}\right)$ is the emissivity of the scan cavity in the direction of the scan mirror $\varphi_{i} ; L\left(T_{C A V}\right)$ is the radiance of the scan cavity at temperature $T_{C A V} ; \varepsilon_{M}\left(\theta_{i}\right)$ is the emissivity of the scan mirror in the direction $\theta_{i} ; L\left(T_{M}\right)$ is the radiance of the scan mirror at temperature $T_{M} ; \tau_{O P T}$ is the transmission of the instrument optics; $\varepsilon_{O P T}$ is the emissivity of the instrument optics; $L\left(T_{O P T}\right)$ is the radiance of the instrument optics at temperature $T_{O P T}$, and $D N_{\text {offset }}$ is the electronic noise offset in the instrument. On the right side of Eq. (10.11), the first term represents the scene radiance reflected by the scan mirror. The second term represents the radiance emitted by the scan cavity and reflected by the scan mirror into the instrument. The third term represents the radiance emitted by the mirror, and the fourth term represents the radiance emitted by the instrument optics.

For instrument views of the on-board blackbody, the detected infrared radiance can be represented by

$$
\begin{aligned}
& D N_{i, j, B B}= \\
& G\left\{\left[\rho_{M}\left(\theta_{B B}\right) \cdot \varepsilon_{B B}\left(\theta_{B B}\right) L\left(T_{B B}\right)+\rho_{M}\left(\theta_{B B}\right) \cdot \varepsilon_{C A V}\left(\varphi_{B B}\right) \cdot L\left(T_{C A V}\right)+\varepsilon_{M}\left(\theta_{B B}\right) \cdot L\left(T_{M}\right)\right] \cdot \tau_{O P T},(10.12)\right. \\
& \left.+\varepsilon_{O P T} \cdot L\left(T_{O P T}\right)\right\}+D N_{\text {offet }}
\end{aligned}
$$

where $D N_{i, j, B B}$ is the digital signal from instrument detector $i$ in band $j$ while viewing the on-board blackbody; $\rho_{M}\left(\theta_{B B}\right)$ is the reflectance of the instrument scan mirror in the direction $\theta_{B B} ; \varepsilon_{B B}\left(\theta_{B B}\right)$ is the emissivity of the blackbody; $L\left(T_{B B}\right)$ is the radiance of the blackbody at temperature $T_{B B} ; \varepsilon_{C A V}\left(\varphi_{B B}\right)$ is the emissivity of the scan cavity in the direction of the blackbody $\varphi_{B B}$; and $\varepsilon_{M}\left(\theta_{B B}\right)$ is the emissivity of the scan mirror in the direction $\theta_{B B}$. On the right side of Eq. (10.12), the first term represents the blackbody radiance reflected by the scan mirror. The second term represents the radiance emitted by the scan cavity and reflected by the scan mirror. The third term represents the radiance emitted by the mitror, and the fourth term represents the radiance emitted by the instrument optics.

For instrument views of deep space, the detected infrared radiance can be represented by 


$$
\begin{aligned}
& D N_{i, j, S V}= \\
& G\left\{\left[\rho_{M}\left(\theta_{S V}\right) \cdot \varepsilon_{S V}\left(\theta_{S V}\right) L\left(T_{S V}\right)+\rho_{M}\left(\theta_{S V}\right) \cdot \varepsilon_{C A V}\left(\varphi_{S V}\right) \cdot L\left(T_{C A V}\right)+\varepsilon_{M}\left(\theta_{S V}\right) \cdot L\left(T_{M}\right)\right] \cdot \tau_{O P T},\right. \\
& \left.+\varepsilon_{O P T} \cdot L\left(T_{O P T}\right)\right\}+D N_{o f f s e t}
\end{aligned}
$$

where $D N_{i, j, S V}$ is the digital signal from detector $i$ in band $j$ when looking at deep space; $\rho_{M}\left(\theta_{S V}\right)$ is the reflectance of the instrument scan mirror in the direction $\theta_{S V} ; \varepsilon_{S V}\left(\theta_{S V}\right)$ is the emissivity of the blackbody; $L\left(T_{S V}\right)$ is the radiance of deep space at its temperature of $T_{S V}$; $\varepsilon_{C A V}\left(\varphi_{S V}\right)$ is the emissivity of the scan cavity in the direction $\varphi_{S V}$; and $\varepsilon_{M}\left(\theta_{S V}\right)$ is the emissivity of the scan mirror in the direction $\theta_{S V}$.

Assuming that the infrared radiance from deep space is essentially zero, the infrared radiance from the scene can be calculated by subtracting Eq. (10.13) from Eq. (10.11) and grouping similar terms:

$$
\begin{aligned}
& D N_{i, j, E S}-D N_{i, j, S V}= \\
& G \cdot \tau \cdot\left\{\rho_{M}\left(\theta_{i}\right) \cdot L\left(T_{E S}\right)-\left[\rho_{M}\left(\theta_{S V}\right) \cdot \varepsilon_{C A V}\left(\varphi_{S V}\right)-\rho_{M}\left(\theta_{E S}\right) \cdot \varepsilon_{C A V}\left(\varphi_{E S}\right)\right] \cdot L\left(T_{C A V}\right)\right. \\
& \left.-\left[\varepsilon_{M}\left(\theta_{S V}\right)-\varepsilon_{M}\left(\theta_{i}\right)\right] \cdot L\left(T_{M}\right)\right\}
\end{aligned}
$$

Likewise, the infrared radiance from the on-board blackbody can be calculated by subtracting Eq. (10.13) from Eq. (10.12) and grouping similar terms:

$$
\begin{aligned}
& D N_{i, j, B B}-D N_{i, j, S V}= \\
& G \cdot \tau \cdot\left\{\rho_{M}\left(\theta_{B B}\right) \cdot \varepsilon\left(\theta_{B B}\right) \cdot L\left(T_{B B}\right)-\left[\rho_{M}\left(\theta_{S V}\right) \cdot \varepsilon_{C A V}\left(\varphi_{S V}\right)-\rho_{M}\left(\theta_{B B}\right) \cdot \varepsilon_{C A V}\left(\varphi_{B B}\right)\right] \cdot L\left(T_{C A V}\right)\right. \\
& \left.-\left[\varepsilon_{M}\left(\theta_{S V}\right)-\varepsilon_{M}\left(\theta_{B B}\right)\right] \cdot L\left(T_{M}\right)\right\}
\end{aligned}
$$

The second and third terms on the right of Eqs. (10.14) and (10.15) are essentially zero. This leads to:

$$
\begin{gathered}
D N_{i, j, E S}-D N_{i, j, S V}=G \cdot \tau \cdot \rho_{M}\left(\theta_{i}\right) \cdot L\left(T_{E S}\right) \\
D N_{i, j, B B}-D N_{i, j, S V}=G \cdot \tau \cdot \rho_{M}\left(\theta_{B B}\right) \cdot \varepsilon_{B B}\left(\theta_{B B}\right) \cdot L\left(T_{B B}\right)
\end{gathered}
$$

The changing on-orbit thermal environment of the instrument and drift in the detector responsivity requires frequent views of the on-board blackbody for instrument calibration. The ratio of the measured infrared Earth scene radiance and the measured blackbody radiance comprises the basic measurement approach. From this ratio, the infrared Earth scene radiance is calculated according to

$$
\left.L\left(T_{E S}\right)=\frac{\rho_{M}\left(\theta_{B B}\right) \cdot \varepsilon_{B B}\left(\theta_{B B}\right) \cdot L\left(T_{B B}\right)}{\rho_{M}\left(\theta_{i}\right) \cdot\left[D N_{i, j, B B}-D N_{i, j, S V}\right.}\right] \cdot\left[D N_{i, j, E S}-D N_{i, j, S V}\right]
$$

\subsubsection{The Importance of Multiple Measurement Methodologies in Earth Remote Sensing}

Confidence in the correct interpretation of Earth science remote sensing data in the study of Earth science and environmental processes requires confidence in the quality of the on-orbit data used to study those processes. Confidence in the accuracy of on-orbit remote sensing data is increased if those data are validated through the use of multiple, independent measurement methodologies and approaches. Multiple measurement 
methodologies include inter-comparisons of measurements from instruments on the same or different satellites and from ground-based, balloon-based, and airborne validation campaigns. Validation can therefore be defined as the process of assessing, by independent means, the quality of data products derived from satellite instrument measurements.

This chapter provides examples of current, established approaches in the prelaunch and on-orbit radiometric calibration, spectral characterization and calibration, and validation of fundamental metrological measurements made by Earth remote sensing instruments. Included are brief descriptions of innovative and state-of-the-art approaches in the field including references, where appropriate. The examples are confined to optical measurements made in the air-ultraviolet through thermal infrared wavelength regions from $190 \mathrm{~nm}$ to $100 \mu \mathrm{m}$. The chapter concludes by identifying a number of challenging areas in the calibration and characterization of remote sensing instruments, several of which are currently the objects of significant and promising research in remote sensing metrology.

\subsection{The Role of Pre-launch Calibration and Characterization}

\subsubsection{The Air Ultraviolet and Solar Reflective Range (190 $\mathrm{nm}$ to $2500 \mathrm{~nm})$}

\subsubsection{Introduction}

Remote sensing of the Earth at wavelengths between $190 \mathrm{~nm}$ and $2500 \mathrm{~nm}$ involves detecting that portion of incident solar radiation which is either backscattered or reflected in the direction of the satellite instrument. The wavelength region between 190 $\mathrm{nm}$ and $400 \mathrm{~nm}$, a region in this chapter referred to as the air ultraviolet, is important in studies of upper atmospheric chemistry and solar physics. The region between $190 \mathrm{~nm}$ and $300 \mathrm{~nm}$ is strongly dominated by atmospheric ozone absorption. At visible wavelengths between $400 \mathrm{~nm}$ and $700 \mathrm{~nm}$, near infrared wavelengths between $700 \mathrm{~nm}$ and $1000 \mathrm{~nm}$ and shortwave infrared wavelengths between $1000 \mathrm{~nm}$ and $2500 \mathrm{~nm}$, the remotely sensed processes of transmission, absorption, and reflection of incident solar radiation can be used to qualitatively and quantitatively identify a wide range of water, land, vegetative, and atmospheric conditions and properties. It is the reflectance spectrum, or the fractional amount of reflected incident solar radiation as a function of wavelength, of geophysical features which provides the basis of characterizing and identifying these conditions and properties on the Earth.

Ultraviolet measurements from satellites, the Space Shuttle, and the ground have been used to measure stratospheric profiles and total columns of ozone [8]. The importance of ozone monitoring, its biological impacts and anthropogenic causes began in 1978 with the launch of the Total Ozone Mapping Spectrometer (TOMS)/Solar Backscatter UltraViolet (SBUV) experiment on Nimbus-7 [9]. The Nimbus-7 TOMS instrument viewed the Earth at six ultraviolet wavelengths between $312.3 \mathrm{~nm}$ and 379.9 $\mathrm{nm}$ at nadir and measured total column ozone. The Nimbus-7 SBUV instrument viewed the Earth in $12 \mathrm{UV}$ wavelengths between $255 \mathrm{~nm}$ and $340 \mathrm{~nm}$ at nadir and measured total column ozone and ozone profiles. The success of these instruments led to the 1989 National Plan for Stratospheric Monitoring which mandated continuing ozone 
measurements on the National Oceanic and Atmospheric Administration (NOAA) Polar Orbiting Environmental Satellites (POES) using SBUV and SBUV/2 instruments $[9,10]$. International recognition of the importance of ozone measurements led to flights of a number of overlapping instruments. This included the TOMS instruments on the Earth Probes (EP), Meteor, and the Advanced Earth Observing Satellite (ADEOS) platforms, SBUV/ 2 instruments on NOAA-9, $-11,-16$ and -17 , the Global Ozone Monitoring Experiment (GOME) and Scanning Imaging Absorption Spectrometer for Atmospheric Chartography (SCIAMACHY) instruments on the European Remote Sensing Satellite-2 (ERS-2) and the Environmental Satellite (ENVISAT) [11-13], respectively, the Ozone Monitoring Instrument (OMI) on EOS Aura [14], the SAGE instruments on the Earth Radiation Budget Satellite (ERBS) and Meteor [15], and the upcoming flight of the Ozone Mapping and Profiling Suite (OMPS) instrument on the National Polar Orbiting Environmental Satellite System (NPOESS) and NPOESS Preliminary Project (NPP) satellites [16]. Continuous monitoring of ozone concentrations by these instruments enabled the detection of depletion in global ozone of $2 \%$ to $3 \%[17,18]$ and $5 \%$ to $8 \%$ in upper stratospheric ozone [19]. Moreover, data from these satellite instruments complemented by both ground-based, and airborne atmospheric chemistry measurements indicated that these depletions are anthropogenic in origin [20] due primarily to the release and slow diffusion of man-made chloroflouorcarbons into the stratosphere. Data from these satellites and instruments input to atmospheric chemistry models predicted that a phase-out of chlorofluorocarbon emissions would restore ozone concentrations to pre-1980 levels by 2030 [21]. Early evidence of this turnaround and recovery is of extreme interest to a number of atmospheric scientists [22,23].

Visible, near infrared, and shortwave infrared measurements from satellite platforms have been used to identify, examine, and monitor a number of features on and above the Earth. Ocean color, aerosols, clouds, vegetation, water vapor, snow, and ice are examples of Earth geophysical properties that have been studied through the detection of transmitted, absorbed, or reflected solar radiation by instruments on satellite platforms. The ability of Earth remote sensing in the visible through shortwave infrared to examine these and other geophysical properties and processes has resulted in the on-orbit deployment of a large number of satellite instruments. The need to monitor these processes for purposes of climate research or environmental study has produced a correspondingly large number of temporally overlapping heritage sensors. The high number of satellite remote sensing instruments operating in this wavelength region precludes embarking on an extensive review as part of this chapter; however, examples of two heritage missions and their geophysical relevance are provided. Marine phytoplankton use carbon dioxide which has settled into the ocean for photosynthesis, making the oceans Earth's primary storage sinks for that greenhouse gas. Marine phytoplankton also respond rapidly and often dramatically to environmental change. Remote sensing of the chlorophyll pigment of marine phytoplankton provides a sensitive measure of that change. The Coastal Zone Color Scanner (CZCS) on Nimbus-7, operating from 1978 to 1986 , produced the first, high quality global distribution map of ocean chlorophyll. The measurement of chlorophyll by CZCS was continued by the Japanese Ocean Color Temperature Scanner (OCTS) on ADEOS from 1996 to 1997, the Sea Viewing Wide Field of View Sensor (SeaWiFS) on OrbView 2 from 1997 to present, the Moderate Resolution Imaging Spectroradiometer (MODIS) on Terra and Aqua from 
1999 and 2002 to present, the Medium Resolution Imaging Spectrometer (MERIS) on ENVISAT from 2002 to present, and the Global Imager (GLI) on ADEOS-II from 2002 to 2003. A second, excellent example of a heritage system of remote sensing satellite instruments operating in the reflective solar wavelength region is Landsat. Since 1972, Landsat has provided the remote sensing community with a continuous stream of data and images of the Earth's land surface and coastal regions. Landsat data have been used to monitor a variety of environmental processes including, but by no means limited to, deforestation, population growth, and a variety of natural disasters. The first instrument, originally called the Earth Resources Technology Satellite (ERTS) and later renamed Landsat-1, included a 4 band MultiSpectral Scanner (MSS) and a return beam vidicon (RBV). The MSS was included on Landsats-2 and -3, launched in 1975 and 1978, respectively. Landsats-4 and -5, launched in 1982 and 1984, respectively, were equipped with an improved MSS called the Thematic Mapper (TM) [24]. The TM added three new bands and had improved spatial resolution over the MSS design. Landsat-5 is currently still in operation. Landsats- 6 and -7 were equipped with TM instruments containing 7 channels and a high resolution panchromatic sensor. Landsat-6 was launched in 1993 and never achieved orbit; Landsat-7 was launched in 1999 and is currently in operation.

\subsubsection{The Radiometric Calibration of UV Earth Remote Sensing Instruments}

A variety of laboratory or facility-based sources can be used in the radiance and irradiance calibration of ultraviolet remote sensing instrumentation between $190 \mathrm{~nm}$ and $400 \mathrm{~nm}$. The spectral power distribution of synchrotron emission from relativistic electrons in a storage ring can be expressed in terms of the electron current, the orbital radius, and the magnetic flux density. The spectral radiance of a blackbody, where thermal emission is in equilibrium with the solid cavity material, is known in terms of its thermodynamic temperature and the measurement wavelength. However, temperatures are limited to about $3000 \mathrm{~K}$ using graphite sources with inert gas purge at ambient pressure, and solid blackbody sources are practical for the spectral region longer than 250 $\mathrm{nm}$. An exception is emission from optically-thick resonance lines of trace elements in high temperature plasma sources $(\sim 12,000 \mathrm{~K})$, which are blackbody line sources for calibration at discrete wavelengths in the ultraviolet [25]. A third class of ultraviolet source is the simple plasma for which the necessary atomic or molecular data are known. For example, a high temperature $(\sim 20,000 \mathrm{~K})$, wall-stabilized, hydrogen arc is a source of known spectral radiance in the air ultraviolet from $190 \mathrm{~nm}$ to $360 \mathrm{~nm}$, given the continuum emission coefficient and the plasma length [25,26]. It is also possible to generate sources with known relative spectral distributions. An example of this type of source is realized through the electron impact excitation of atoms and molecules combined with knowledge of cross-sections, branching ratios, and transition probabilities [27].

The most common sources used in the calibration of ultraviolet remote sensing instruments are transfer standard sources. Transfer standard sources are portable and easier to use than the calculable sources described above; once calibrated they can be used to disseminate spectral radiance, irradiance, or intensity values. Emission lines from metal-rare gas hollow cathode sources are used as radiant intensity standards, and operation in the vacuum ultraviolet is possible $[28,29]$. The argon mini-arc is a 
secondary standard that has a line-free continuum between $194 \mathrm{~nm}$ and $330 \mathrm{~nm} \mathrm{[30].}$ Originally developed with windows as a spectral radiance standard, later modifications included windowless operation, useful for the air ultraviolet region, and for use as an irradiance standard [31,32].

Deuterium arc lamps, which utilize a low pressure plasma, are common transfer standards in the ultraviolet [33]. NIST issues modified commercial $30 \mathrm{~W} \mathrm{D}_{2}$ lamps that are calibrated for spectral irradiance from $200 \mathrm{~nm}$ to $400 \mathrm{~nm}$ [34]. It is also possible to assign spectral radiance values to $\mathrm{D}_{2}$ lamps, and they have been used as transfer standards in international intercomparisons of spectral radiance [35].

From $250 \mathrm{~nm}$ through $400 \mathrm{~nm}$, NIST issues a $1000 \mathrm{~W}$ tungsten quartz halogen lamp (TQH), type FEL [36] as a standard of spectral irradiance. The double coiled tungsten filament, enclosed by a quartz envelope and surrounded by a halogen-doped inert gas, results in a stable source with a relative spectral distribution equivalent to a blackbody at about $3000 \mathrm{~K}$. The FEL lamp is the most common source used in radiance and irradiance calibrations of remote sensing instruments operating from $250 \mathrm{~nm}$ to 2500 $\mathrm{nm}$ ); further discussion of this source can be found later in this chapter. For spectral radiance standards, gas-filled tungsten strip lamps are possible [36].

Ultraviolet satellite instruments used to determine total column ozone and ozone profiles measure the earth's albedo, or the ratio of the Earth's backscattered radiance to incoming solar irradiance, at a number of wavelengths between $230 \mathrm{~nm}$ and $425 \mathrm{~nm}$. From $230 \mathrm{~nm}$ to $340 \mathrm{~nm}$, the absorption cross-section of ozone increases rapidly with increasing wavelength. The accuracy of ozone measurements made by these satellite instruments depends on the accuracy of their pre-launch albedo calibrations, linearity characterizations, and wavelength calibrations. Consistency in the pre-launch calibration and characterization of ozone measuring instruments on the same and different spacecraft is critical in continuing the decadal ozone data record.

In the pre-launch timeframe, ultraviolet albedo measuring satellite instruments are calibrated for radiance and irradiance in the laboratory. The radiance calibration determines the instrument response in its on-orbit radiance measurement mode, that is, while looking at the Earth. The irradiance calibration determines the instrument response in its on-orbit irradiance measurement mode, that is, while measuring incident solar irradiance reflected off or transmitted through its on-board solar diffuser. In the radiance calibration, the satellite instrument views a laboratory diffuse target with a known spectral bidirectional reflectance distribution function (BRDF) illuminated by an irradiance standard FEL lamp. Confidence in this calibration is established by employing a series of standard lamps and diffuse targets and comparing the results [37]. More recently, an integrating sphere has been employed in this calibration $[38,39]$. The integrating sphere was a $50.8 \mathrm{~cm}$ diameter aluminum shell with a $20.3 \mathrm{~cm}$ diameter output aperture. The interior of the sphere was coated with barium sulfate paint and was internally illuminated by eight $200 \mathrm{~W}$ tungsten halogen bulbs. In this approach, the satellite instrument was used to transfer the irradiance calibration from an irradiance standard FEL lamp to the aperture of the integrating sphere. The instrument viewed a diffuse target initially illuminated by a spectral irradiance standard FEL lamp and then by the integrating sphere. The spectral radiance of the sphere was calculated using the technique described by Walker et al. [40] employing the radii of the integrating sphere and instrument apertures and their separation distance. The integrating sphere, calibrated 
for spectral radiance, was then viewed directly by the satellite instrument. This technique effectively eliminated the uncertainty in the knowledge of the BRDF of the diffuse target. The agreement between the integrating sphere-based and established diffuser-based techniques was on the order of $1 \%$.

In the pre-launch irradiance calibration, an irradiance standard FEL lamp is used to illuminate the satellite instrument's on-board diffuser in an optical geometry similar to that of the Sun on-orbit. A goniometric calibration of the instrument and its on-board diffuser is also performed to determine the instrument's angular response. While the ratio measurement methodology of the albedo measurement causes many variables to cancel, uncertainty in the BRDF of the on-board diffuser remains. Therefore, determination of the BRDF, and any changes in the BRDF, of the on-board diffuser is critical in the on-orbit measurement of incident solar irradiance and the calculation of atmospheric ozone concentration.

\subsubsection{Spectral Characterization of UV Earth Remote Sensing Instruments}

Many of the ultraviolet albedo measuring satellite instruments are dispersive instruments employing either fixed or scanning gratings or prisms to spectrally resolve the backscattered and incident solar ultraviolet light. For these instruments, spectral calibration involves establishing their absolute wavelength scales and determining their spectral responsivities. Key to this process is the determination of an instrument's slit function, or the monochromatic image of its entrance and exit slits. The slit function determines the spectral resolution of the instrument. For a scanning instrument, the instrument grating or prism is scanned while viewing a monochromatic source calibrated for wavelength. For a fixed instrument, incident monochromatic light, calibrated for wavelength, is scanned over the instrument's operating channels. Most commonly, this monochromatic light is produced using a broadband light source and a monochromator, with the spectral bandpass of this light being smaller than the bandpass of the satellite instrument channel being measured. For this reason, this monochromator-based technique often suffers from low signal to noise. By monitoring the output of the monochromatic calibration source during the calibration using a second reference detector calibrated for spectral responsivity, the spectral responsivity of the remote sensing instrument can be determined.

Several innovative approaches in the spectral calibration of ultraviolet remote sensing instruments have appeared in the literature. System level responsivity measurements, particularly with monochromators equipped with broadband sources, often require a long time to acquire sufficient in-band and out-of-band data. It is also difficult for system level spectral characterizations to fill the instrument's entrance pupil. In the spectral calibration of OMI on EOS Aura, a xenon lamp illuminated echelle grating was used to produce multiple monochromatic lines at high grating orders [41]. The multiple spectral lines produced by this system enabled the complete operational wavelength range of OMI to be scanned using a step size of $0.01 \mathrm{~nm}$. Using this source, the slit function of OMI was determined through the instrument's nadir, Sun, and calibration ports. Tunable ultraviolet lasers are high photon flux, monochromatic sources capable of providing a high signal to noise measurement of spectral responsivity. Slit functions for the six spectral bands of the QuikTOMS instrument were measured using 
tunable ultraviolet light obtained by frequency doubling the output of a ring dye laser pumped by a Nd: $\mathrm{VO}_{4}$ laser [42]. In addition, this technique successfully established the wavelength centers for the six QuikTOMS bands to better than $0.1 \mathrm{~nm}$.

\subsubsection{The Radiometric Calibration of Visible/Near Infrared/Shortwave Infrared Earth Remote Sensing Instruments}

In the visible through shortwave infrared, remote sensing instruments are calibrated for irradiance and radiance in the pre-launch timeframe using a variety of filament lamps deployed in stand-alone configurations, with reflectance targets, or inside integrating spheres. Similar to work in the ultraviolet, the $1000 \mathrm{~W}$ quartz tungsten halogen FEL lamp is the most common irradiance standard source. Historically, the spectral irradiance values of working standard FEL lamps at NIST were assigned using a chain of comparisons based on the spectral radiance of a blackbody at the freezing temperature of gold [36]. In 2000, the procedure was revised; now the spectral irradiance values of the working standard lamps are assigned by direct comparison to the spectral irradiance produced from a high temperature blackbody. The blackbody temperature is determined using a set of absolute filter radiometers [43]. The great advantage to the new method is a reduction in the uncertainties in spectral irradiance by a factor of between 2 and 10.

For decades, diffuse targets illuminated by irradiance standard lamps and internally illuminated integrating spheres have been used as radiance standards for the calibration of satellite instruments from the visible through the shortwave infrared $[44,45]$. The use of lamps and diffuse targets in the calibration of remote sensing instruments was thoroughly reviewed as part of the Fourth SeaWiFS Intercalibration Round-robin Experiment (SIRREX-4) in May 1995 [46]. Briefly, accurate radiance calibration using a lamp illuminated diffuse target requires measurement of the BRDF of the target over the range of incident and view angles, spatial locations and wavelengths corresponding to the on-orbit operational instrument configuration. Following BRDF characterization, the target must be stored, handled, and deployed in such a manner as not to contaminate or change its reflectance. At the typical distances that irradiance lamps are used with diffuser targets (i.e. $50 \mathrm{~cm}$ to $100 \mathrm{~cm}$ ), the distribution of the lamp irradiance across the panel is not uniform. This non-uniformity coupled with the angular or goniometric response of the instrument under calibration must be characterized and understood. Lastly, the use of a $1000 \mathrm{~W}$ FEL lamp in a laboratory requires meticulous attention to baffling and stray light control.

With integrating spheres, internal diffuse sphere coatings, commonly barium sulfate paint or polytetrafluroethylene (PTFE), scatter the light from filament lamps that provide the source of their illumination. The spheres are designed to provide a source of uniform flux for instruments with large entrance apertures. Care is taken to provide spatial and angular uniformity across the exit aperture of the calibration spheres. Over past decades, incremental improvements have been made to these radiance sources [47]; but the basic design of the spheres has remained the same. In general, the spheres are calibrated with transfer radiometers that view, in an alternating fashion, the output aperture of the sphere and a source of known spectral radiance. The calibration references in the visible through shortwave infrared for the spheres use standard 
irradiance FEL lamps. As discussed previously, the irradiance from these lamps can be scattered from diffuse reflecting plaques to provide the radiance reference for the transfer radiometer [48]. Alternately, it is possible for the reference lamp to be viewed directly by the transfer radiometer [40]. Over the past decade, the development of stable, portable transfer radiometers has allowed independent verifications of the spectral radiance outputs from these calibration spheres. In a recent experiment [49], the measured radiances by these radiometers confirmed the calibration of such a sphere at the $3 \%$ level in the visible and near infrared and at the $4 \%$ level in the shortwave infrared.

A principal shortcoming of calibration spheres and diffuse targets illuminated using filament lamps is the mismatch of the distribution of their spectral radiance from that of Earth scenes viewed by the satellite instruments that they calibrate. The lamps produce a maximum flux output in the near infrared, around $1000 \mathrm{~nm}$, and relatively little output in the blue and green portions of the spectrum, near $400 \mathrm{~nm}$ and $500 \mathrm{~nm}$. For Earth observing satellites, blue and green Earth scenes are particularly important. A new type of calibration sphere using a spectrally tunable light source has been developed to resolve the problem with spectral mismatch [50]. The sphere uses solid-state light emitting diodes (LEDs) for illumination. Individual diodes produce light with different colors throughout the visible spectrum. Combinations of these diodes allow the production of radiance spectra corresponding to the range of Earth scenes viewed from orbit. In addition, the diodes of each color are sufficiently bright, that when used in combination, they are able to match the light levels from the brightest Earth scenes. An externally controlled, multiple channel power supply provides the current to the light emitting diodes in the set, which numbers 144 diodes in the current application. A fiber coupled spectroradiometer monitors the sphere output, controlling the power supply and the spectrum from the sphere by determining the differences of its measured values from an input target spectrum.

\subsubsection{The Spectral Characterization of Visible/Near Infrared/Shortwave Infrared Earth Remote Sensing Instruments}

Measurement methodologies for the determination of the spectral responsivity of remote sensing instruments operating in the visible through shortwave infrared are largely identical to those previously described for the ultraviolet, differing only in the sources employed. Briefly, the choice of measurement methodology depends on whether the instrument employs a fixed or scanning dispersive device, such as a grating or prism, or a series of fixed wavelength filters. For fixed grating or prism and filter instruments, a monochromator equipped with a quartz tungsten halogen lamp with an output bandwidth narrower than the remote sensing instrument to be calibrated is scanned over each instrument channel. By monitoring the output of this system with a calibrated reference detector the spectral responsivity of the remote sensing instrument is determined. The signal to noise obtained with this approach in the visible through shortwave infrared is typically higher than that obtained in the ultraviolet due to higher source photon flux and optical throughput at those wavelengths. The absolute wavelength scale and spectral responsivity of a scanning instrument can be determined using a monochromator equipped with a tungsten lamp, gas discharge lamps containing mercury and rare gases such as xenon, argon, krypton, and neon. 
An alternative to using monochromator-based sources or atomic discharge lamps for the measurement of spectral responsivity uses tunable lasers [51]. At NIST, the facility providing this measurement service is referred to by the acronym, SIRCUS, for Spectral Irradiance and Radiance Responsivity Calibrations with Uniform Sources. The laser sources in the SIRCUS facility provide a high signal-to-noise determination of the wavelength scale and absolute spectral responsivity of an instrument. In SIRCUS, the laser-based light source is monochromatic, and the wavelength of the source is tunable from $200 \mathrm{~nm}$ to $1800 \mathrm{~nm}$. The response of an instrument under test is calibrated against a reference detector with known spectral responsivity. These reference detectors are calibrated on a wavelength-by-wavelength basis over the full range of their response, including wavelength regions where their response is small. As the requirements for Earth-observing satellite instruments continue to develop, the isolation of the measurements of individual instrument channels to narrow ranges of wavelengths becomes increasingly important. The laser-based calibration method provides the basis for techniques to separate a channel's response in a desired operating wavelength region from its response to wavelengths outside of that region (i.e. the channel's spectral out-ofband responsivity). A bright, spectrally tunable light source covering a broad wavelength range, as discussed above, provides reference spectra that can test those techniques.

\subsubsection{The Thermal Emissive Range $(2500 \mathrm{~nm}$ to $100 \mu \mathrm{m})$}

\subsubsection{Introduction}

Observations of the Earth in the thermal infrared spectral region are important for quantitative analysis of the Sun-Earth system because the temperatures of terrestrial systems result in thermal emission for wavelengths greater than about $2.5 \mu \mathrm{m}$. In addition, the total fraction of solar radiation, which can be approximated by a blackbody distribution at $5870 \mathrm{~K}$, is less than about $3.4 \%$ for wavelengths longer than $2.5 \mu \mathrm{m}$; reflected solar flux is therefore not a major source of contamination.

The list of existing and historical sensors or programs with infrared channels is extensive. In the United States, NOAA specifies and operates sensors for near-real time storm warnings and other evaluations primarily using satellites in geostationary orbits (e.g. the Geostationary Operational Environmental Satellite (GOES) series), and for longer term weather forecasting and climate studies primarily using satellites in low Earth orbits (e.g. the Polar-orbiting Operational Environmental Satellite (POES) series). Currently, key instruments with TIR channels are the Advanced Very High Resolution Radiometer (AVHRR) and the High Resolution Infrared Radiation Sounder (HIRS), which are in the POES series, and the GOES Imager and Sounder, which replaced the GOES Visible Infrared Spin Scan Radiometer (VISSR) in 1994. Operational observations from polar orbits for civilian (e.g., POES) and military (e.g., the Defense Meteorological Satellite Program (DMSP)) programs are combined for future missions as the NPOESS program. The first of satellite platform in the NPOESS series, termed the NPOESS Preparatory Project or NPP, has four sensors, two of which have thermal infrared channels: the Visible/Infrared Imager Radiometer Suite (VIIRS) and the Crosstrack Infrared Sounder (CrIS). The next major series in the GOES program, termed GOES-R, is scheduled for enhanced capabilities such as increased spectral, temporal, and 
spatial resolution in the thermal infrared. In NASA's Earth Observing System (EOS) program, the Moderate-Resolution Imaging Spectroradiometer (MODIS), which is on the Terra and Aqua platforms, has heritage with AVHRR and HIRS. The Clouds and the Earth's Radiant Energy System (CERES) instrument, on the Tropical Rainfall Measuring Mission (TRMM), Terra, and Aqua platforms, and the Atmospheric Infrared Sounder (AIRS), on Aqua, are other examples. The Thematic Mapper (TM) and Enhanced Thematic Mapper Plus (ETM+) instruments on the Landsat series of satellites have one channel in the thermal infrared. A similar listing of sensors could be assembled for missions of the European Space Agency (ESA) and other countries.

A major application of absolute spectral radiance measurements in the thermal infrared is the determination of temperature. The simplest example of deriving the temperature of an object from absolute radiometric measurements is the observation of a blackbody with no atmospheric absorption - the spectral radiance and total exitance are given by Planck's Law or the Stefan-Boltzmann Law, respectively. Measurements in the thermal infrared of Earth scenes must be designed to account for, or provide corrections for, physical effects such as atmospheric absorption and thermal emission, diurnal variation in the solar illumination, the thermal radiative properties of the target object, and sources of non-thermal emission.

Regions of low atmospheric absorption, or "windows", are used to determine surface temperatures. The primary windows for this in the thermal infrared are from $3.8 \mu \mathrm{m}$ to $4.0 \mu \mathrm{m}$ and from $10.2 \mu \mathrm{m}$ to $12.5 \mu \mathrm{m}$. Correction for atmospheric absorption by water vapor is required; typically, measurements of the water vapor feature at $6.3 \mu \mathrm{m}$ are used for this purpose. The emittance of the surface must be known, since it is not an ideal blackbody radiator. For sea surface temperature (SST) measurements, which are typically performed at $11 \mu \mathrm{m}$ and $12 \mu \mathrm{m}$, emittance values for seawater are known, but there is a significant "skin effect" that must be accounted for accurate determinations of the bulk temperature. The temperatures of land, snow, or ice can be determined in similar ways if the target is classified properly so its emittance can be assigned.

Values for the temperature of the atmosphere as a function of altitude are determined by radiance measurements at multiple discrete wavelengths that overlap a broad absorption line of a well mixed atmospheric gas such as $\mathrm{CO}_{2}$. For these spectrallyresolved measurements of atmospheric absorption features from space, the optical depth at the measurement wavelength is a strong function of wavelength-near the center of the absorption feature, the optical depth is small with the observed thermal emission originating high in the atmosphere; measurements at wavelengths closer to the edge of the absorption feature sample the temperature of the atmosphere at lower altitudes. This technique is termed atmospheric sounding [52]. Two features in $\mathrm{CO}_{2}$ are typically used for temperature sounding, one near $4.47 \mu \mathrm{m}$ and the other near $14.95 \mu \mathrm{m}$. These studies began with filter radiometry. The finite number of measurement wavelengths that can be placed in filter radiometers such as HIRS limits the vertical resolution of the temperature retrievals. High resolution grating or interferometric systems do not suffer this limitation. AIRS is a grating spectrometer with coverage from $3.74 \mu \mathrm{m}$ to $15.4 \mu \mathrm{m}$ [53]. Use of Fourier transform spectrometers for sounding of the Earth's atmosphere began in 1969 with the Infrared Interferometer Spectrometer (IRIS) on Nimbus [54]. Currently, the limb-scanner named the Michelson Interferometer for Passive Atmospheric Sounding (MIPAS) is on the ESA's Environmental Satellite (ENVISAT) [55] and the Tropospheric 
Emission Spectrometer (TES) is on EOS Aura. In the near future, the Infrared Atmospheric Sounding Interferometer (IASI) will fly on ESA's Meteorological Operational satellite (MetOP) and the Crosstrack Infrared Sounder (CrIS) on NPP/NPOESS. The increased spectral resolution using CrIS is expected to improve the vertical resolution in the temperature profiles by a factor of two or three [56].

Another broad application of thermal infrared measurements involves cloud studies, see Menzel [57] for example. On-orbit observations at $10.7 \mu \mathrm{m}$ give the brightness temperature of the top of the cloud. Since the cloud-top temperature is close to the atmospheric temperature, and the temperature profile is known, the height of the cloud can be determined. Cloud detection algorithms incorporate visible imagery with the thermal infrared imagery. In a typical image, pixels that are bright in the visible channels and dim (i.e. cold) in the thermal infrared channels are probably clouds, since, compared to the surface below, clouds reflect more incident solar flux but are cooler because of the cloud top's position in the atmosphere.

Many other products are derived using thermal infrared measurements, such as the vertical distribution of water vapor, total ozone levels, thermal inertial studies, and the Earth's radiation budget. As shown in Fig. 10.2, the emitted thermal radiation and the incoming and reflected solar flux are the three components of the Earth's radiation budget. Values for and variations in these parameters are critical for accurate understanding of global climate change. The CERES instrument is designed to measure these parameters [58].

\subsubsection{The Radiometric Calibration of Thermal Infrared Remote Sensing Instruments}

The most common calculable sources for the thermal emissive spectral range are based on blackbody physics. Several blackbody sources are described in Chapter 5 . For ideal blackbodies, Planck's Law specifies the spectral radiance from an ideal blackbody in terms of its thermodynamic temperature and the measurement wavelength. In "fixedpoint" blackbodies, the temperature is set by surrounding the blackbody cavity by a pure, molten metal that is undergoing a phase transition. With the temperature at a constant value during the transition, the spectral radiance is calculable. Values for the relevant temperatures of the reference materials are given in The International Temperature Scale of 1990 (ITS-90) [59]. Reference points in the temperature range of interest are the triple points of $\mathrm{Hg}, \mathrm{H}_{2} \mathrm{O}$, and the melting point of $\mathrm{Ga}$.

Fixed-point blackbodies are expensive, tedious to operate, and exhibit substantial temperature gaps in their coverage. The diameter of the cavity exit aperture is generally small compared to the entrance apertures of Earth-observing sensors. Instead, variable temperature blackbody standards are constructed with various materials and instrumented with calibrated contact thermometers, such as thermistors or platinum resistance thermometers (PRTs). Thus the traceability of spectral radiance values is established using temperature standards that are calibrated according to ITS-90.

If a cavity is black with unity emittance and its temperature is uniform, the uncertainty of the spectral radiance is determined only by the uncertainty of the temperature and associated fundamental constants. Real blackbodies are only an approximation of this ideal, and therefore they must be characterized to determine the emittance, spatial and angular uniformity, stability, and so forth. For large-area 
blackbodies, it is difficult to achieve unity emittance. If the background environment is not cooled to low temperatures $(\sim 80 \mathrm{~K})$, as in a thermal-vacuum chamber with cooled inner walls or shrouds, the reflection of the background radiance from the blackbody must be considered.

In general, a blackbody source is designed to function either as a laboratory reference standard or as a component of the flight sensor. Pre-flight measurements by the sensor of the laboratory reference blackbody source are typically performed in a thermalvacuum chamber over a range of blackbody temperatures. During flight, measurements by the sensor of the internal "on-board" blackbody source are used to account for changes in the sensor responsivity. In addition, measurements of the internal blackbody by the sensor during the pre-flight calibration establish traceability to the reference blackbody, provided the uncertainties in each step, which may include corrections for bias and other effects that are difficult to quantify (e.g., the stability of the on-board source, the effects of launch, the variation in reflectance of the scan mirror with angle of incidence, or stray sources of illumination), are described in complete detail. Many sensors are also designed to have a view of space during part of the measurement procedure so that the sensor output to a cold source (i.e. approximately zero radiance) can be determined.

The laboratory reference blackbody is designed to achieve an emittance as close to unity as possible and to provide full-aperture illumination for the sensor over its dynamic range by operation at different temperatures. Isothermal cavities with small exit apertures compared to their overall length are preferred, since this geometry allows for multiple reflections, resulting in higher emittance compared to flat plate sources [60]. Cavity-type blackbody sources were used, for example, to calibrate CERES [58] and MODIS [61]. However, long structures increase the size and cost of the thermal vacuum chamber, and a common compromise is to use a flat-plate structure with grooves in combination with a temperature-controlled, cylindrical baffle. This design concept was used to calibrate, for example, the Improved Stratospheric and Mesospheric Sounder (ISAMS) [62] and the Advanced Spaceborne Thermal Emission and Reflection Radiometer (ASTER) that is on Terra [63]. The on-board blackbody sources are generally of the flat plate design, in order to comply with the sensor's size and mass restrictions.

The result of detailed characterization and modeling are spectral radiance values, traceable to temperature standards, with the uncertainty components arising from all possible sources: the measurement of the bulk temperature, the emittance of the cavity based on its geometric design and optical properties of the coating, the effect of temperature gradients, the effect of incident irradiance, and so forth. The temperature sensors can be calibrated once they are mounted to the blackbody by use of an isothermal bath [64]. The cavity emittance can be calculated for a range of parameters, including non-isothermal conditions, using Monte Carlo methods [65]. The specular and diffuse reflectance of the coating or assembled cavity can be measured using established techniques in IR spectrophotometry; however the low reflectance values may result in uncertainties that are larger than desired. A complete, system level thermal and radiative analysis of the blackbody source its environment within the thermal vacuum chamber is often performed to identify and quantify sources of bias. Finally, the spectral radiance of the blackbody source can be determined within the exit aperture as a function of position, 
view angle, and operating temperature. Comparison of the output as a function of size of the exit aperture is also informative.

Advances in detectors have made it possible to verify the output of blackbody sources by direct measurement of the spectral radiance or exitance. These measurements are critical for validating the characterization and calibration of the blackbody source. The NIST Low Background Infrared Calibration Facility (LBIR) uses an absolute cryogenic radiometer to determine the radiance temperature of a user's blackbody from exitance measurements $[66,67]$. In some cases the radiometrically-determined temperatures were in poor agreement with the blackbody contact thermometry, resulting in improvements to the blackbody design.

It is not always possible to send a source to an external facility for calibration, and in the thermal infrared, differences in thermal environment between the host chamber and the NIST facility may result in misleading results. The portable Thermal Infrared Transfer Radiometer (TXR) was developed by NIST with support from NASA/EOS and the Department of Defense (DOD) so that the spectral radiance of a blackbody source could be verified at two wavelengths $-5 \mu \mathrm{m}$ using a photovoltaic indium antimonide (InSb) detector and $10 \mu \mathrm{m}$ using a photovoltaic mercury cadmium telluride (MCT or $\mathrm{HgCdTe}$ ) detector [68]. The detectors, filters, and reflective optics are built into a liquidnitrogen cryostat with a $\mathrm{ZnSe}$ window. A variable-temperature, vacuum compatible blackbody that can rotate in front of the TXR window under computer control is used to monitor the stability of the TXR during deployments. A convenient feature of the TXR is that it can be operated either in a vacuum chamber or on a laboratory bench under typical laboratory conditions (i.e. an "ambient" environment).

Calibration of the TXR has been performed using multiple approaches. Initially, the NIST water-bath blackbody [69] was used. More recently, the TXR was calibrated in the NIST Medium Background Infrared (MBIR) facility [70] using its cryogenic blackbody. Note both of these methods establish traceability to temperature standards. At the present time, the TXR uncertainty is $<0.1 \mathrm{~K}$ at $300 \mathrm{~K}(k=2)$. In the future, the spectral characterization will be improved using tunable laser measurements on the NIST Infrared SIRCUS facility, and the MBIR cryogenic blackbody source will be validated using an electrical substitution radiometer (ESR) based on high-Tc superconducting temperature sensors.

The TXR has been used on multiple occasions to verify thermal infrared spectral radiance values. In July 1999 and August 2001, it was deployed to the remote sensing radiometric calibration facility at Los Alamos National Laboratory (LANL) in support of DOE programs [71,72]. In July 2001, the TXR was deployed to the GOES-Imager radiometric calibration chamber at ITT in Ft. Wayne, Indiana [73]. The ITT chamber is not equipped with cooled shrouds. The reference blackbody for the GOES Imager is the Earth Calibration Target (ECT), and a cold blackbody source is used for offset determinations. The ITT procedure involves correcting for temperature gradients in the ECT, which were believed to be driven by the thermal background of the chamber [74]. During the TXR deployment, measurements were made of the cold blackbody, and the ECT and the TXR check standard blackbody at a range of temperatures. An analysis procedure was developed that enabled parameterization of the results in terms of a nonunity emittance and a temperature gradient in the ECT. The results are in qualitative agreement with the existing GOES model, and more analysis is planned. More recently, 
in the fall of 2003 the TXR was used to measure a blackbody source at Santa Barbara Remote Sensing (SBRS) in Goleta, California in support of DOD research. Then, early in 2004, the TXR measured an additional blackbody source at SBRS [75]. This source was used to calibrate MODIS [53], and it will be used to calibrate the Visible/Infrared Imager/Radiometer Suite (VIIRS) on NPP/NPOESS. The experiment was interesting in that a variable temperature scene plate was used and this information was exploited to determine the blackbody emittance [75].

\subsubsection{The Spectral Characterization of Thermal Infared Remote Sensing Instruments}

The measurement facilities and procedures necessary for sensor characterization in the thermal infrared are similar to those in the visible/near infrared and the shortwave infrared, with a couple of major exceptions. First, at ambient $(\sim 300 \mathrm{~K})$ temperatures, all objects are sources of radiant flux, so care must be taken to separate signal from background, even when chopping shutters are used. Second, radiometric artifacts or systems that play a critical role in the visible/near infrared and the shortwave infrared, such as reliable and relatively inexpensive transfer standard radiometers employing silicon (Si) photodiode trap detectors and commercially-available, broadly tunable lasers, are not available.

General approaches for thermal infrared spectral characterization methods are given in texts such as in Wyatt [76]. For example, the determination of the sensor's response to quasi-monochromatic flux that fills the entrance pupil and is varied spectrally to cover the full range of possible detector response defines the spectral responsivity function. The wavelength and bandwidth of the input flux is determined by the source, which is usually a continuous source filtered by a monochromator or interferometer. A broadband, spectrally-flat, calibrated detector is used to correct for the variation of output flux with wavelength. Typically, the sensor is operated in the thermal-vacuum chamber, and best results will be obtained if the relevant temperatures (e.g. the instrument housing temperature, electronic components, scan mirror, etc.) are varied over the range of values expected during flight. There are numerous examples in the literature $[61,63,77]$.

The determination of an instrument's spectral responsivity function is often calculated using measurement results of the individual components, but this may not account for the effects of component temperature, inter-reflections, diffraction, scatter, and differences in the $\mathrm{f} / \#$ of the incident flux. System level measurements that fill the entrance pupil, provided sufficient flux can be produced, are more accurate [78]. Accuracy is essential: in atmospheric sounding sensors such as HIRS, small discrepancies in the wavelength scale of the channel can induce large errors in temperature retrievals (e.g., a $3 \mathrm{~cm}^{-1}$ shift in center frequency at $14.95 \mu \mathrm{m}$ results in a $10 \mathrm{~K}$ error for stratospheric temperatures [79]). Because HIRS is an operational system, results from sensors on different platforms are often intercompared. However, real but unquantified differences in the sensors' spectral responsivities make this very difficult [80]. As part of this study, NIST measured filter witness samples for NOAA-N' HIRS at four temperatures between $15^{\circ} \mathrm{C}$ and $30^{\circ} \mathrm{C}$ with a geometry matched to the HIRS (f/8) geometry [81]. The observed differences with the results provided by the vendor are a likely explanation for some of the large observed inter-satellite radiances [80]. 
Feb 212005

Recent advances in tunable lasers and transfer detectors with responsivity values traceable to absolute cryogenic radiometry have resulted in a Spectral Irradiance and Radiance responsivity Calibrations using Uniform Sources (SIRCUS) facility at NIST. Because of the high flux levels, the narrow bandpass, low uncertainty in wavelength, unpolarized nature of the flux, and the ability to chop at the source using a SIRCUS-type facility, the uncertainties in the sensor's radiometric calibration and spectral characterization can be greatly reduced. There are many examples of applications for remote sensing in the spectral region from about $380 \mathrm{~nm}$ to $1000 \mathrm{~nm}$ [82]. Measurements with tunable lasers are also possible out to about $5 \mu \mathrm{m}$, and several filter radiometers have been characterized [83]. Plans call for extension of the spectral range past $5 \mu \mathrm{m}$, and this would greatly benefit a wide range of remote sensing instruments.

\subsection{The Measurement of Total Solar Irradiance (TSI)}

\subsubsection{The Importance of TSI Measurements in Climate Studies}

The driving energy source for the Earth system is the Sun. The interaction of the Sun's radiant flux with the Earth's land, oceans, atmosphere, and cryosphere influence a number of processes on the Earth including climate, weather, photosynthesis, temperature, and ocean dynamics. The radiant output of the Sun varies with wavelength and time [84]. One example of temporal solar variation with time is the well-known 11 year solar cycle discovered in 1843 by Heinrich Schwabe by counting sunspot activity over a 17 year period [85]. Long-term variations in the radiant output of the Sun are potential causes of natural climate change [86] while short term variations are important in gaining a better understanding of the fundamental physics of the Sun. Understanding the long term and often subtle variations and trends in the Sun's radiant output, therefore, is critically important in being able to differentiate overall between natural and anthropogenic climate change processes on Earth. The importance of measurements of long term change in the Sun's radiant output was underscored in a 1994 publication by the National Research Council on research priorities for solar influences on global change [87]. In that publication, the NRC emphasized the importance of solar measurements by recommending that highest priority be given to "monitoring total and spectral solar irradiance from an uninterrupted series of spacecraft radiometers employing in-flight sensitivity tracking".

The key parameter in the measurement and monitoring of the radiant output of the sun is total solar irradiance (TSI). In general, TSI can be defined as the power of all optical wavelengths reaching the Earth from the Sun. TSI can more precisely be defined as the radiant energy emitted by the Sun over all spectral regions falling each second on one square meter at the mean Earth-Sun distance. Measurements of TSI have historically been made using ground-based instruments, balloon-borne instruments, aircraft instruments, shuttle-based instruments, and satellite instruments [88-98]. Comparisons of the long history of TSI measurements have led to the realization that highest accuracy TSI measurements would need to be made above the Earth's atmosphere from satellite platforms. Long duration, high accuracy measurements of TSI from space began with the launch of the Earth Radiation Budget Experiment (ERBE) on the Nimbus 7 satellite in November 1978. High accuracy TSI measurements by ERBE were realized through the 
use of electrical substitution radiometry. Table 3 lists the long-term TSI satellite instruments, all of which employed electrical substitution radiometry, and their on-orbit measurement data records beginning with the Nimbus 7 ERBE. Figure 10.3 presents the historical total solar irradiance data base produced by several of these instruments. From the data in Fig. 10.3, the instruments have shown good internal consistency or precision based on their ability to reproduce the relative magnitudes of the 11 year solar cycles. $<$ Figure 10.3>

However, the differences in the absolute values of the TSI reported by these instruments are several times the $1.3 \mathrm{~W} / \mathrm{m}^{2}$ amplitude of a typical solar cycle and in several cases are larger than the instruments' reported measurement uncertainties. These differences coupled with temporal gaps in the historical database have led to ambiguities and controversial assumptions in the overall determination of the absolute TSI. For example, both Willson and Mordvinov [99] and Frohlich and Lean [100] have attempted to span a 28 month gap in the measurements of TSI by the ACRIM1 and ACRIM2 instruments between solar cycles 21 and 23 using TSI measurements from other on-orbit instruments. In order to span the data gap, Willson and Mordvinov used Nimbus7/ERB results [97] while Frohlich and Lean used ERBS results [101]. The results of Willson and Mordvinov show an upward trend of $0.05 \%$ per decade in TSI between consecutive solar minima while the results of Frohlich and Lean do not. Willson has claimed the upward decade minimum-to-minimum trend to be significant and to have important implications for long-term climate studies. On a positive note, the differences in on-orbit TSI measurements have led to an increased realization by the TSI community of the importance of meticulous instrument pre-launch calibration and characterization, the accurate assessment of instrument on-orbit degradation, and the need for stronger cooperation between the scientific and national metrological laboratories in an effort to understand and reduce TSI measurement uncertainties.

\subsubsection{The Operation of TSI Instruments}

Since 1978 , the majority of TSI measuring satellite instruments have been electrical substitution radiometers $[90,102]$. These satellite instruments employ at least two identical cavity sensors. During operation, one cavity is "active" and the other serves as a reference. These cavities are highly emissive and thermally connected so that they initially experience the same thermal environment and hence the same temperature. The cavities are electrically heated to a common temperature. Upon exposure of the active cavity to the Sun, the incident solar flux is converted to heat by the highly emissive cavity. This causes the temperature of the active cavity to rise relative to the reference, introducing an imbalance between the temperatures of the cavities. An amount of electrical heat is subtracted from the active cavity in order to induce temperature equivalence with the reference cavity. This amount of electric heat is equivalent to the amount of incident solar flux and proportional to the total solar irradiance.

From 1978 to 2002, TSI was measured by satellite-borne electrical substitution radiometers using a time domain analysis $[91,93,95,97]$. In this method of operation, a shutter is opened at some time, $t$, exposing the active cavity to solar flux for a time equal to $\Delta \mathrm{t}$, during which a signal offset in digital numbers, $\Delta \mathrm{DN}$, is recorded proportional to the total solar irradiance through the standard watt. Measurements are made only after 
the cavity temperatures are completely stabilized following shutter openings or closings. Since February, 2003, the Total Irradiance Monitor (TIM) instrument on the EOS Solar Radiation and Climate Experiment (SORCE) $[96,103,104]$ has acquired total solar irradiance measurements using phase sensitive or lock-in detection. In this method of operation, all digital data are used during the shutter cycles and the irradiance is quantified using analysis in the frequency domain. The advantages of this approach include increased signal to noise and a more simplified description of temporal and thermal system behavior.

\subsubsection{The Calibration and Characterization of TSI Instruments}

Given a typical on-orbit satellite instrument lifetime of 5 years, the approach toward monitoring long-term, decadal changes in total solar irradiance has been to employ an overlapping time series of satellite instruments. The required absolute accuracy and precision of the on-orbit measurement of TSI are $0.01 \%$ and $0.001 \%$, respectively. From the historical TSI data shown in Fig. 10.3, the agreement between instruments is on the order of $0.3 \%$, a factor of 30 higher than the required absolute accuracy. Moreover, the $0.01 \%$ accuracy and $0.001 \%$ precision goals for the measurement of TSI are extremely ambitious when one considers that the best radiometric accuracy claimed by national measurement laboratories in the measurement of radiant flux in a laser beam using an absolute cryogenic radiometer is $0.01 \%$ [105]. The TIM instrument on the EOS SORCE mission was designed to make TSI measurements with an absolute accuracy of $0.01 \%$ and a precision of $0.001 \%[86,103]$. The determination of the measurement uncertainty of the TIM instrument was based on the propagation of subsystem level uncertainties in the parameters which comprise the TIM measurement equation and not on a system level measurement. Parameters included in the TIM analysis included uncertainties in the spacecraft/Sun distance, the thermal equivalence between solar and electrical heating of the detector cavities, on-board electrical standards, shutter waveform, instrument gain, cavity absorption and determination of its on-orbit degradation, diffraction effects, and the area of the limiting aperture.

Understanding the differences between the measurements of TSI by satellite instruments as shown in Fig. 10.3 depends on extensive pre-launch instrument characterization and an accurate assessment of on-orbit instrument degradation. A significant contributor in TSI measurement uncertainty and an important characterization parameter of TSI instruments is the accurate determination of the area of the instrument limiting aperture. Aperture area measurements for TSI instruments have been performed using both contact and non-contact methods [106]. Preliminary results have been recently been published on an international comparison of aperture area measurements made by solar irradiance research groups [106]. The results of this study indicate that for the two participating laboratories, the aperture area measurements of the laboratories are consistently higher than those made by NIST and differences between the laboratory measurements are greater than their combined measurement uncertainties. The average difference of the two laboratories from NIST are $0.013 \%$ and $0.065 \%$, accounting for a portion of the $0.3 \%$ difference in the TSI historical database. On-orbit degradation of the response of TSI instrumentation to solar flux is monitored using multiple cavity detectors 
exposed at different duty cycles over the mission lifetime. The rate of degradation of the emissivity of these cavities is dependent on the surface treatment of the interior of the cones. Before 2002, TSI instruments employed cavities with interiors painted with organic specular or diffuse black paints. The TIM instrument on EOS SORCE is the first TSI instrument to use a metallic nickel phosphide (NiP) black surface treatment on the absorbing interior of their cavities. Sudden changes in the emissivity/reflectance of the TIM cavity is monitored using photodiodes positioned to view the cavity interiors.

\subsubsection{Future Developments and Directions in the Measurement of TSI}

The influence of changes in TSI on climate will only be understood if there is a continued commitment to fly an overlapping long-term series of well-characterized and calibrated new and redundant instruments. The state-of-the-art requirements for the characterization and calibration of TSI instruments will require greater involvement by national measurement institutes (NMIs) in the instruments' design, testing, and review processes.

\subsection{Spectral Solar Irradiance (SSI)}

\subsubsection{The Importance of Measurements of SSI in Earth Remote Sensing}

Over the past several decades, there has been a concerted effort to understand the spectral irradiance from the Sun. Earth remote sensing instruments do not measure this irradiance, a central component in interpreting Earth remote sensing results. It is necessary in the conversion between radiance and reflectance data products [107], and, in some cases, in the intercomparison of results from remote sensing instruments [108]. As a result, the solar spectral irradiance is incorporated into remote sensing analysis procedures as an ancillary data set. In general, the quality of solar spectral irradiance measurements has improved over time. And in general, individual instruments and measurement campaigns do not provide the solar spectral irradiance over the full wavelength range required for the various types of Earth remote sensing measurements. As a result, there are several sets of irradiance compilations in the literature. Four representative compilations are listed in Table 10.4 .

$<$ Table 10.4>

Thekaekara [109] produced an early compilation, which at the time was given the informal titles of the "Standard Irradiance Table" and the "NASA Standard". The compilation was based on aircraft-based solar measurements plus additional values from literature references in the ultraviolet and infrared [110]. A subsequent compilation by the World Radiation Center and the World Climate Research Program by Wehrli $[111,112]$ used ground-based measurements over wavelengths from $0.2 \mu \mathrm{m}$ to $0.31 \mu \mathrm{m}$ by Brasseur and Simon [113], from $0.31 \mu \mathrm{m}$ to $0.33 \mu \mathrm{m}$ by Arvesen et al. [114], from $0.33 \mu \mathrm{m}$ to $0.87 \mu \mathrm{m}$ by Neckel and Labs [115], from $0.87 \mu \mathrm{m}$ to $2.5 \mu \mathrm{m}$ by Arvesen et al. [114], and from $2.5 \mu \mathrm{m}$ to $20 \mu \mathrm{m}$ by Smith and Gottlieb [116]. As a reference spectrum for the Hubble Space Telescope, Colina et al. [117] compiled a set of measurements based on measurements by the Upper Atmosphere Research Satellite from $0.12 \mu \mathrm{m}$ to $0.41 \mu \mathrm{m}$ by Woods et al. [118], from $0.41 \mu \mathrm{m}$ to $0.87 \mu \mathrm{m}$ by Neckel and Labs [115], and 
from $0.87 \mu \mathrm{m}$ to $0.96 \mu \mathrm{m}$ by Arvesen et al. [114]. For wavelengths from $0.96 \mu \mathrm{m}$ to $2.5 \mu \mathrm{m}$, Colina et al. [117] used a model spectrum citing deficiencies in the available measured solar irradiance spectra.

The Moderate Resolution Atmospheric Transmittance and Computer Model (MODTRAN) [119] includes several compiled solar irradiance spectra. With the need for calculations at a spectral resolution unobtainable by current solar-monitoring instruments, these irradiance spectra are derived, in part, by computation $[120,121]$. Computation is a standard procedure for the production of very high spectral resolution solar irradiance spectra.

\subsubsection{Recent Measurements of SSI}

Recently, Thuillier has published sets of solar spectral irradiance measurements made from the Space Shuttle. The measurements were made using three spectrometers, with the ultraviolet measurements published in 1997 [122], the visible and near infrared results published in 1998 [123], and the full set of measurements published as a single solar spectrum from $0.2 \mu \mathrm{m}$ to $2.4 \mu \mathrm{m}$ published in 2003 [124]. These results have been designated as the reference solar spectrum for the Committee on Earth Observing Satellites (CEOS). However, there is no single spectrum mandated for universal use.

The Spectral Irradiance Monitor (SIM) [125,126] was launched in January 2003 onboard the EOS Solar Radiation and Climate Experiment (SORCE) satellite. The measurements from SIM should provide the next step in the determination of the solar irradiance spectrum from the ultraviolet to the shortwave infrared. However, for instruments that measure in the mid-wave infrared, $3.5 \mu \mathrm{m}$ to $4 \mu \mathrm{m}$ (e.g. MODIS [127]), the best available measurements of the solar irradiance are three decades old (see Table 10.4). This marks a fundamental deficiency in our understanding of the solar spectral irradiance.

\subsection{Transferring Pre-launch Calibration and Characterization to On-orbit Operation}

The possibility of change in the calibration of satellite instruments from the time of their laboratory characterization to the start of on-orbit operation is a principal source of uncertainty in their measurements. The determination of this change generally involves the measurement of an artifact within the instrument, both before and after the transfer to orbit. Several attempts have been made using onboard lamps as the artifact. The results of the Advanced Land Imager (ALI) [128] on the EO-1 platform are typical of those attempts. For ALI there was a noticeable increase in the output of the lamp in the visible and near infrared at the start of on-orbit operations. This change was attributed to the loss of convective cooling within the lamp and the zero gravity environment on-orbit. The reduced cooling increased the temperature of the lamp's filament and, thus, the lamp's output. For the MODIS instrument onboard the Terra spacecraft, an effort was made to account for the change in filament temperature of onboard lamps in the Spectroradiometric Calibration Assembly (SRCA) from pre-launch to on-orbit. This was done in a series of pre-launch experiments by tracking the radiance from the reference lamp as a function of the resistance of the lamp's filament [129]. 
However, the results of the on-orbit measurements with the reference lamp have not been presented. This is due to the decision to use the pre-launch characterization of the instrument's solar diffuser as the reference for the sensor's measurements in the visible, near infrared, and shortwave infrared wavelength regions [130,131]. This decision negated the plan to use the SRCA to transfer the MODIS pre-launch radiance calibration to orbit. For Terra MODIS, there was no attempt to determine changes in the characteristics of the onboard diffuser during the transfer to orbit.

The Sea-viewing Wide Field-of-view Sensor (SeaWiFS) used measurements of the Sun outdoors at the instrument manufacturer's facility to predict the instrument outputs during solar measurements immediately after launch [132]. Because an on-board diffuser plate is required for these measurements, the experiment measured changes in the instrument-diffuser system. The largest uncertainty in the experiment comes from the determination of the atmospheric transmission in the pre-launch measurements, and the overall uncertainty in the experiment is $3 \%$. For the eight SeaWiFS bands, the initial instrument outputs averaged $0.8 \%$ higher than expected with a standard deviation of $0.9 \%$. Within the uncertainty of the experiment, there were no changes in the responses of the SeaWiFS bands from the completion of the instrument's manufacture to its insertion into orbit.

Remote sensing instruments operating at thermal infrared wavelengths typically use their on-board blackbody sources to transfer their pre-launch laboratory radiance calibrations to on-orbit operation. As outlined in section 10.2.2.2, the radiance scale from a high quality, laboratory blackbody is transferred pre-launch to the instrument's onboard blackbody. With proper handling and storage of the instrument before, during, and after integration onto the spacecraft, the instrument's on-board blackbody is assumed to maintain its scale through launch. For high quality on-board blackbodies, such as those employing cavity-based designs, the pre-launch radiance calibration of the on-board blackbody can be carried directly into orbit.

\subsection{The Role of Post-launch Calibration and Characterization}

\subsubsection{The Ultraviolet and Solar Reflective Range}

\subsubsection{Air Ultraviolet and Solar Reflective On-board Radiometric Calibration}

The pre-launch radiance and irradiance calibrations of remote sensing instruments are transferred to on-orbit operation and monitored over their complete mission lifetimes. Techniques for performing on-orbit calibration and monitoring of remote sensing instruments operating in the ultraviolet and solar reflective wavelength range between $190 \mathrm{~nm}$ and $2500 \mathrm{~nm}$ employ dedicated hardware systems such as reflective and transmissive solar diffuse targets, lamp sources, and views of extensive, natural targets such as playas, snow fields, deserts, thick clouds, and celestial targets such as the Moon and stars. 


\subsection{Solar Diffusers}

On-board solar diffuse targets illuminated by the sun are commonly used to perform and monitor on-orbit radiance and irradiance calibrations of remote sensing instruments. With knowledge of the spectral solar irradiance, the solar irradiance incident elevation and azimuthal angles, the instrument view angle on the diffuser, and the bidirectional reflectance distribution function (BRDF) in the case of a reflective diffuser or the bidirectional transmission distribution function (BTDF) in the case of a transmissive diffuser, the radiance reflected by the diffuser into the satellite instrument is given by

$$
L\left(\theta_{i}, \varphi_{i}, \theta_{s}, \varphi_{s}, \lambda\right)=\operatorname{BRDF}\left(\theta_{i}, \varphi_{i}, \theta_{s}, \varphi_{s}, \lambda\right) \cdot E_{\text {sun }}(\lambda) \cdot \cos \left(\theta_{i}\right) / d_{\text {earth-sun }}^{2}
$$

where $L$ is the radiance off or through the solar illuminated diffuser at wavelength, $\lambda ; \theta_{i}$ is the incident elevation angle of solar illumination onto the diffuser; $\varphi_{i}$ is the incident azimuthal angle of solar illumination onto the diffuser; $\theta_{s}$ is the elevation angle at which the instrument views the diffuser; $\varphi_{s}$ is the azimuthal angle at which the instrument views the diffuser; $E_{\text {sun }}$ is the solar irradiance at wavelength, $\lambda$, at 1 astronomical unit (AU), and $d_{\text {earth-sun }}$ is the distance from the earth to the sun at the time which the instrument views the diffuser. Incident and viewing elevation and azimuthal angles can be specified relative to the diffuser normal. Carefully sized and appropriately positioned in a satellite instrument, the solar-illuminated diffuser can provide a full-system, full aperture, on-orbit radiometric calibration using the Sun-the same source which illuminates the remotely sensed Earth. In addition to being a full aperture illuminator, solar diffusers have other desirable properties. These include being chemically and optically stable and a Lambertian, spectrally featureless, spatially uniform reflector or transmitter.

While the basic measurement application of solar diffusers in the on-orbit calibration of remote sensing instruments has largely remained unchanged for roughly four decades, advances in the optical, chemical, and mechanical testing and properties of materials and coatings has led to the evolution and use of a variety of types of diffusers. Table 10.5 lists a number of reflective and transmissive diffuser materials and coatings flown on the instruments listed.

$<$ Table 10.5>

The diffuser materials and coatings listed in Table 10.5 can be categorized according to whether they are bulk scatterers (i.e. permit incident photons to penetrate the diffuse material and undergo multiple scattering events before exiting) or surface scatters (i.e. largely reflect incident photons in a single scattering event). Of the materials listed, Spectralon, a form of pressed and sintered PTFE manufactured by Labsphere, is the best bulk scatterer and most closely approximates a Lambertian scatterer. However, significant research and development was necessary to produce Spectralon of sufficient optical stability to be used on-orbit. This was largely attributed to the undesirable property of Spectralon to readily absorb hydrocarbon contaminants. This research and development work, spearheaded by NASA's Jet Propulsion Laboratory and Labsphere Incorporated, included extensive analyses of the manufacturing, handling, and on-orbit degradation of Spectralon [156-158] and directly led to the development of space-grade Spectralon. 
On-orbit use of space-grade Spectralon diffusers has been largely confined to those remote sensing instruments operating in the visible, near infrared, and shortwave infrared wavelength regions between $400 \mathrm{~nm}$ and $2500 \mathrm{~nm}$. Spectralon is not used in the on-orbit calibration of ultraviolet instruments operating between $200 \mathrm{~nm}$ and $400 \mathrm{~nm}$ due to its tendency to undergo significant reflectance degradation in that wavelength region. In the ultraviolet region, the diffuser material of choice historically has been roughened aluminum with aluminum or an aluminum alloy overcoat. The reflectance stability of aluminum diffusers, particularly for ultraviolet applications, is thought to arise from the formation over time of a protective, optically stable aluminum oxide overcoat on the diffuser. The Ozone Monitoring Instrument (OMI), launched in July 2004 on the EOS Aura platform, is equipped with two reflective aluminum diffusers, a quartz transmissive diffuser, and a reflective quartz plate volume diffuser. The two reflective aluminum diffusers are used in the on-orbit irradiance calibration of the instrument. The quartz transmissive diffuser is used to uniformly illuminate the OMI entrance slit during a measurement of an on-board white light source. The quartz plate volume diffuser is used daily in measurements of the solar irradiance spectrum. Interestingly, spectral interference effects first seen in reflective aluminum diffuser measurements during the pre-launch characterization of OMI are greatly reduced using the quartz plate volume diffuser [159].

Using clever instrument optical designs, some remote sensing instruments are able to use their solar illuminated diffusers to realize multiple radiance levels. A simple design to do this is provided by the MODIS instruments on Terra and Aqua [127]. The MODIS instruments are able to view their solar diffusers under the conditions of full solar illumination and $8 \%$ solar illumination. The $8 \%$ illumination level is realized using an on-board, deployable transmissive screen mounted on the instrument solar diffuser door. The Advanced Land Imager (ALI) instrument on EO-1 deploys a slotted mask in front of the diffuser to realize multiple illumination levels [139]. The mask is comprised of seven slots of varying area designed to provide signal levels off the diffuser from $0 \%$ to $90 \%$ equivalent diffuse Earth reflectance. During on-orbit solar reflective calibrations, a slide covering the mask is withdrawn, enabling the incident solar flux to pass through the exposed slots onto the solar diffuser. Illuminated in this manner, the solar diffuser effectively provides a series of uniform scenes of increasing radiance.

A key aspect of the use of solar diffusers in the on-orbit radiance calibration of remote sensing instruments is the ability to monitor on-orbit, temporal changes in the diffusers' reflective or transmissive optical properties. In order to do this, some Earth remote sensing instruments have flown dedicated detector-based hardware in addition to multiple diffusers. An example of a detector-based system used to monitor solar diffuser reflectance degradation is the Solar Diffuser Stability Monitor (SDSM) flown on the MODIS Terra and Aqua instruments $[134,160]$. The SDSM is a $5 \mathrm{~cm}$ diameter integrating sphere with 9 filtered silicon photodiode detectors embedded in the sphere wall [160]. The detectors are filtered at a number of visible/near infrared wavelengths. In order to track on-orbit reflectance changes in the solar diffuser, the SDSM operates as a ratioing radiometer in that it is used to view both the Sun and the illuminated solar diffuser. The SDSM aperture is equipped with a $2 \%$ transmissive screen to bring the solar diffuser view signal and the Sun view signal to similar levels. 
The Total Ozone Mapping Spectrometer (TOMS) instrument launched in 1991 on a Russian Meteor-3 spacecraft first demonstrated the approach of using multiple diffusers to track and model on-orbit reflectance changes [142,161]. To do this, three roughened aluminum diffusers, designated cover, working, and reference, were flown on the TOMS instruments and each were exposed to the Sun for varying amounts of time. The cover diffuser was exposed to the Sun constantly; the working diffuser was exposed for a few minutes per week; and the reference diffuser was exposed for a few minutes every 15 days. The data from TOMS viewing the three diffusers were used successfully to determine the reflectance degradation behavior of the working diffuser. This multiple diffuser approach was adopted by the Meteor-3 TOMS follow-on instruments flown on the Earth Probes and QuikTOMS missions and by the recently launched OMI instrument on EOS Aura.

\subsection{On-board Lamp Systems}

While solar diffusers represent a passive approach to the on-orbit calibration and monitoring of satellite instrument radiance responsivity, lamps represent an active and sometimes more challenging source-based approach. Transferring a lamp's absolute radiometric scale from pre-launch to on-orbit and maintaining that scale over the course of a mission is more complicated for several reasons. The thermal operational environment experienced by a lamp during on-orbit operation is vastly different than the thermal environment surrounding a lamp during its pre-launch calibration in a laboratory, resulting in a difference between the pre-launch and on-orbit brightness temperature. A change in brightness temperature alters the spectral irradiance, with the greatest change occurring in the ultraviolet. The filament temperature is affected by convective heat transfer of the internal and external gases as well as by conductive and radiative heat transfer. On-orbit, external gases are absent and there is no gravity to drive convection of the gas within the lamp envelope. Exhausting the heat from the lamp requires careful thermal design within the remote sensing instrument, and consideration must be given to the duty cycles, so that the lamp is fully stabilized without compromising the sensor's thermal environment. A spectral disadvantage of using lamps as on-board calibrators is their inability to provide a solar-like spectrum due to low emission at blue and green wavelengths. An advantage of using lamps for on-orbit calibration is the availability of performing a calibration whenever desired or necessary, including immediately before launch and after attaining orbit.

The Advanced Spaceborne Thermal Emission and Reflection Radiometer (ASTER) currently flying on the Earth Observing System (EOS) Terra satellite employs lamp-based on-board calibrators for the calibration of its visible/near infrared (VNIR) and shortwave infrared (SWIR) instruments [162]. Briefly, ASTER uses two doublyredundant sets of silicon photodiode-monitored, halogen lamps in its on-orbit calibration. In the pre-launch timeframe, the radiance scale from a copper point blackbody was transferred to the ASTER VNIR on-board lamps using ultrastable transfer radiometers and an integrating sphere source. For the SWIR instrument, the radiance scale from a zinc point blackbody was transferred to the ASTER SWIR lamps in similar fashion. Since its launch in December 1999, the lamp-based on-board calibration systems of ASTER have been used to trace the VNIR and SWIR instrument on-orbit radiance 
response history to pre-launch. Moreover, the systems have detected a decrease in the responsivity of the VNIR bands while the SWIR bands have remained stable.

Many of the on-orbit radiometric applications of lamps have been restricted to their use in stability monitoring capacities. For example, the ALI instrument on EO-1 uses an on-board lamp-based source to monitor on-orbit radiometric stability [163]. The source is comprised of 3 Welch Allyn gas filled lamps mounted in an integrating sphere. The output of the illuminated sphere fills the ALI focal plane. By sequentially powering down the lamps, the source provides three radiance level inputs to the ALI. The ALI lamp source has shown good on-orbit stability [163]. Also on the EO-1 spacecraft, the Hyperion instrument's Internal Calibration Source (ICS) uses four Welch Allyn quartz tungsten halogen lamps to illuminate the YB 71-painted back of the instrument telescope cover [152]. The telescope cover then functions as a diffuse source.

Remote sensing instruments in the Landsat, Earth Radiation Budget Experiment (ERBE), and SCAnner for RAdiation Budget (SCARAB) projects have long histories of using on-board lamp sources in monitoring changes in instrument radiance responsivity at visible, near infrared, and shorwave infrared wavelengths. The Landsat 5 Thematic Mapper (TM) and Landsat 7 Enhanced Thematic Mapper Plus (ETM+) instruments used miniature quartz tungsten halogen lamps, the outputs from which were optically coupled to the instruments' focal planes using fiber optics and sapphire light rods $[164,165]$. The non-scanning active cavity radiometers (ACRs) flown on the ERBE missions between 1984 and 1986 were equipped with a ShortWave Internal Calibration Source (SWICS) comprised of a silicon photodiode-monitored tungsten lamp coupled to fiber optics [166]. The output of the SWICS was used to monitor the irradiance responsivity of the ERBE Shortwave Medium Field-of-View (SMFOV) and Shortwave Wide Field-of-View (SWFOV) instruments. The ERBE follow-on instrument, the Clouds and the Earth's Radiant Budget Experiment (CERES) instruments flown on the EOS Terra and Aqua satellites successfully continued this application of lamps as on-board responsivity monitors [167]. Similar to the ERBE and CERES instruments, the Scanner for Radiation Budget (SCaRaB) radiometers flown on the Russian Meteor 3M and RESURS platforms in the mid to late 1990's were designed to monitor the Earth's radiation budget at the top of the atmosphere. These instruments were equipped with multiple on-board lamps operated over an overlapping, wide range of duty cycles in an effort to monitor lamp degradation and to maintain a reference with the pre-launch calibration [168].

\subsection{Use of Natural Targets}

A third approach in monitoring the on-orbit radiometric calibration and degradation of remote sensing instruments at visible through near infrared wavelengths is the use of repeated views of natural targets. Ideally, the targets chosen for this application should provide a range of reflectances corresponding to that range of reflectances or radiances detected by the satellite instrument. In addition, the targets should be spectrally flat and spatially uniform. The targets must be of sufficient size to eliminate or reduce any sensor size-of-source effects. Finally, the atmosphere above the targets must be stable and capable of being modeled. Natural targets have been used for both absolute and relative calibration of satellite sensors. Ocean, cloud, and desert scenes have been used to absolutely calibrate the Visible and Infrared Spin Scan Radiometer (VISSR) cameras on the Geostationary Operating Environmental Satellite 5 (GOES 5) 
and 6 (GOES 6) [169], the Advanced Very High Resolution Radiometer (AVHRR) on the NOAA-7, -9, -11, and -14 satellites [170-174] and the Systeme Pour l'Observation de la Terre (SPOT) Haute Resolution Visible (HRV) radiometers [175]. For ocean views, the technique is based on the dominance of molecular scattering over the ocean relative to the radiance originating from aerosol scattering, ocean reflected skylight, underwater reflectance, and ozone absorption. High bright clouds over ocean scenes are used as spectrally invariant on-orbit diffuse targets.

Non-extended natural sources have also been used in the on-orbit monitoring of satellite instrument stability and degradation in the ultraviolet through shortwave infrared. For example, the Moon has been successfully used by the SeaWiFS, MODIS, and Advanced Land Imager (ALI) projects to monitor long-term degradation in instrument radiance responsivity in the visible through shortwave infrared $[163,176]$. Similarly, stars have been used to monitor on-orbit degradation of the GOES 8 and 9 imagers and sounders in the visible [177] and the Solar Stellar Irradiance Calibration Experiment (SOLSTICE) in the ultraviolet [178-180].

\subsubsection{Solar Reflective On-board Spectral Characterization and Calibration}

Changes in the spectral calibration of satellite instrument wavelength bands are typically monitored on orbit using dedicated on-board hardware systems and wavelengthspecific atmospheric and solar absorption features. The European Space Agency's MERIS instrument performed on-orbit determinations of the central wavelengths of its bands using a solar illuminated Erbium doped "pink" diffuser, by observing the atmospheric $\mathrm{O}_{2} \mathrm{~A}$ absorption feature at $760 \mathrm{~nm}$, and by observing number of solar Fraunhofer lines [181]. The MODIS Terra and Aqua instruments are equipped with a Spectroradiometric Calibration Assembly (SRCA) [182]. The SRCA is essentially an "instrument within an instrument" capable of performing not only spectral on-orbit calibrations, but also radiometric and spatial calibrations. The SRCA is comprised of a light source, monochromator, and collimator. The light source is an integrating sphere containing $10 \mathrm{~W}$ and $30 \mathrm{~W}$ embedded lamps. The monochromator is a single grating Czerny-Turner instrument capable of producing monochromatic light from $400 \mathrm{~nm}$ to $2200 \mathrm{~nm}$. The collimator is an on-axis inverted telescope. The spectral output of the monochromatic light from the SRCA is monitored using a didymium filtered, calibrated silicon photodiode detector. The unfiltered monochromatic output of the SRCA which is viewed by the MODIS instrument is monitored using a second reference silicon photodiode detector embedded in the collimator secondary mirror. The ratio of the signals from the calibration and reference photodiodes produce the known didymium absorption profile, providing an on-orbit confirmation of the SRCA output spectrum. Another approach to the on-orbit spectral calibration of remote sensing instruments is provided by the European Space Agency's GOME 1 and 2 instruments. These instruments have employed on-board, neon-filled hollow platinum cathode lamps for purposes of spectral calibration $[143,144]$.

\subsubsection{The Thermal Emissive Range}




\subsubsection{Thermal Infrared On-board Radiometric Calibration}

In remote sensing, the thermal infrared wavelength region extends from $2.5 \mu \mathrm{m}$ to $100 \mu \mathrm{m}$. From 2.5 to $3.5 \mu \mathrm{m}$, the Earth's atmosphere is opaque, prohibiting remote sensing measurements. Above $3.5 \mu \mathrm{m}$, the amount of solar radiation reflected by the Earth and its atmosphere is exceeded by the amount of radiation thermally emitted. It is above $3.5 \mu \mathrm{m}$ that atmospheric sounding and sea and land surface temperature are manifested as small infrared signatures superimposed on what is thermally designed to be a slowly varying, well characterized and calibrated instrument infrared background. The ability to distinguish these subtle infrared geophysical signals from background requires regular, repeated calibration of infrared channels using stable, well characterized onboard sources.

In filter-based, prism or grating-based, and interferometer-based infrared remote sensing, on-board blackbody sources in combination with views of cold space are commonly used to account for changes in instrument radiance responsivity or gain and linearity, and offset. The on-board blackbody is a full aperture, system-level calibrator which provides a stable reference temperature against which scene temperatures can be determined. The use of a blackbody requires, at a minimum, a two point temperature calibration. In its simplest application, a blackbody can be operated either at the instrument surrounding temperature or at the temperature of the scene to be remotely sensed. The second temperature is commonly obtained by viewing cold space. Operating the blackbody at the temperature of its surrounds eliminates thermal gradients across the blackbody. Operating the blackbody at or near the temperature of the scene to be remotely sensed, effectively reduces concerns about response non-linearity. Blackbodies are also operated at two temperatures corresponding to the extreme temperatures of remotely sensed scenes. These blackbodies often are capable of being ramped between these two temperatures providing an on-orbit check of instrument linearity. For all instruments employing blackbodies, the linearity and gain of the satellite instrument's thermal infrared bands must be carefully determined in pre-launch testing. Moreover, since infrared measurements are obtained during day and night orbital segments, this non-linearity must be measured over the complete range of on-orbit instrument operating temperatures through carefully designed thermal/vacuum tests.

The uncertainty of the radiance from the on-board blackbody directly determines the uncertainty of the radiance measured by the satellite instrument. Therefore, the emissivity, temperature uniformity, and temperature measurement accuracy of the blackbody must be established pre-launch and known on-orbit. As shown in Table 10.6, a number of blackbody designs have been used in an effort to stay within often tight instrument mass and volume constraints while at the same time providing an isothermal, high emissivity target. The thermal mass and position of the blackbody within the instrument should minimize thermal excursions from orbit to orbit. The background or thermal offset signal of the satellite instrument due to thermal emission from optics and instrument and spacecraft structures is measured on-orbit using space views and monitored using strategically placed temperature sensors throughout the instrument. $<$ Table 10.6> 


\subsubsection{Thermal Infrared On-board Spectral Calibration}

On-orbit spectral calibration of infrared satellite instruments is performed using on-board hardware and established, known spectra of gaseous atmospheric molecules. For example, the grating-based AIRS instrument employs an on-board parylene-coated mirror. This mirror is used in retroreflection enabling the instrument to view itself as a cold target modified by the known absorption spectrum of parylene. In this configuration, parylene provides AIRS with broad features suitable for trending instrument spectral stability [198]. The AIRS detector spectral response functions were determined through pre-flight testing to be insensitive to the predicted on-orbit temperature environment. Given this result, AIRS developed a technique to monitor the detector wavelength centroids by correlating measured upwelling atmospheric radiance spectra with modeled spectra [199]. The high spectral resolution of satellite interferometer-based infrared instruments enables on-orbit wavelength calibrations using measurements of upwelling atmospheric radiance and models of well-known sharp spectral features from molecular species such as $\mathrm{CO}_{2}, \mathrm{CO}, \mathrm{H}_{2} \mathrm{O}, \mathrm{CH}_{4}, \mathrm{O}_{3}$, and $\mathrm{N}_{2} \mathrm{O}$ [200203]. The interferometer spectral scale, spectral sampling interval, and instrument line shape (ILS) are determined pre-launch and monitored on-orbit. In a manner similar to that used by high resolution grating-based instruments, spectral scale is established through a comparison of measured and modeled atmospheric spectra. The stability of the spectral sampling interval is monitored on-orbit using a wavelength stabilized laser source, often referred to as a metrology laser or source. The metrology laser on the Infrared Atmospheric Sounding Interferometer (IASI) is a particularly novel design in which the output of a diode laser is locked onto an absorption line of ${ }^{13} \mathrm{C}_{2} \mathrm{H}_{2}$ [204].

\subsubsection{Vicarious Calibration Techniques}

Vicarious calibration is a key component in the validation of the on-orbit calibration of Earth remote sensing satellite instruments and in the assessment of the quality of their fundamental radiance and reflectance measurements. Vicarious calibration employs both ground-based and airborne sensors making simultaneous radiometric measurements of optically and spatially well-characterized Earth targets at the times of satellite instrument overpasses. Vicarious calibration is used to monitor onorbit instrument calibration over full mission lifetimes and can be used to cross-calibrate different instruments on different or the same spacecraft. Because vicarious calibration uses the same illumination source as the satellite instrument, that is, the Sun, calibration source color temperature concerns are largely eliminated. Lastly, vicarious calibration is used to complement and validate results obtained from on-board calibration systems, effectively providing a valuable multiple measurement methodology to establish confidence in those on-board systems. In contrast, for instruments such as the Advanced Very High Resolution Radiometer (AVHRR), the Polarization and Directionality of the Earth's Reflectances (POLDER) instrument, and the Systeme Probatoire Pour l'Observation de la Terre (SPOT) instruments, the lack of on-board calibration systems dictates a total reliance on vicarious calibration for their on-orbit calibration. The main drawback concerning vicarious calibration remains the limited frequency at which ground-based and airborne campaigns can be undertaken and the efficiency at which 
vicarious calibration results are made available to satellite instrument teams. The former issue is being addressed through research in the establishment of un-manned, instrumented vicarious calibration target sites [205]. The latter is being addressed through projects such as the development of Quality Assurance and Stability Reference (QUASAR) test sites [206].

Vicarious calibration sites have a number of desirable characteristics. The optical properties of a vicarious calibration site should include spectral and spatial homogeneity and time invariance. Time invariance requires the site to have a reasonably robust surface with minimum human intervention. While minimal human intervention often translates to a remote location for the site, the site must not be so remote that site accessibility by personnel and their instrumentation is impossible. In thermal infrared vicarious calibration, water sites are particularly attractive because they exhibit small temperature excursions over the timeframes of typical vicarious measurements. The ideal vicarious site should be located at a high altitude with clear skies overhead for a significant portion of the year. In order to eliminate unwanted adjacency effects, the site should be at least 3 pixels by 3 pixels larger than the ground instantaneous field-or-view (GIFOV) of the satellite to be calibrated [207]. The site should provide a range of reflectances or radiances covering the operating range of the satellite instrument. This dynamic range requirement is often met only by employing a number of sites of different types. Reflectance from the site should be reasonably Lambertian. Examples of sites used in the vicarious calibration of satellite sensors in the visible through thermal infrared are provided in Table 10.7 .

$<$ Table 10.7>

\subsubsection{Visible/near infrared/shortwave infrared Techniques}

The vicarious calibration of satelilite sensors with bands between $400 \mathrm{~nm}$ and $2500 \mathrm{~nm}$ is accomplished using ground-based or airborne measurements of the reflectance or radiance from vicarious calibration sites at the times of satellite instrument overpasses. The University of Arizona Optical Sciences Center's Remote Sensing Group has developed and refined three vicarious calibration techniques: the reflectance-based, radiance-based, and irradiance (or improved reflectance) based techniques [207]. In the reflectance based technique, the nadir reflectance of the vicarious calibration site is measured using ground-based or airborne radiometers over an area corresponding to the GIFOV of the overflying satellite instrument to be calibrated. During the course of the ground-based measurements, measurements are also made of the relectance of a fielddeployed panel whose reflectance was carefully measured in the laboratory. The site reflectances are ratioed to the known panel reflectances. For satellite instruments with non-nadir fields-of-view, such as the Multiangle Imaging SpectroRadiometer (MISR) instrument on the EOS Terra platform, the bidirectional reflectance factor (BRF) or the bidirectional reflectance distribution factor (BRDF) of the site must be measured using ground-based or airborne (e.g. AirMISR) instruments. Since vicarious calibration involves the comparison of at-satellite radiances, careful characterization of the atmosphere above the calibration site is crucial and requires a suite of additional groundbased instruments in addition to the nadir-measuring radiometer. These instruments include the following: an all-sky camera taking real-time photos of the sky, a 
pyranometer acquiring measurements of total solar irradiance, a line-of-site radiometer measuring sky radiance in the direction of the satellite instrument, and a solar radiometer measuring variation of solar irradiance, the data from which are used to determine the input parameters to an atmospheric radiative transfer model. The output of the radiative transfer model is a top-of-the-atmosphere radiance, which when convolved with the system spectral responsivity of a particular satellite instrument band, can be compared to the satellite measured radiance. In the radiance based technique, a well-calibrated, fully characterized radiometer is flown in the airspace below the satellite instrument to be calibrated and above the vicarious calibration site. In this measurement configuration, the airborne radiometer measures the upwelling radiance from the test site above a significant fraction of the aerosols and water vapor in the atmosphere. Simultaneously, measurements can be made on the ground of the site reflectance, and the effect of the intervening atmosphere on the airborne measurement can be derived. The aircraft measurements are corrected for the fraction of the atmosphere above the aircraft and are compared to the satellite radiance measurements. In addition to a reduced atmospheric effect, the radiance-based technique can cover a significantly larger area than the groundbased reflectance technique. In the irradiance based (or improved reflectance based) technique, the diffuse to global irradiance is measured in addition to the test site reflectance, panel reflectance [240], and atmospheric characterization measurements made in the reflectance based technique. The diffuse to global irradiance is determined by measuring the reflectance panel with direct solar irradiance blocked and un-blocked and is extrapolated to those satellite and solar zenith angles at the time of vicarious calibration. In this technique, the calculated at-satellite radiance has a reduced dependence on the accuracy of the size distribution of atmospheric aerosols.

While the reflectance, radiance, and irradiance-based vicarious calibration techniques have been developed and refined over bright land targets, the Marine Optical BuoY (MOBY) system has been developed for the vicarious calibration of ocean color satellite instruments [223]. For ocean color measurements from space, the water-leaving radiance is calculated from the top-of-the-atmosphere radiance, that is, from the radiance leaving the ocean-atmosphere system [241]. Since the ocean is dark, approximately $90 \%$ of the top-of-the-atmosphere radiance comes from the atmosphere, it is necessary to have low uncertainty in the at-satellite radiances. MOBY provides water-leaving radiances which, when combined with the atmospheric correction, are used to provide a calibration for the on-orbit radiances from the satellite instrument [243]. In this use, the calibration coefficients for the satellite instrument are adjusted so that the radiances from the satellite instrument-atmosphere system agree with the water-leaving radiances from MOBY. In general, this type of vicarious calibration is not applied in the derivation of land and atmosphere products from the ocean color satellite instrument [244].

MOBY contains two spectrographs that measure flux from $340 \mathrm{~nm}$ to $950 \mathrm{~nm}$ [223]. The blue spectrograph separates light into 512 channels from $340 \mathrm{~nm}$ to $640 \mathrm{~nm}$, with the red spectrographs covering the spectrum from $650 \mathrm{~nm}$ to $950 \mathrm{~nm}$ in 512 channels. The upwelling radiance is measured from three arms extending from the buoy's central column, each at its own depth from the surface. The radiances from the arms are transmitted to the spectrographs via fiber-optic cables. These upwelling radiance measurements are used to calculate the water-leaving radiance [223,243]. The 
characterization and calibration of MOBY has been carried out in a long-term collaboration with the National Institute of Standards and Technology [44,82,245].

Since the mid 1990's, the United States Geologic Survey (USGS) in Flagstaff

Arizona has developed a photometric model of the Moon for use as a common, vicarious calibration target for satellite instruments that make remote sensing measurements of the Earth [246-248]. This lunar reflectance model has been produced from ground-based measurements. The model accounts for the effects of solar and lunar distance, and of lunar phase and libration in the ground-based observations. Using this model of reflectance, phase, and libration, the irradiance for a given spacecraft's lunar observation can be calculated. Kieffer has shown that the lunar surface is photometrically stable over a period of $10^{6}$ years [249]. However, the actual comparisons of the model with the instruments include the time-dependent, cyclical changes in the lunar irradiance as viewed by the satellite instruments. Comparisons with the USGS lunar model have shown the Moon to be an exceptionally stable reference for instruments making longterm climate change measurements [250]. This has been demonstrated for measurements by individual instruments covering limited ranges of lunar phase angles [176]. The applicability of the Moon as a cross-calibration reference for instruments that measure at different phase angles has yet to be confirmed. In addition, calibration measurements to determine the absolute reflectance of the Moon [251] have yet to be completed.

\subsubsection{Thermal Infrared Techniques}

Ideal sites for the vicarious calibration of satellite sensors operating in the thermal infrared should possess known emissivity and large spatial and long temporal temperature uniformity. For these reasons, water sites are particularly well suited as thermal infrared vicarious calibration sites. Ground sites such as playas, deserts, and snow fields are also used as thermal infrared calibration targets which span the low to high temperature calibrations of satellite instruments. The vicarious calibration of the thermal instrument in the Advanced Spaceborne Thermal Emission and Reflection Radiometer (ASTER) is a joint effort between research groups in Japan and the United States which has advanced both radiance-based and temperature-based thermal infrared vicarious calibration techniques [252]. In the radiance-based technique, a well-calibrated radiometer is flown above the test site. The radiometer measures the thermal infrared radiance upwelling from the test site. With careful co-registration of the satellite and airborne instrument fields-of-view and proper accounting of any spatial out-of-field radiance contributions for each instrument, this radiance is corrected for residual scattering between the airborne radiometer and the satellite instrument and compared to the satellite measurements. In the temperature-based approach, a ground or water-based sensor measures the thermal infrared radiance of the site. This measured radiance is corrected for downwelling atmospheric and along path radiance contributions using a radiative transfer model with either measured (e.g. temperature and humidity radiosonde measurements) or climatological atmospheric profiles. The radiance is also corrected for the non-unity emissivity of the surface. The surface temperature is determined by inverting the Planck equation using this corrected measured radiance. These temperatures are propagated to at-satellite instrument radiance using the aforementioned radiative transfer model. The predicted satellite instrument radiance is calculated by 
convolving this at-satellite instrument radiance with the system level spectral responsivities for those satellite instrument bands to be vicariously calibrated. The radiance measured by the satellite instrument is compared to this predicted radiance.

\subsubsection{Comparison of Radiometers and Sources Used in Vicarious Calibration}

Determinations of the measurement uncertainties, stabilities, and repeatabilities of the radiometers and sources used in vicarious calibration are essential in ascertaining whether vicarious calibration results are of sufficient quality to be used either in the validation or determination of satellite instrument calibration coefficients. A key, first step in this process includes validating, in the laboratory, measurements made by vicarious calibration radiometers viewing well-calibrated, stable uniform radiance sources and determining the stability, repeatability, and uniformity of those calibration sources used before, during, and after radiometer field deployments. In addition, the wavelength accuracy, spectral and spatial stray light rejection, and spectral responsivity of the vicarious calibration radiometers should be characterized. NASA's Earth Observing System (EOS) and NIST have coordinated a number of these laboratory-based comparisons [253-256]. In 1997, an intercomparison of field instruments operating at visible, near infrared, and shortwave infrared wavelengths was performed in the laboratory of the University of Arizona Optical Sciences Center's Remote Sensing Group in advance of a field deployment to Lunar Lake and Railroad Valley, Nevada [254]. This intercomparison focused on the stability and short-term repeatability of the field instruments. The intercomparison revealed large variations in the response of certain field instruments, due to insufficient warm-up and basic instrument design deficiencies such as the lack of detector temperature stabilization. In 1998 and 2001, an intercomparison of field radiometers and blackbody calibration sources operating in the thermal infrared was held at the University of Miami's Rosenstiel School of Marine and Atmospheric Science. These ship-borne infrared radiometers measure the sea surface skin temperature which is used to validate satellite retrieved sea surface temperatures. In the 1998 comparison, commercial and custom infrared radiometers measured the NIST calibrated, water-based blackbody. In the 2001 comparison, the NIST Thermal Transfer Radiometer (TXR) measured four blackbodies used to calibrate ship-borne radiometers. Following the laboratory measurements, the radiometers were mounted aboard the RV Walton Smith and made sea surface temperature measurements during a two day roundtrip between Miami and the Bahamas. These laboratory and ship based experiments produced sea surface temperature measurement discrepancies between the radiometers of less than $0.1 \mathrm{~K}$ at ambient temperatures and confirmed the ability of the radiometers to validate satellite sea surface temperature measurements [257].

\subsection{Cross-calibration of Earth Remote Sensing Instruments}

Cross-calibration of instruments on the same or different satellite platforms is important in establishing confidence in the quality of satellite remote sensing data. Cross-calibration can be used to validate that the satellite instruments are making remote sensing measurements calibrated to the same physical scale or to establish the relative offsets between satellite instruments calibrated to different scales. Cross-calibration can 
be used to normalize remote sensing measurements from different instruments, producing continuous remote sensing data sets necessary for the study of short and long-term climate change. Repeated cross-calibration between satellite instruments provides a means of monitoring their individual on-orbit operations over time, validating the information provided by their on-board calibration subsystems.

The cross-calibration of successive generations of the same instrument or different instruments on the same platform or different platforms ideally requires that a spatially and spectrally uniform, large, cross-calibration target scene be viewed under stable atmospheric and identical illumination conditions by each instrument at the same time. However, in the real world, such optically ideal targets do not exist. Instruments have different spectral responsivities and ground instantaneous fields-of-view (GIFOVs). In addition, instruments, particularly on different platforms, are often unable to view the same target at precisely the same time. For these reasons, the spectral reflectance or radiance of the target and the system level spectral responsivities of the instrument bands must be accurately known [258]. Instrument scenes must be carefully co-registered. For non-simultaneous views, changing atmospheric and illumination conditions, including polarization effects, must be considered.

Cross-calibration studies of satellite instruments on the same platform and on different platforms employ a variety of instrumented and non-instrumented sites as common targets. Cross-calibration of the visible/near infrared/shortwave infrared channels of the Moderate Resolution Imaging Spectroradiometer (MODIS), the Multiangle Imaging Spectroradiometer (MISR), and the Advanced Spaceborne Thermal Emission and Reflection Radiometer on the EOS Terra platform has been performed by Thome et al. using coincident ground measurements at Railroad Valley, Nevada [212]. Frequent near nadir coincident views of snow, ice, and open ocean near the north and south poles by polar orbiting satellites have also been used in instrument crosscalibrations [259]. Examples of instruments cross-calibrated using these scenes include the $11 \mu \mathrm{m}$ and $12 \mu \mathrm{m}$ bands on MODIS and the AVHRRs on NOAA-16 [260] and the visible/near infrared channels of GLI, MODIS, SeaWiFS, MERIS and the AVHRRs on NOAA-16 and 17 [261]. The stable, consistent albedos provided by deep convective clouds have also been used to cross-calibrate those same AVHRR instruments and MODIS on Terra and Aqua [262]. Desert scenes have been used in cross-calibration studies of visible, near infrared, and shortwave infrared channels on MODIS and the AVHRR on NOAA-9 [263]; SeaWiFS, VGT, AVHRR and POLDER [264]; and MODIS and ATSR-2 [265].

Minnis et al. [266,267] performed an extensive cross-calibration study using the visible and shortwave infrared on-board calibration systems of VIRS and CERES, respectively, in an effort to monitor the on-orbit calibration of a number of research and operational instruments in geostationary and low Earth orbits. Both VIRS and CERES are currently flying on the Tropical Rainfall Measuring Mission (TRMM). The ability of the VIRS solar diffuser to accurately monitor the on-orbit, solar diffuser-based calibration of its $0.65 \mu \mathrm{m}$ and $1.6 \mu \mathrm{m}$ channels was validated through comparisons with stable, broadband shortwave calibrated radiances from CERES using ocean and desert scenes. Using common Earth scenes, a series of comparisons were then made between the 0.65 $\mu \mathrm{m}$ channel of VIRS, the $0.62 \mu \mathrm{m}$ channel of the GOES- 8 imager, the $0.645 \mu \mathrm{m}$ channel of MODIS on the Terra satellite, the broad channel 1 of the Geostationary Meteorological 
Satellite (GMS) Visible Infrared Spin Scan Radiometer (VISSR), and the $0.67 \mu \mathrm{m}$ channel of the ATSR-2 on ERS-2. This technique was successfully extended by Minnis et al. [268] in a comparison of thermal infrared radiances measured by these instruments in the vicinity of the VIRS $3.7,10.8$, and $12.0 \mu$ m channels.

Formation flying of spacecraft provides a large number of excellent opportunities for the on-orbit cross-calibration of remote sensing instruments. One example of this is the cross-calibration of the ETM+ on Landsat-7 and the TM on Landsat-5 in 1999 [269]. Following its launch on April 15, 1999, Landsat-7 was placed into an orbit $6 \mathrm{~km}$ below Landsat-5. This enabled the ETM+ and TM instruments to view hundreds of nearcoincident scenes for purposes of cross-calibrating 3 visible, 1 near infrared and 2 shortwave infrared channels. On April 14, 2003, the close, on-orbit flying formation of the EO-1 and Terra spacecraft was used to cross-calibrate a number of visible, near infrared, and shortwave infrared instruments using the Moon as a common target. The EO-1 and Terra spacecraft orbit the Earth at $705 \mathrm{~km}$ with an orbital inclination of $98.2^{\circ}$ and $98.1^{\circ}$ respectively. More importantly, the equatorial crossing times of EO- 1 and Terra are 10:01 and 10:30 Local Solar Time (LST). On April 14, 2003, these spacecraft performed maneuvers to enable the ALI and Hyperion instruments on EO-1 and the MODIS, MISR and ASTER instruments on Terra to view the Moon at essentially the same lunar phase and libration. In addition, the SeaWiFS instrument on the SeaStar satellite, at $705 \mathrm{~km}$ altitude, 98 degrees inclination and 12:00 LST equatorial crossing time, was maneuvered to also view the Moon approximately 17 minutes after the last instrument on Terra. Using the USGS lunar irradiance model as a reference comparison spectrum and to correct for small differences in lunar phase, the cross-calibration of these EO-1 and Terra instruments using the Moon reproduced the trends seen in previous cross-calibrations using vicarious techniques.

\subsection{Continuing Issues and New Developments in Earth Remote Sensing}

\subsubsection{Stability, Absolute Calibration, and Characterization}

The study of climate change requires a temporally continuous stream of remote sensing measurements of the Earth made by multiple instruments on different spacecraft platforms. In an effort to understand and predict climate trends, the United States Climate Change Research Program has identified the need to accurately quantify the short and long-term uncertainties in the fundamental measurements made by those Earth remote sensing instruments [270]. The application of Earth remote sensing data in the study of climate change is strongly dependent on the ability of instrument scientists and engineers to separate satellite instrument change from geophysical change. Realization of this goal is fundamentally dependent on the determination and monitoring of on-orbit instrument stability over orbit-to-orbit and mission timeframes. Without on-orbit instrument stability, or the ability to accurately monitor it, the next steps of absolutely calibrating a remote sensing instrument and cross-calibrating of successive or similar follow-on instruments are difficult if not impossible to accomplish. The production of long-term high quality geophysical data from multiple satellite instruments strongly depends on confidence that the satellite instruments have been calibrated against common physical standards and the ability of instruments to view the same well-characterized 
target. A lack or incomplete knowledge of the on-orbit stability of remote sensing instruments often leads to a significant and often unforeseen investment in interpreting or perhaps salvaging data and often leads to severe delays in the release of validated data to the science public.

The determination of instrument stability is one of several exercises in instrument characterization which must be addressed not only on-orbit but also pre-launch. Climate requirements on earth remote sensing data have driven not only instrument calibration, but also characterization requirements to state-of-the-art levels. Satellite instruments are complex electro-optical systems often with complicated focal planes continuously operating in the changing thermal and radiation environments of space. Complex instruments require more extensive characterization. For example, the increasing use of charge coupled device (CCD) detectors in remote sensing instruments brings a set of new, additional challenges in instrument characterization. Characterization issues such as light leaks, ghost reflections, optical scattering or blooming, and polarization sensitivity must be understood pre-launch in order to prevent on-orbit "surprises" resulting in delays in the release of science data to the remote sensing community.

Satellite instrument calibration and characterization ideally should be performed under environmental conditions which mimic on-orbit operation. Certain pre-launch instrument characterization tasks, such as setting instrument gains, can be performed in ambient. However, most characterization tasks must be performed in thermal/vacuum over a range of temperatures encompassing those experienced by the instrument during its on-orbit mission lifetime. Instrument on-orbit stability, particularly long-term stability, is a challenging characterization measurement which the on-orbit operational environment is approximated by having the instrument view a stable radiance source over a series of repeated thermal cycles. Because instrument thermal vacuum characterization tests require a significant block of time and are chronologically situated close to the date for instrument delivery to the spacecraft integrator, these tests are often truncated, feebly replaced by a less time consuming ambient surrogate test, or eliminated altogether. The net result is incomplete knowledge of sensor performance with potentially serious onorbit consequences.

\subsubsection{New Developments and Future Needs}

Recent developments and applications of electro-optical technologies in the field of remote sensing instrument calibration and characterization have increased the volume and have improved the overall quality of data from space-borne, ground-based, and airborne instrumentation. Close, international-scale, collaborative efforts between a number of remote sensing institutions and agencies and national measurement institutes (NMIs) have produced many of these advances. For example, the Spectral Irradiance and Radiance Responsivity Calibrations with Uniform Sources (SIRCUS) facility at NIST $[51,80,271]$ and the National Laser Radiometry Facility (NLRF) at NPL are detectorbased facilities capable of accurately determining the subsystem or system level absolute spectral irradiance or radiance responsivity of remote sensing instruments. The facilities' tunable, laser-based light sources, with their high photon fluxes enabling higher signal-tonoise measurements, improve on previous monochromator-based and piece-part calculation approaches for the determination of remote sensing instrument responsivity. 
In an effort to adapt to fixed instrument deployment and flight schedules, NIST designed a portable version of their SIRCUS facility called "Travelling SIRCUS" capable of being deployed at satellite and vicarious calibration instrument facilities. In 2003, "Travelling SIRCUS" successfully characterized the spectral-out-of-band response of two CCDbased spectrographs for the MOBY project in Hawaii [272] and measured the relative inband spectral profiles of eight channels of the Robotic Lunar Observatory's (ROLO's) visible/near infrared telescope system located at the USGS in Flagstaff, Arizona [251]. NMI's have also been actively involved in the pre-launch and on-orbit application of absolute cryogenic radiometry in elucidating the current $0.36 \%$ difference between onorbit measurements of total solar irradiance. In the pre-launch laboratory calibration of total solar irradiance satellite instruments, the comparison of radiative power measurements made by satellite instruments and absolute cryogenic radiometers is being extensively discussed. NPL's Absolute Radiometric Measurements in Space (ARMS) project proposes to construct the first cryogenic solar radiometer to fly in space, potentially producing a ten-fold improvement in the total solar irradiance measurement uncertainty [273]. Another technologically promising area for improvement in remote sensing data quality is the application of light emitting diodes (LEDs) in the pre-launch and on-orbit calibration of remote sensing instruments. NIST has developed an LEDbased integrating sphere source with spectrally tunable output approximating the color distributions of remotely sensed scenes [50]. Improvements in brightness, stability, and spectral output coupled with low power consumption and insensitivity to gravitational effects, led to the examination of LEDs as possible on-board calibration sources for Earth remote sensing instruments [274] and, ultimately, to their deployment on instruments such as OMI on EOS Aura. The OMI instrument uses LEDs in the vicinity of their focal planes to perform on-orbit evaluations of electronic gains and pixel performance $[145,146]$.

There are several areas in the calibration and characterization of Earth remote sensing instruments that, with additional commitment on the part of remote sensing agencies and institutions, would significantly improve data quality. One area is the continuing development of celestial objects such as the Moon, stars, and planets as common on-orbit calibration and characterization sources. Since 1993, the ROLO project at USGS in Flagstaff has acquired images of the Moon in 23 visible/near infrared and 9 shortwave infrared bands for purposes of producing models of lunar irradiance and radiance suitable for use in calibrating and cross-calibrating satellite instruments. The ROLO lunar irradiance data has been successfully used to monitor the long term response degradation of the eight bands of the SeaWiFS instrument to $0.1 \%$ [176,250]. Current work on ROLO is focused on reducing the 5 to $10 \%$ absolute calibration uncertainty of the telescope systems through the determination of the system-level absolute and relative spectral response for the ROLO bands and concurrent examination of the ROLO data reduction, atmospheric correction, and modeling software [251]. The absolute calibration scale for ROLO is currently based on historical, published photometric observations of the star Vega. Therefore, understanding the differences between the Vega-based calibration of ROLO and that using ground-based sources with radiant output traceable to the SI would provide an important link between the astronomical stellar and SI scales.

The radiance calibration specifications for remote sensing instruments are usually written for uniform, extended scenes such as the output of an integrating sphere, lamp 
illuminated diffuse target, or blackbody. Unfortunately, most remote sensing instruments view spatially inhomogeneous scenes of varying contrast. An aspect of quantitative remote sensing which is often neglected or not properly understood in instrument characterization is the radiometric effect of an instrument's encircled energy response function or size of source effect. The size of source effect is a resolution-dependent component in any instrument's measurement uncertainty budget which due to optical degradation can change over the course of a mission. Instrumentation to quantify the effect pre-launch through careful measurement of instrument point spread and modulation transfer functions should be carefully designed and calibrated [275,276]. Moreover, the effect should be monitored on-orbit using high contrast scenes of varying extent and views of celestial objects such as the Moon.

The specification document for a satellite instrument contractually presents to the instrument vendor the performance, testing, assurance, and calibration/characterization requirements for that instrument. For instruments used in the validation or vicarious calibration of satellite instrument measurements, no such specification documents exist. The degree to which ground-based, airborne, or balloon-borne validation instruments are calibrated and characterized is a function of the degree of importance the instrument user or institution places on calibration and characterization. Given the importance of the role field instruments have and will continue to play in the remote sensing field, the remote sensing community must be pro-active in a number of areas. One area is the development of measurement protocols for field instruments to ensure the production of consistent measurements of sufficiently high quality. A second area is the increased use of workshops to inform and illustrate to members of the remote sensing community good metrological practices. A third area is participation in measurement comparisons both in the laboratory and in the field. Excellent examples of activities in all these areas were the SeaWiFS Intercalibration Round-Robin Experiments (SIRREXs) held on eight occasions between July 1992 and December 201 [46,277-283]. The purpose of the SIRREX experiments were to ensure that radiometric standards used by institutions involved in the validation of SeaWIFS measurements were consistently calibrated to the same radiance and irradiance scale traceable to the Systeme Internationale (SI). Dovetailed into the SIRREX program was the equally important, clear articulation of protocols for the measurement of ocean color and environmental optical properties [284] by these institutions. These measurement protocols were based on the requirement to validate the SeaWiFS $5 \%$ water leaving radiance and $35 \%$ chlorophyll a concentration specifications. Only through activities such as these will remote sensing data be of sufficiently high quality to be used to validate satellite measurements or to determine satellite instrument calibration coefficients.

\subsection{References}

1. L. J. Allison and E. A. Neal, "Final Report on the TIROS 1 Meteorological Satellite System," NASA Technical Report R-131, NASA's Goddard Space Flight Center, Greenbelt, MD, 1962.

2. W. Quinn, V. T. Neal and S. E. A. Mayolo, El Nino Occurrences Over the Past Four and a Half Centuries, J. Geophys. Res. 92, 14449-14461 (1987). 
3. P. M. Baede, E. Ahlonsou, Y. Ding and D. Schimel, "The Climate System: An Overview," Climate Change 2001: The Scientific Basis, Third Assessment Report of the Intergovernmental Panel on Climate Change, 2001.

4. D. A. Quattrochi, J. C. Luvall and M.G. Estes, Jr. "Project ATLANTA (Atlanta Land Use Analysis: Temperature and Air quality)-A Study of How the Urban Landscape Affects Meteorology and Air Quality Through Time," $2^{\text {nd }}$ Urban Environments Meeting, American Meteorological Society, Albuquerque, NM, 1998.

5. J. T. Kiehl and K. E. Trenberth, Earth's Annual Global Mean Energy Budget, Bull. Amer. Meteor. Soc. 78, 197-208 (1997).

6. "Satellite Instrument Calibration for Measuring Global Climate Change," G. Ohring, B. Weilicki, R. Spencer, W. Emery and R. Datla, eds., National Institute of Standards and Technology, Publication NISTIR 7047, Gaithersburg, MD, 2002, p. 101.

7. J. J. Butler and B. C. Johnson, Calibration in the EOS Project Part 2: Implementation, The Earth Observer 8, 26-31 (1996).

8. R. P. Cebula, E. Hilsenrath and B. Guenther, Calibration of the Shuttle Borne Solar Backscatter Ultraviolet Spectrometer, Optical Radiation Measurements II, Proc. SPIE 1109, 205-218 (1989).

9. D. F. Heath, A. J. Krueger, H. R. Roeder and B. D. Henderson, The Solar Backscatter Ultraviolet and Total Ozone Mapping Spectrometer (SBUV/TOMS) for Nimbus G, Opt. Eng. 14, 323-331 (1975).

10. J. E. Frederick, R. P. Cebula and D. F. Heath, Instrument Characterization for the Detection of Long-term Changes in Stratospheric Ozone: An Analysis of the SBUV/2 Radiometer, J. Atmos. Oceanic Technol. 3, 472-480 (1986).

11. J. P. Burrows, M. Weber, M. Buchwitz, V.Rozanov, A. Ladstatter-Weissenmayer, A. Richter, R. De Beek, R. Hoogen, K. Bramstedt, K. W. Eichmann, M. Eisinger and D. Perner, The Global Ozone Monitoring Experiment (GOME): Mission Concept and First Scientific Results, J. Atmos. Sci. 56, 151-175 (1999).

12. H. Bovensmann, M. Buchwitz, J. Frerick, R. W. M. Hoogeveen, Q. Kleipool, G. Lichtenberg, S. Noel, A. Richter, A. Rozanov, V. V. Rozanov, J. Skupin, C. von Savigny, M. W. Wuttke and J. P. Burrows, SCIAMACHY on ENVISAT: In-flight Optical Performance and First Results, Proc. SPIE 5235, 160-173 (2004).

13. S. Noel, H. Bovensmann, J. P. Burrows, J. Frerick, K. V. Chance, A. P. H. Goede and C. Muller, SCIAMACHY on ENVISAT-1, Proc. SPIE 3498, 94-104 (1998).

14. J. de Vries, G. H. J. van den Oord, E. Hilsenrath, M. B. te Plate, P. F. Levelt and R. Dirksen, Ozone Monitoring Instrument, Proc. SPIE 4480 315-325 (2002).

15. W. P. Chu, L. E. Mauldin, Overview of the SAGE III Experiment, Proc. SPIE 3756, 102-109, (1999).

16. L. Flynn, C. Seftor, J. Larsen and P. Xu, "The Ozone Mapping and Profiler Suite (OMPS)", book chapter to be published by Springer Verlag, 2004.

17. R. Stolarski, R. Bojkov, L. Bishop, C. Zerofos, J. Stachelin and J. Zawodny, Measured Trends in Stratospheric Ozone, Science 256, 342-349 (1992).

18. R. D. Bojkov, L. Bishop, W. J. Hill, G. C. Reinsel and G. C. Tsao, A Statistical Trend Analysis of Revised Dobson Total Ozone Data Over the Northern Hemisphere, $J$. Geophys. Res. 95, 9785-9807 (1990). 
19. L. L. Hood, R. D. McPeters, J. P. McCormack, L. E. Flynn, S. M. Hollandsworth and J. F. Gleason, Altitutde Dependence of Stratospheric Ozone Trends Based on Nimbus-7 SBUV Data, Geophys. Res. Lett. 21, 2667-2670 (1993).

20. World Meteorological Organization/United Nations Environment Programme (WMO/UNEP), "Scientific Assessment of Ozone Depletion, Global Ozone Research and Monitoring Project", Report No. 25, 1991.

21. World Meteorological Organization/United Nations Environment Programme (WMO/UNEP), "Scientific Assessment of Ozone Depletion, Global Ozone Research and Monitoring Project", Report No. 37, 1994.

22. E. C. Weatherhead, G. C. Reinsel, G. C. Tiao, C. H. Jackman, L. Bishop, S.M. Hollandsworth Frith, J. DeLuisi, T. Keller, S. J. Oltmans, E. L. Fleming, D. J. Wuebbles, J. B. Kerr, A. J. Miller, J. Herman, R. McPeters, R. M. Nagatani and J. E. Frederick, Detecting the Recovery of Total Column Ozone, J. Geophys. Res. 105, 22201-22210 (2000).

23. G. C. Reinsel, E. C. Weatherhead, G. C. Tiao, A. J. Miller, R. M. Nagatani, D. J. Wuebbles and L. E. Flynn, On Detection of Turnaround and Recovery in Trend for Ozone, J. Geophys. Res. 107, D10, 4078 (2002).

24. B. L. Markham, J. C. Storey, D. L. Williams and J. R. Irons, Landsat Sensor Performance: History and Current Status, IEEE Trans. On Geoscience and Remote Sensing 42, 269-2694 (2004).

25. W. R. Ott, P. Fieffe-Prevost and W. L. Wiese, VUV Radiometry with Hydrogen Arcs. 1: Principle of the Method and Comparisons with Blackbody Calibrations from 1650 Angstroms to 3600 Angstroms, Appl. Opt. 12, 1618-1629 (1973).

26. W. R. Ott, K. Behringer and G. Gieres, Vacuum Ultraviolet Radiometry with Hydrogen Arcs. 2: The High Power Arc as an Absolute Standard of Spectral Radiance from $124 \mathrm{~nm}$ to $360 \mathrm{~nm}$, Appl. Opt. 14, 2121-2128 (1975).

27. J. M. Ajello, D. E. Shemansky, B. Franklin, J. Watkins, S. Srivastava, G. K. James, W. T. Simms, C. W. Hord, W. Pryor, W. McClintock, V. Argabright and D. Hall, Simple Ultraviolet Calibration Source With Reference Spectra and Its Use With the Galileo Orbiter Ultraviolet Spectrometer, Appl. Opt. 27, 890-914 (1988).

28. J. Hollandt, M. C. E. Huber and M. Kuhne, Hollow-cathode Transfer Standards for the Radiometric Calibration of VUV Telescopes of the Solar and Heliospheric Observatory (SOHO), Metrologia 30, 381-388 (1993).

29. J. Hollandt, M. Kuhne, M. C. E. Huber and B. Wende, High-current Hallow-cathode Source as a Radiant Intensity Standard in the 40-125 nm Wavelength Range, Appl. Opt. 33, 68-71 (1994).

30. J. M. Bridges and W. R. Ott, Vacuum Ultraviolet Radiometry. 3: The Argon Mini-arc as a New Secondary Standard of Spectral Radiance, Appl. Opt. 16, 367-376 (1977). 31. J. M Bridges, Development and Calibration of UV/VUV Radiometric Sources, Proc. SPIE 1764, 262-270 (1993).

32. J. M. Bridges, J. Z. Klose and W. R. Ott, Argon Mini-arc Source-Recent Developments, J. Opt. Soc. Am. 72, 1804-1804 (1982).

33. R. D. Saunders, W. R. Ott and J. M. Bridges, Spectral Irradiance Standard for the Ultraviolet: the Deuterium Lamp, Appl. Opt. 17, 593-600 (1978).

34. J. H. Walker, R. D. Saunders and A. T. Hattenburg, "Spectral Radiance Calibrations", SP 250-1, U.S. Department of Commerce, Gaithersburg, MD. 
35. R. P. Lambe, R. D. Saunders, C. Gibson, J. Hollandt and E. Tegeler, A CCPR International Comparison of Spectral Radiance Measurements in the Air-ultraviolet" Metrologia 37, 51-54 (2000).

36. J. H. Walker, R. D. Saunders, J. K. Jackson and D. A. McSparron, "Spectral Radiance Calibrations", SP 250-20, U.S. Department of Commerce, Gaithersburg, MD.

37. H. Park, A. Kreuger, E. Hilsenrath, G. Jaross and R. Haring, Radiometric Calibration of Second Generation Total Ozone Mapping Spectrometer, Proc. SPIE 2820, 162-173 (1996).

38. D. F. Heath, Z. Wei, W. K. Fowler and V. W. Nelson, Comparison of Spectral Radiance Calibrations of SBUV-2 Satellite Ozone Monitoring Instruments Using Integrating Sphere and Flat-plate Diffuser Techniques, Metrologia 30, 259-264 (1993).

39. S. E. Janz, E. Hilsenrath, J. Butler and R. P. Cebula, Uncertainties in Radiance Calibrations of Backscatter Ultraviolet (BUV) Instruments as Determined from Comparisons of BRDF Measurements and Integrating Sphere Calibrations, Metrologia 32, 637-641 (1996).

40. J. H. Walker, C. L. Cromer and J. T. McLean, A Technique for Improving the Calibration of Large-area Sphere Sources, Proc. SPIE 1493, 224-230 (1991).

41. K. Smorenburg, M. Dobber, E. Schenkeveld, R. Vink and H. Visser, Slitfunction Measurement Optical Stimulus, Proc. SPIE 4881, 511-520 (2003).

42. R. E. Haring, F. L. Williams. U. G. Hartman, D. Becker, G. Vanstone, H. Park, P. K. Bhartia, R. D. McPeters, G. Jaross and M. Kowalewski, Spectral Band Calibration of the Total Ozone Mapping Spectrometer (TOMS) Using a Tunable Laser Technique, Proc. SPIE 4135, 421-431 (2000).

43. H. W. Yoon, C. E. Gibson and P. Y. Barnes, Realization of the National Institute of Standards and Technology Detector-based Spectral Irradiance Scale, Appl. Opt. 41, 5879. 5890 (2002).

44. R. D. Jackson, T. R. Clarke and M. S. Moran, Bidirectional Calibration Results for 11 Spectralon and 16 Barium Sulfate Reference Reflectance Panels, Remote Sensing of the Environment 40, 231-239 (1992).

45. W. A. Hovis and J. S. Knoll, Characteristics of an Internally Illuminated Calibration Sphere, Appl. Opt. 22, 4004-4007 (1983).

46. B. C. Johnson, S. S. Bruce, E. A. Early, J. M. Houston, T. R. O'Brian, A. Thompson, S. B. Hooker and J. L. Mueller, "The Fourth SeaWiFS Intercalibration Round-robin Experiment, SIRREX-4, May 1995”, NASA Tech. Memo 104566, Vol. 37, S. B. Hooker and E.R. Firestone, Eds., NASA Goddard Space Flight Center, Greenbelt, MD, 65pp. 47. S. W. Brown and B. C. Johnson, Development of a Portable Integrating Sphere Source for the Earth Observing System's Calibration Validation Programme, Int. J. Remote Sensing 24, 215-224 (2003).

48. E. A. Early, P. Y. Barnes, B. C. Johnson, J. J. Butler, C. J. Bruegge, S. F. Biggar, P. R. Spyak and M. M. Pavlov, Bidirectional Reflectance Round-robin in Support of the Earth Observing System Program, J. Atmos. Oceanic. Technol. 17, 1077-1091 (2000). 49. J. J. Butler, B. C. Johnson, S. W. Brown, R. D. Saunders, S. F. Biggar, E. F. Zalewski, B. L. Markham, P. N. Gracey, J. B. Young and R. A. Barnes, Radiometric Measurement Comparison on the Integrating Sphere Source Used to Calibrate the Moderate Imaging Spectroradiometer (MODIS) and the Landsat 7 Enhanced Thematic Mapper (ETM+), J. Res. Natl. Inst. Stand. Technol. 108, 199-228 (2003). 
50. S. W. Brown and B. C. Johnson, Advances in Radiometry for Ocean Color, Proc. SPIE, 5151, 441-453 (2003).

51. S. W. Brown, G. P. Eppeldauer and K. R. Lykke, NIST Facility for Spectral Irradiance and Radiance Responsivity Calibrations with Uniform Sources, Metrologia 37, 579-582 (2000).

52. W. G. Rees, "Physical Principles of Remote Sensing”, Cambridge University Press, Cambridge, UK, 2003.

53. P. G. Morse, J. C. Bates, C. R. Miller, M. T. Chahine, F. O'Callaghan, H. H. Aumann and A.R. Karnik, Development and Test of the Atmospheric Infrared Sounder (AIRS), Proc. SPIE, 3759, 236-253 (1999).

54. R. A. Hanel, B. Schlachman, D. Rogers and D. Vanous, Nimbus 4 Michaelson Interferometer, Appl. Opt. 10, 1376-1382 (1972).

55. M. Ridolfi, L. Magnani, M. Carlotti and B.M. Dinelli, MIPAS-ENVISAT Limbsounding Measurements: Trade-off Study for Improvement of Horizontal Resolution, Appl. Opt. 43, 5814-5824 (2004).

56. C. Cao, personal communication.

57. W. P. Menzel, Cloud Tracking with Satellite Imagery: From the Pioneering Work of Ted Fujita to the Present, Bull. Amer. Meteor. Soc. 82, 33-47 (2002).

58. R. B. Lee, B. R. Barkstrom, G. L. Smith, J. E. Cooper, L. P. Kopia, R. W. Lawrence, S. Thomas, D. K. Pandey and D. A. Crommelynck, The Clouds and the Earth's Radiant Energy System (CERES) Sensors and Preflight Calibration Plans, J. Atmos. Oceanic Tech. 13, 300-313 (1996).

59. H. Preston-Thomas, Metrologia 27, 3-10; 107 (1990).

60. J. R. Chandos and R. E. Chandos, Radiometric Properties of Isothermal, Diffuse Wall Cavity Sources, Appl. Opt. 13, 2142-2152 (1974).

61. B. Guenther, W. Barnes, E. Knight, J. Barker, J. Harnden, R. Weber, M. Roberto, G. Godden, H. Montgomery and P. Abel, MODIS Calibration: A Brief Review of the Strategy for the At-launch Calibration Approach, J. Atmos. Oceanic Tech. 13, 274-285 (1996).

62. T. J. Nightingale and J. Crawford, A Radiometric Calibration System for the ISAMS Remote Sounding Instrument, Metrologia 28, 233-237 (1991).

63. A. Ono, F. Sakuma, K. Arai, Y Yamaguchi, H. Fujisada, P. N. Slater, K. J. Thome, F. D. Palluconi and H. H. Kieffer, Pre-flight and In-flight Calibration Plan for ASTER, J. Atmos. Oceanic Tech. 13, 321-335 (1996).

64. D. A. Byrd, F. D. Michaud, S. C. Bender, A. L. Luettgen, R. F. Holland, W. H. Atkins, T. R. O'Brian and S. R. Lorentz, Design, Manufacture and Calibration of Infrared Radiometric Blackbody Sources, Proc. SPIE, 2743, 216-226 (1996).

65. A. V. Prokhorov, Monte Carlo Method in Optical Radiometry, Metrologia 35, 465471 (1998).

66. A. C. Carter, T. M. Jung, A. Smith, S. R. Lorentz and R. Datla, Improved Broadband Blackbody Calibrations at NIST for Low-background Infrared Applications, Metrologia 40, S1-S4 (2003).

67. R. U. Datla, M. C. Croarkin and A. C. Parr, Cryogenic Blackbody Calibrations at the National Institute of Standards and Technology Low-background Infrared Calibration Facility, J. Res. NIST 99, 77-87 (1994). 
68. J. P. Rice and B. C. Johnson, The NIST EOS Thermal-infrared Transfer Radiometer, Metrologia 35, 505-509 (1998).

69. J. B. Fowler, A 3rd-generation Water Bath Based Blackbody Source, J. Res. NIST 100, 591-599 (1995).

70. J. B. Fowler, B. C. Johnson, J. P. Rice and S. R. Lorentz, The New Cryogenic Vacuum Chamber and Black-body Source for Infrared Calibrations at NIST's FARCAL Facility, Metrologia 35, 323-327 (1998).

71. J. P. Rice, S. C. Bender and W. H. Atkins, Thermal Infrared Scale Verifications at 10 $\mu \mathrm{m}$ Using the NIST EOS TXR, Proc. SPIE, 4135, 96-107 (2000).

72. J. P. Rice, S. C. Bender, W. H. Atkins and F. J. Lovas, Deployment Test of the NIST EOS Thermal-infrared Transfer Radiometer, Int. J. Remote Sensing 24, 367-388 (2003). 73. J. P. Rice, "Verification of the GOES Imager Absolute Calibration Model Using the NIST Thermal-infrared Transfer Radiometer", NIST memo, Gaithersburg, MD), 2003. 74. W. H. Farthing, "Imager S/N 03 Channel 2 Non-linearity", Swales Aerospace Memorandum, Beltsville, MD, 1993.

75. J. P. Rice, "Measurements of the Raytheon Santa Barbara Remote Sensing Blackbody Calibration Source using the NIST Thermal-infrared Transfer Radiometer", NIST memo, Gaithersburg, MD, 2004.

76. C. L. Wyatt, "Radiometric Calibration: Theory and Methods", Academic Press, New York, 1978.

77. M. H. Weiler, L. Strow, S. Hannon, S. Gaiser, R. Schindler, K. Overoye and H. H. Aumann, Spectral Test and Calibration of the Atmospheric Infrared Sounder, Proc. SPIE, 4483, 44-52 (2002).

78. S. Hansen, J. Peterson, R. Esplin and J. Tansock, Component Level Prediction Versus System Level Measurement of SABER Relative Response, Int. J. Remote Sensing 24, 389-402 (2003).

79. C. Cao, M. Weinreb and S. Kaplan, "Verification of the HIRS Spectral Response Functions for More Accurate Atmospheric Sounding", Proceedings of Calcon, Utah State University, Logan, UT, 2004.

80. C. Cao, H. Xu, J. Sullivan, L. McMillin, P. Ciren and Y.-T. Hou, submitted for publication in J. Atmos. Oceanic Tech. (2004).

81. S. Kaplan, "Transmittance Measurements of 19 Witness Infrared Bandpass Filters from the HIRS/4 Instrument", NIST memo, Gaithersburg, MD, 2003.

82. S. W. Brown, G. P. Eppeldauer, J. P. Rice, J. Zhang and K. R. Lykke, Spectral Irradiance and Radiance Responsivity Calibrations Using Uniform Sources (SIRCUS) Facility at NIST, Proc. SPIE, 5542, 363-374 (2004).

83. G.P. Eppeldauer, J.P. Rice, J. Zhang, J. and K.R. Lykke, Spectral Irradiance Responsivity Measurements Between $1 \mu \mathrm{m}$ and $5 \mu \mathrm{m}$, Proc. SPIE, 5543, 248-257 (2004). 84. J. Lean, The Sun's Variable Radiation and Its Relevance for Earth, Ann. Rev. Astron. Astrophys. 35, 33-67, (1997).

85. H. Schwabe, Solar Observations During 1843, Astronomische Nachrichten 20, 495, (1843).

86. J. Lean and D. Rind, Climate Forcing by Changing Solar Radiation, J. Climate 11, 3069-3094, (1998).

87. National Research Council, "Solar Influences on Global Change, National Academy Press", Washington, DC, 1994. 
88. C. Frohlich, History of Solar Radiometry and the World Radiometric Reference, Metrologia 28, 111-115, (1991).

89. K. Angstrom, The Absolute Determination of the Radiation of Heat with the Electrical Compensation Pyroheliometer, With Examples of the Application of this Instrument, Astrophysics 9, 332, (1899).

90. F. Hengstberger, "Absolute Radiometry: Electrically Calibrated Thermal Detectors of Optical Radiation", Academic Press, 1989.

91. R. Willson and R.S. Helizon, EOS/ACRIM III Instrumentation, Proc. SPIE 3750, 233-242, 1999.

92. R. C. Willson, Irradiance Observation of SMM Spacelab 1, UARS and ATLAS Experiment, in "The Sun as a Variable Star: Solar and Stellar Irradiance Variations", J.M. Pap and C. Frohlich, eds. Cambridge University Press, 1994.

93. C. Frohlich, B. N. Anderson, T. Appourchaux, B. Berthomieu, D. A. Crommelynck, V. Domingo, A. Fichot, M. F. Finsterle, M. F. Gomez, D. Gough, A. Jimenez, T. Leifsen, M. Lombaerts, J. M. Pap, J. Provost, T. Roca Cortes, J. Romero, H. Roth, T. Sekii, U. TellJohann, T. Toutain and C. Wehrli, "The First Results from SOHO”, B. Fleck and Z. Svestka, Eds. Kluwer Academic Publishers, Dordrect, 1997.

94. J. C. Romero, C. Wehrli and C. Frohlich, Solar Total Irradiance Variability from SOVA2 On Board EURECA, Sol. Phys. 152, 23-29, (1994).

95. D. A. Crommelynck and S. Dewitte, Metrology of Total Solar Irradiance Monitoring", Adv. Space Res. 24, 195-204, (1999).

96. G. M. Lawrence, G. Rottman, G. Kopp, J. Harder, W. McClintock and T. Woods, The Total Irradiance Monitor (TIM) for the EOS Source Mission, Proc. SPIE 4135, 215-224, (2000).

97. D. V. Hoyt, H. L. Kyle, J. R. Hickey and R. H. Maschoff, The Nimbus 7 Solar Total Irradiance: A New Algorithm for Its Derivation, J. Geophys. Res. 97, 148-227, (1992). 98. H. L. Kyle, D. V. Hoyt, J. R. Hickey and G. J. Valette, Nimbus-7 Earth Radiation Budget Calibration History-Part 1: The Solar Channels, NASA Reference Publication 1316, 1993.

99. R. C. Willson and A. V. Mordvinov, Secular Total Solar Irradiance Trend During Solar Cycles 21023, Geophys. Res. Lett. 30, 1199-1203, (2003).

100. C. Frohlich and J. Lean, The Sun's Total Irradiance: Cycles and Trends in the Past Two Decades and Associated Climate Change Uncertainties, Geophys. Res. Lett. 25, 4377-4380, (1998).

101. R. B. Lee III, Long-term Total Solar Irradiance Variability During Sunspot Cycle 22, J. Geophys. Res. 100, 1667-1675, (1995).

102. A. C. Parr, "A National Measurement System for Radiometry, Photometry and Pyrometry Based Upon Absolute Detectors", Optical Radiation Measurement, NIST Technical Note 1421, 1996.

103. G. M. Lawrence, G. Kopp, G. Rottman, J. Harder, T. Woods and H. Loui, Calibration of the Total Irradiance Monitor, Metrologia 40, S78-S80, (2003). 105. G. M. Lawrence, G. Rottman, J. Harder and T. Woods, Solar Total Irradiance Monitor, Metrologia 37, 407-410, (2000).

105. R. Goebel, M. Stock and R. Kohler, "Report on the International Comparison of Cryogenic Radiometers Based on Transfer Detectors", BIPM Report B IPM-2000/9, 2000, pp. 1-68. 
106. B. C. Johnson, M. Litorja and J. J. Butler, Preliminary Results of Aperture Area Comparison for Exo-atmospheric Solar Irradiance, Proc. SPIE 5151, 454-461, (2003). 107. R. A. Barnes and E. F. Zalewski, Reflectance-based Calibration of SeaWiFS. II. Conversion to Radiance, Appl. Opt. 42, 1648-1660 (2003).

108. K. S. Thome, S. Biggar and P. Slater, Effects of Assumed Solar Spectral Irradiance in Intercomparisons of Earth Observing Sensors, Proc. SPIE, 4540, 260-269 (2001).

109. M. P. Thekaekara, Extraterrestrial Solar Spectrum, 3000-6100 Angstroms at 1Angstrom Intervals, Appl. Opt. 13, 518-522 (1974).

110. M. P. Thekaekara, Extraterrestrial Solar Spectral Irradiance, in "The Extraterrestrial Solar Spectrum", A. J. Drummond and M. P Thekaekara, eds., Mt. Prospect, Illinois, Institute of Environmental Sciences, 1973, pp. 71-133.

111. C. Wehrli, "Extraterrestrial Solar Spectrum", Publ. 615, PhysikalischMeterologisches Observatorium Davos and World Radiation Center, Davos-Dorf, Switzerland, 1985.

112. C. Wehrli, "Spectral Solar Irradiance Data", World Climate Research Program (WRCP) Publication Series No. 7, WMO ITD No. 149, World Meteorological Organization, Geneva, Switzerland, 1986, pp. 119-126.

113. G. Brasseur and P. C. Simon, Stratospheric Chemical and Thermal Response to Long-term Variability in Solar Uv Irradiance, J. Geophys. Res. 86, 7343-7362 (1981).

114. J. C. Arvesen, R. N Griffen, Jr. and B. D. Pearson, Jr., Determination of extraterrestrial solar spectral irradiance from a research aircraft, Appl. Opt. 8, 2215-2232 (1969).

115. H. Neckel and D. Labs, The Solar Radiation Between 3300 and $12500 \AA$ A, Solar Physics 90, 205-258 (1984).

116. E. V. P. Smith and D. M. Gottlieb, Solar Flux and its Variations, Space Sci. Rev. 16, 771-802 (1974).

117. L. Colina, R. C. Bolin and F. Castelli, The 0.12-2.5 um Absolute Flux Distribution of the Sun for Comparison with Solar Analog Stars, Astronom. J. 112, 307-315 (1996). 1.18. T. N. Woods, D. K. Prinz, G. J. Rottman, J. London, P.C. Crane, R. P. Cebula, E. Hilsenrath, G. E. Brueckner, M. D. Andrews, O. R. White, M. E. VanHoosier, L.E. Floyd, L. C. Herring, B. G. Knapp, C. K. Pankratz and P. A. Reiser, The Validation of the UARS Solar Ultraviolet Irradiances: Comparison with the ATLAS 1 and 2 Measurements, J. Geophys. Res. 101, 9541-9569 (1996).

119. A. Berk, L. S. Bernstein and D. C. Robertson, "MODTRAN: A Moderate Resolution Model for LOWTRAN7", Tech. Report GL-TR-90-0122, Geophysical Directorate Phillips Laboratory, Hanscom AFB, Massachusetts, 1990.

120. R. L. Kurucz, The Solar Spectrum: Atlases and Line Identifications, in "Laboratory and Astronomical High Resolution Spectra", A. J. Saval, R. Blomme and N. Grevesse, eds., San Francisco, Astronomical Society of the Pacific, 1995, pp. 17-31.

121. R. L. Kurucz, The Solar Irradiance by Computation, in "Proceedings of the Conference on Atmospheric Transmission Models (17th)", Tech. Memo. PL-TR-952060, G. P. Anderson, R. H. Pikard and J. H. Chetwynd, eds. (Phillips Laboratory, Hanscomb Air Force Base, Ma., 1995, pp. 333-334. 
122. G. M. Thuillier, M. Hersé, P. C. Simon, D. Labs, H. Mandel and D. Gillotay, "Observation of the UV Solar Spectral Irradiance Between 200 and $350 \mathrm{~nm}$ During the Atlas I Mission by the SOLSPEC Spectrometer, Solar Phys. 171, 283-302 (1997).

123. G. M. Thuillier, M. Hersé, P. C. Simon, D. Labs, H. Mandel, D. Gillotay and T. Foujols, The Visible Solar Spectral Irradiance from 350 to $850 \mathrm{~nm}$ as Measured by the SOLSPEC Spectrometer During the Atlas I Mission, Solar Phys. 177, 41-61 (1998).

124. G. M. Thuillier, M. Hersé, D. Labs, T. Foujols, W. Peetermans. D. Gillotay, P. C. Simon and H. Mandel, The Solar Spectral Irradiance from 200 to $2400 \mathrm{~nm}$ as Measured by the Solspec Spectrometer from the Atlas and Eureca Missions, Solar Phys. 214, 1-22 (2003).

125. J. W. Harder, G. M. Lawrence, G. J. Rottman and T. N. Woods, Spectral Irradiance Monitor (SIM) for the SORCE Mission, Proc. SPIE 4135, 204-214 (2000).

126. J. Harder, G. M. Lawrence, G. Rottman and T. Woods, Solar Spectral Irradiance Monitor (SIM), Metrologia 37, 415-418 (2000).

127. W. L. Barnes, T. S. Pagano and V. V. Salomonson, Prelaunch Characteristics of the Moderate Resolution Imaging Spectroradiometer (MODIS) on EOS-AM1, IEEE Trans. Geosci. Remote Sens. 36, 1088-1100 (1998).

128. J. A. Mendenhall, D. E. Lencioni, D. R. Hearn and C. J. Digenis, Flight Tests of the Earth Observing-1 Advanced Land Imager, Earth Observing Systems VII, Proc. SPIE 4814, 296-305 (2002).

129. H. N. Montgomery, N. Che and J. Bowzer, Methodology for Determining Band Radiance Changes Under SRCA Illumination, Proc. SPIE, 3870, 369-376 (1999). 130. J. A. Walker Jr., M. M. Pavlov. and M. L. Byers, Characterization of the Solar Diffuser as the Primary Standard for On-orbit Calibration of the Moderate Resolution Spectroradiometer, Sensors, Systems and Next-Generation Satellites II, Proc. SPIE 3498, 496-505 (1998).

131. B. Guenther, X. Xiong, V. V. Salomonson, W. L. Barnes and J. Young, On-orbit Performance of the Earth Observing System Moderate Resolution Imaging Spectroradiometer: First Year of Data, Remote Sens. Environ. 83, 16-30 (2002). 132. R. A. Barnes, R. E. Eplee, Jr., S. F. Biggar, K. J. Thome, P. N. Slater and A. W. Holmes, SeaWiFS Transfer-to-Orbit Experiment, Appl. Opt. 39, 5620-5631 (2000). 133. B. Guenther, W. Barnes, E. Knight, J. Barker, J. Harnden, R. Weber, M. Roberto, G. Godden, H. Montgomery and P. Abel, MODIS Calibration: A Brief Review of the Strategy for the At-launch Calibration Approach, J. Atmos. Ocean. Technol. 13, 274-285 (1996).

134. X. Xiong, K. Chiang, J. Esposito, B. Guenther and W. Barnes, MODIS On-orbit Calibration and Characterization, Metrologia 40, S89-S92 (2003).

135. W. L. Barnes, X. Xiong, B. W. Guenther and V. Salomonson, Development, Characterization and Performance of the EOS MODIS Sensors, Proc. SPIE 5151, 337 345 (2003).

136. C. J. Bruegge, N. C. L. Chrien, B. G. Chafin, D. J. Diner and R. R. Ando, In-flight Calibration of the EOS/Multi-angle Imaging SpectroRadiometer (MISR), Proc. SPIE 419, 36-46 (2001). 
137. N. L. Chrien, C. J. Bruegge and R. R. Ando, Multi-angle Imaging SpectroRadiometer (MISR) On-board Calibrator (OBC) In-flight Performance Studies, IEEE Trans. on Geoscience and Remote Sensing 40, 1493-1499 (2002). 138. M. Rast and J. L. Bezy, The ESA Medium Resolution Imaging Spectrometer MERIS: A Review of the Instrument and its Mission, Int. J. Remote Sens. 20, 1681-1702 (1999).

139. J. A. Mendenhall, D. E. Lencioni and A. C. Parker, Radiometric Calibration of the EO-1 Advanced Land Imager, Proc. SPIE 3750, 117-131 (1999).

140. K.-H. Sumnich and H. Schwarzer, In-flight Calibration of the Modular Optoelectronic Scanner (MOS), Int. J. Remote Sensing 19, 3237-3259 (1998).

141. S. Kurihara, H. Murakami, K. Tanaka, T. Hashimoto, Il. Asanuma, J. Inoue, Calibration and Instrument Status of ADEOS-II Global Imager, Proc. SPIE 5234, 11-19 (2004).

142. G. Jaross, A. J. Krueger, R. P. Cebula, C. J. Seftor, U. Hartmann, R. Haring and D. Burchfield, Calibration and Postlaunch Performance of the Meteor 3/TOMS Instrument, J. Geophys. Res. 100, 2985-2995 (1995).

143. R. Hoekstra, C. Olij, A. E. Zoutman and H. G. Werij, Pre- and In-flight Calibration of GOME, Proc. SPIE 2957, 312-321 (1997).

144. J. Callies, E. Corpaccioli, M. Eisinger, A. Lefebvre, R. Munro, A. Perez-Albinana, B. Ricciarelli, L. Calamai, G. Gironi, R. Veratti, G. Otter, M. Eschen and L. van Riel, GOME-2 the Ozone Instrument On-board the European METOP Satellites, Polarization Science and Remote Sensing, Proc. SPIE 1-11 (2003).

145. P. Stammes, P. Levelt, J. de Vries, H. Visser, B. Kruizinga, C. Smorenburg, G. Leppelmeier and E. Hilsenrath, Scientific Requirements and Optical Design of the Ozone Monitoring Instrument on EOS-CHEM, Proc. SPIE 3750, 221-232 (1999).

146. P. F. Levelt and R. Noordheok, OMI Algorithm Theoretical Basis Document, Volume 1: OMI Instrument, Level 0-1b Processor, Calibration and Operations, available at http://eospso.gsfc.nasa.gov/eos hompage/for_scientists/atbd/docs/OMI/ATBD-OMI01.pdf

147. E. Zoutman and C. Olij, Calibration Approach for SCIAMACHY, Proc. SPIE 3117, 306-317 (1997).

148. B. L. Markham, W. C. Boncyk, D. L. Helder and J. L. Barker, Landsat-7 Enhanced Thematic Mapper Radiometric Calibration, Can. J. Remote Sensing 23, 318-332 (1997). 149. B. L. Markham, J. L. Barker, E. Kaita and I. Gorin, Landsat-7 Enhanced Thematic Mapper Plus: Radiometric Calibration and Prelaunch Performance, Proc. SPIE 3221, 170-17 (1997).

150. R. A. Barnes and E. F. Zalewski, Reflectance-based Calibration of SeaWiFS, I. Calibration Coefficients, Appl. Opt. 1629-1647 (2003).

151. C. H. Lyu, W. L Barnes, R. A. Barnes, First Results from the On-orbit Calibrations of the Visible and Infrared Scanner for the Tropical Rainfall Measuring Mission, $J$. Atmos. Ocean. Technol. 17, 385-394 (2000).

152. P. Jarecke, K. Yokohama and P. Barry, On-orbit Solar Radiometric Calibration of the Hyperion Instrument, Proc. SPIE 4480, 225-230 (2002).

153. R. B. Lee III, Flight Solar Calibrations Using the Mirror Attenuator Mosaic (MAM) Low Scattering Mirror, Proc. SPIE 1493, 267-280 (1991). 
154. R. B. Lee III, B. R. Barkstrom, G. L. Smith, J. E. Cooper, L. P. Kopia and R. W. Lawrence, The Clouds and the Earth's Radiant Energy System (CERES) Sensors and Preflight Calibration Plans, J. Atmos. Ocean. Technol. 13, 300-313 (1996).

155. J. C. Bremer, H. J. Wood and G. Si, Attenation of Direct Solar Radiation by a Perforated Plate for On-orbit Calibration, Proc. SPIE 4135, 374-383 (2000).

156. A. E. Stiegman, C. J. Bruegge and A. W. Springsteen, Ultraviolet Stability and Contamination Analysis of Spectralon Diffuse Reflectance Material, Opt. Eng. 32, 799 804 (1993).

157. C. J. Bruegge, A. E. Stiegman, R. A. Rainen and A.W. Springsteen, Use of Spectralon as a Diffuse Reflectance Standard for In-flight Calibration of Earth-orbiting Sensors, Opt. Eng. 32, 805-814 (1993).

158. E. Hilsenrath, H. Herzig, D. E.Williams, C. J. Bruegge and A. E. Stiegman, Effects of Space Shuttle Flight on the Reflectance Characteristics of Diffusers in the Nearinfrared, Visible and Ultraviolet Regions, Opt. Eng. 33, 3675-3682 (1994). 159. J. de Vries, E. C. Laan, E. Schenkeveld, G. van den Oord and D.de Winter, OMI Flight Model Performance Test Results, Proc. SPIE 4881, 137-146 (2003). 160. J. Q. Sun, X. Xiong and B. Guenther, MODIS Solar Diffuser Stability Monitor Performance, Proc. SPIE 4483, 156-164 (2001).

161. J. R. Herman, P. A. Newman, R. McPeters, A. J. Krueger, P. K. Bhartia, C. J. Seftor, O. Torres, G. Jaross, R. P. Cebula, D. Larko and C. Wellmeyer, Meteor 3 Total Ozone Mapping Spectrometer Observations of the 1993 Ozone Hole, J. Geophys. Res. 100, 2973-2983 (1995).

162. F. Sakuma, A. Ono, M. Kudoh, H. Inada, S. Akagi, H. Ohmae, ASTER On-board Calibration Status, Proc. SPIE 4881, 407-418 (2003).

163. J. A. Mendenhall, D. R. Hearn, D. E. Lencioni, C. J. Digenis and L. Ong, Summary of the EO-1 ALI Performance During the First 2.5 Years On-orbit, Proc. SPIE 5151, 574585 (2003).

164. B. L. Markham, J. C. Seiferth, J. Smid and J.L. Barker, Lifetime Responsivity Behavior of the Landsat-5 Thematic Mapper, Proc. SPIE 3427, 420-431 (1998). 165. R. R. Turtle, Modified Internal Calibration Lamp Source for ETM+ on Landsat 7 , Proc. SPIE 3439, 423-430 (1998).

166. S. Thomas, K. J. Priestley, R. B. Lee III, P. L. Spence, R. S. Wilson, A. Al-Hajjah, J. Paden and D. K. Pandey, Performance Studies of CERES Sensors on Earth Science Enterprise (ESE) Terra Mission Using On-borad Calibrations and Other Validation Methods, Proc. SPIE 4886, 172-181 (2003).

167. R. B. Lee III, J. Paden, D. K. Pandey, R. S. Wilson, K. A. Bush and G. L. Smith, On-orbit Radiometric Calibrations of the Earth Radiation Budget Experiment (ERBE) Active-cavity Radiometers on the Earth Radiation Budget Satellite (ERBS), Proc. SPIE 4814, 369-379 (2002).

168. J. L. Monge, R. Kandel, L. A. Pakhomov and V. I. Adasko, The SCaRaB Earth Radiation Budget Scanning Radiometer, Metrologia 28, 261-264 (1991).

169. R. S. Fraser and Y. J. Kaufman, Calibration of Satellite Sensors after Launch, Appl. Opt. 25, 1177-1185 (1986).

170. E. Vermote, R. Santer, P. Y. Deschamps and M. Herman, In-flight Calibration of Large Field of View Sensors at Short Wavelengths Using Rayleigh Scattering, Int. J. Remote Sensing 13, 3409-3429 (1992). 
171. Y. J. Kaufman and B. N. Holben, Calibration of the AVHRR Visible and Near-IR Bands by Atmospheric Scattering, Ocean Glint and Desert Reflection, Int. J. Remote Sensing 14, 21-52 (1993).

172. E. Vermote and Y.J. Kaufman, Absolute Calibration of AVHRR Visible and Nearinfrared Channels Using Ocean and Cloud Views, Int. J. Remote Sensing 16, 2317-2340 (1995).

173. C. R. N. Rao and J. Chen, Inter-satellite Calibration Linkages for the Visible and Near-infrared Channels of the Advance Very High Resolution Radiometer on NOAA-7, 9 and -11 Spacecraft, Int. J. Remote Sensing 16, 1931-1942 (1995).

174. C. R. N. Rao and J. Chen, Post-launch Calibration of the Visible and Near-infrared Channels of the Advanced Very High Resolution Radiometer on the NOAA-14 Spacecraft, Int. J. Remote Sensing 17, 2743-2747 (1996). 175. A. Meygret, S. Briottet, P. Henry and O. Hagolle, Calibration of SPOT 4 HRVIR and VEGETATION Camera Over the Rayleigh Scattering, Proc. SPIE 4135, 302-313 (2004).

176. J. J. Butler, G. Meister, F. S. Patt and R. A. Barnes, Use of the Moon as a Reference for Satellite-based Climate Change Measurements, Proc. SPIE 5570, 328-341 (2004). 177. J. C. Bremer, J. G. Baucom, H. Vu, M. P. Weinreb and N. Pinkine, Estimation of Long-term Throughput Degradation of GOES 8 \& 9 Visible Channels by Statistical Analysis of Star Measurements, Proc. SPIE 3439, 145-154 (1998).

178. G. J. Rottman and T. N. Woods, In-flight Calibration of Solar Irradiance Measurements by Direct Comparison with Stellar Observations, Proc. SPIE 924, 136143 (1988).

179. G. J. Rottman, T. N. Woods and T. P. Sparn, Solar Stellar Irradiance Comparison Experiment I: 1. Instrument Design and Operation, J. Geophys. Res. 98, 10667-10677 (1993).

180. T. N. Woods, G. J. Rottman and G. Ucker, Solar Stellar Irradiance Comparison Experiment I: 2. Instrument Calibration, . Geophys. Res. 98, 10679-10604 (1993). 181. S. Delwart, L. Bourg and J. P. Huot, MERIS $1^{\text {st }}$ Year: Early Calibration Results, Proc. SPIE 5234, 379-390 (2003).

182. N. Che, X. Xiong and W. Barnes, On-orbit Spectral Characterization Results for Terra MODIS Reflective Solar Bands, Proc. SPIE 5151, 367-373 (2003).

183. J. Delderfeld, D. T. Llewellyn-Jones, R. Bernard, Y. deJavel, E. J. Williamson, I.Mason, D. R. Pick and I. J. Barton, The Along Track Scanning Radiometer (ATSR) for ERS 1, Proc. SPIE 589, 114-120 (1985).

184. R. Bouchard and J. Giroux, Test and Qualification Results on the MOPITT Flight Calibration Sources, Opt. Eng. 36, 2992-3000 (1997).

185. T. S. Pagano, H. H. Aumann, D. E. Kagan and K. Overoye, Prelaunch and In-flight Calibration of the Atmospheric Infrared Sounder (AIRS), IEEE Trans. Geoscience and Remote Sensing 41, 265-273 (2003).

186. E. M. Sparrow and S. H. Lin, Absorption of Thermal Radiation in a V-Groove Cavity, Int. J. Heat Mass Transfer 5, 1111-1115 (1962).

187. X. Xiong, K Chiang, J. Esposito, B. Guenther and W. L. Barnes, MODIS On-orbit Calibration and Characterization, Metrologia 40, 89-92 (2003). 
188. X. Xiong, K. Chiang, B. Guenther and W. L. Barnes, MODIS Thermal Emissive Bands Calibration Algorithm and On-orbit Performance, Proc. SPIE 4891, 392-401 (2002).

189. S. Thomas, K. J. Priestley, R. B. Lee III, P. L. Spence, R. S. Wilson, A. Al-Hajjah and D. K. Pandey, Performance Studies of CERES Sensors on Earth Science Enterprise (ESE) Terra Mission Using On-board Calibrations and Other Validation Methods, Proc. SPIE 4886, 172-181 (2003).

190. "AVHRR/2 Advanced Very High Resolution Radiometer Technical Description", ITT Aerospace/Optical Division, Fort Wayne, IN, NASA Contract Number NAS5$26771,1982$.

191. A. Schwalb, "The TIROS-N/NOAA-G Satellite Series", NOAA Technical Memorandum NESS 95, Washington, D.C., 1978.

192. A. Schwalb, "Modified Version of the TIROS-N/NOAA A-G Satellite Series (NOAA E-J)-Advanced TIROS-N (ATN)", NOAA Technical Memorandum NESS 116, Washington, D.C., 1982.

193. A. Ono and F. Sakuma, ASTER Instrument Calibration Plan, Proc. SPIE 1939, 198209 (1993).

194. T. Maekawa, O. Nishihara, Y. Aoki, K. Tsubosaka and S. Kitamura, Design Challenges of ASTER in the Thermal Infrared Spectral Region, Proc. SPIE 1939, 176186 (1993).

195. K. Thome, K. Arai, S. Hook, H. Kieffer, H. Lang, T. Matsunaga, A. Ono, F. Palluconi, F. Sakuma, T. Takashima, H. Tonooka, S. Tsuchida, R. M. Welch and E. Zalewski, ASTER Preflight and Inflight Calibration and the Validation of Level 2 Products, IEEE Trans. Geoscience and Remote Sensing 36, 1161-1172 (1998).

196. C. Bradley, The GOES I-M System Functional Description, NOAA Technical Rep. NESDIS 40, 1-126 (1988).

197. M. P. Weinreb, "Imager/Sounder Inflight Infrared Calibration and Visible Normalization", GOES I-M Operational Satellite Conference, Arlington, VA, U.S. Department of Commerce, NOAA, 1989, pp. 397-404.

198. P. G. Morse, J. C. Bates, C. R. Miller, M. T. Chahine, F. O'Callaghan, H. H. Aumann and A. R. Karnik, Development and Test of the Atmospheric Infrared Sounder (AIRS), Proc. SPIE 3759, 236-253 (1999).

199. S. L. Gaiser, H. H. Aumann, L.L. Strow, S.E. Hanson and M. Weiler, In-flight Spectral Calibration of the Atmospheric Infrared Sounder, IEEE Trans. Geoscience and Remote Sensing 41, 287-297 (2003).

200. R. Beer, T. A. Glavich and D. M. Rider, Tropospheric Emission Spectrometer for the Earth Observing System's Aura Platform, Appl. Opt. 40, 2356-2367 (2001).

201. M. Endemann, P. Gare, D. J. Smith, K. Hoerning, B. Fladt and R. Gessner, MIPAS Design Overview and Current Development Status, Proc. SPIE 2956, 124-135 (1997). 202. R. Gessner, D. J. Smith, M. Kolm, M. Endermann and P. Gare, MIPAS Onboard ENVISAT: Flight Model Performance, Calibration and Characterization, Proc. SPIE 4169, 133-143 (2001).

203. F. Henault, C. Buil, B. Chidaine and D. Scheidel, Spaceborne Infra-red Interferometer of the IASI Instrument, Proc. SPIE 3437, 192-202 (1998).

204. L. Pujol, J. Lizet and O. Sosnicki, Reference Laser Source for IASI Interferometer, Proc. SPIE 4169, 153-158 (2001). 
205. P. M. Teillet, K. J. Thome, N. Fox and J. T. Morisette, Earth Observation Sensor Calibration Using a Global Instrumented and Automated Network of Test Sites (GIANTS), Proc. SPIE 4540, 246-254 (2001).

206. P. M. Teillet, D. N. H. Horler and N. T. O'Neill, Calibration, Validation and Quality Assurance in Remote Sensing: A New Paradigm, Can. J. Remote Sensing 23, 401-414 (1997).

207. P. N. Slater, S. F. Biggar, K. J. Thome, D. I. Gellman and P. R. Spyak, Vicarious Calibration of EOS Sensors, J. Atmospheric and Oceanic Technol. 13, 349-359 (1996). 208. K. Thome, S. Schiller, J. Conel, K. Arai and S. Tsuchida, Results of the 1996 Earth Observing System Vicarious Calibration Joint Campaign at Lunar Lake Playa, Nevada (USA), Metrologia 35, 631-638 (1998).

209. K. P. Scott, K. J. Thome and M. R. Browlee, Evaluation of the Railroad Valley Playa for Use in Vicarious Calibration, Proc. SPIE 2818, paper number 30 (1996). 210. K. J. Thome, S. F. Biggar and W. Wisniewski, Cross Comparison of EO-1 Sensors and Other Earth Resources Sensors to Landsat-7 ETM+ Using Railroad Valley Playa, IEEE Trans. Geoscience and Remote Sensing 41, 1180-1188 (2003).

211. A. A. Bannari, K. Omari, P. M. Teillet and G. Fedosejevs, Multisensor and Multiscale Survey and Characterization for Radiometric Spatial Uniformity and Temporal Stability of Railroad Valley Playa (Nevada) Test Site Used for Optical Sensor Calibration, Proc. SPIE 5234, 590-604 (2004).

212. K. J. Thome, S. F. Biggar and H. J. Choi, Vicarious Calibration of Terra ASTER, MISR and MODIS, Proc. SPIE 5542, 290-299 (2004).

213. K. Thome, B. Markham, J. Barker, P. Slater and S. Biggar, Radiometric Calibration of Landsat, Photogrammetric Engineering and Remote Sensing 63, 853-858 (1997).

214. Z. Wan, Y. Zhang, X. Ma, M. D. King, J. S. Meyers and X. Li, Vicarious Calibration of the Moderate Resolution Imaging Spectroradiometer Airborne Simulator Thermal Infrared Channels, Appl. Opt. 38, 6294-6306 (1999).

215. P. N. Slater, P. M. Teillet and Y. Ding, "The Absolute Calibration of the Advanced Very High Resolution Radiometer", Semiannual Report, University of Arizona Optical Sciences Center, Tucson, AZ, 1988.

216. E. Villa-Aleman, R. J. Kureja and M. M. Pendergast, Assessment of Ivanpah Playa as a Site for Thermal Vicarious Calibration for the MTI Satellite, Proc. SPIE 5093, 331342 (2003).

217. S. F. Biggar, K. J. Thome and W. Wisniewski, Vicarious Radiometric Calibration of EO-1 Sensors by Reference to High-reflectance Ground Targets, IEEE Trans.

Geoscience and Remote Sensing 41, 1174-1179 (2003).

218. M. S. Moran, R. D. Jackson, T. R. Clarke, J. Qi, F. Cabot, K. J. Thome and B. Markham, Reflectance Factor Retrieval for Landsat TM and SPOT HRV Data for Bright and Dark Targets, Remote Sensing of the Environment 52, 218-230 (1995).

219. R. J. Parada, K. J. Thome and R. P. Santer, Results of Dark Target Vicarious Calibration Using Lake Tahoe, Europto, Proc. SPIE 2957, 332-343(1996). 220. S. J. Hook, G. Chander, J. A. Barsi, R. E. Alley, A. Abtahi, F. D. Palluconi, B. L. Markham, R. C. Richards, S. G. Schladow and D. L. Helder, In-flight Validation and Recovery of Water Surface Temperature with Landsat-5 Thermal Infrared Data Using an Automated High-Altitude Lake Validation Site at Lake Tahoe, IEEE Trans. Geoscience. and Remote Sensing 42, 2767-2776 (2004). 
221. R. Santer, X. F. Gu, G. Guyot, J. L. Deuze, C. Devaux, E. Vermote and M. Verbrugghe, SPOT Calibration at the LaCrau Test Site, Remote Sensing of the Environment 41, 227-237 (1992).

222. R. P. Santer, C. Six and J. P. Buis, Vicarious Calibration on Land Site Using Automatic Ground-based Optical Measurements: Application to SPOT-HRV, Proc. SPIE 4891, 524-534 (2003).

223. D. K. Clark, M. E. Feinholz, M. A. Yarbrough, B. C. Johnson, S. W. Brown, Y. S. Kim and R. A. Barnes, Overview of the Radiometric Calibration of MOBY, Proc. SPIE 4483, 64-76 (2001).

224. P. M. Teillet, G. Fedosejevs and R. P. Gauthier, Operational Radiometric Calibration of Broadscale Satellite Sensors Using Hyperspectral Airborne Remote Sensing of Prairie Rangeland, Metrologia 35, 639-641 (1998).

225. R. O. Green, B. E. Pavri and T. G. Chrien, On-orbit Radiometric and Spectral Calibration Characteristics of EO-1 Hyperion Derived With an Underflight of AVIRIS In Situ Measurements at Salar de Arizaro, Argentina, IEEE Trans. Geoscience and Remote Sensing 41, 1194-1203 (2003).

226. S. Campbell, J. L. Lovell, D. L. B. Jupp, R. D. Graetz, E. A. King, G. Byrne, P. S. Barry, P. Jarecke and J. Pearlman, The Lake Frome Field Campaign in Support of Hyperion Instrument Calibration and Validation, Proc. IGARSS, 2593-2595 (2001). 227. R. M. Mitchell, D. M. O'Brien, M. Edwards, C. C. Elsum and R. D. Graetz, Selection and Initial Characterization of a Bright Calibration Site in the Strzelecki Desert, South Australia, Can. J. Remote Sensing 23, 342-353 (1997).

228. B. Zak, K. Stamnes and K. Widener, "Site Scientific Mission Plan for the DOE/ARM North Slope of Alaska/Adjacent Arctic Ocean (NSA/AAO) Cloud and Radiation Testbed (CART)", U.S. Department of Energy, Office of Science, Office of Biological Research, ARM-00-002, 2000.

229. R. A. Peppler, D. L. Sisterson and P. Lamb, "Site Scientific Mission Plan for the Southern Great Plains CART Site, January-June 2000", U.S. Department of Energy, Office of Science, Office of Biological Research, ARM-00-006, 2000.

230. W. E. Clements, L. A. Jones, C. N. Long and T. P. Ackerman, "Tropical Western Pacific Site Scientific Mission Plan, July-December 2000", U.S. Department of Energy, Office of Science, Office of Biological Research, ARM-00-005, 2000.

231. F. J. Ponzoni, J. Zullo Jr., R. A. C. Lamparelli, G. Q. Pellegrino and Y. Arnaud, Inflight Absolute Calibration of the Landsat-5 TM on the Test Site Salar de Uyuni, IEEE Trans. Geosci. and Remote Sensing 42, 2761-2766 (2004).

232. A. J. Prata and R. P.Cechet, An Assessment of the Accuracy of Land Surface Temperature Determination from the GMS-5 VISSR, Remote Sensing of the Environment 67, 1-14 (1999).

233. A. J. Prata, I. F. Grant, R. P. Cechet and G. F. Rutter, Five Years of Shortwave Radiation Budget Measurements at a Continental Land Site in Southeastern Australia, $J$. Geophys. Res. Atmospheres 103, 26093-26106 (1998).

234. A. J. Prata, "Precipitable Water Retrieval from Multi-filter Rotating Shadowband Radiometer Measurements", CSIRO Atmospheric Research Technical Paper No. 47, 2000 . 
235. S. E. Black, D. L. Helder and S. J. Schiller, Irradiance-based Cross-calibration of Landsat-5 and Landsat-7 Thematic Mapper Sensors, Int. J. Remote Sensing 24, 287-304 (2003).

236. K. M. Havstad, W. P. Kustas, A. Rango, J. C. Ritchie and T. J. Schmugge, Jornada Experimental Range: A Unique Arid Land Location for Experiments to Validate Satellite Systems, Remote Sensing of the Environment 74,13-25 (2000).

237. T. Matsunaga, T. Nonaka, Y. Sawabe, M. Moriyama, H. Tonooka and H Fukasawa, "Cross and Vicarious Calibration Experiments for Terra ASTER and Landsat-7 ETM+ in the Thermal Infrared Region Using Hot Ground Targets", in Proceedings of the CEReS International Symposium on Remote Sensing of the Atmosphere and Validation of Satellite Data, Chiba, Japan, 2001, pp. 143-147.

238. M. Edwards and D. Llewellen-Jones, "The AATSR Validation Programme: An Overview", in Proc. of Envisat Validation Workshop, Frascati, Italy, December 9-13, 2003.

239. D. Wu, Y. Yin, Z. Wang, X. Gu, M. Verbrugghe and G. Guyot, "Radiometric Characterization of Dunhuang Satellite Calibration Test Site (China)", in Physical Measurements and Signatures in Remote Sensing. Rotterdam:Balkema, 1997, pp. 151160 .

240. S. F. Biggar, R. P. Santer and P. Slater, Irradiance-based Calibration of Imaging Sensors, Proc. IGARSS 1283-1285 (1990).

241. R. H. Evans and H. R. Gordon, Coastal Zone Color Scanner System Calibration-A Retrospective Examination, J. Geophys. Res. 99, 7293-7303 (1994).

242. D. K. Clark, H. R. Gordon, K. K. Voss, Y. Ge, W. Brokenow and C. Trees, Validation of Atmospheric Correction Over Oceans, J. Geophys. Res. 102, 209-217 (1997).

243. R. E. Eplee, W. D. Robinson, S. W. Bailey, D. K. Clark, P. J. Werdell, M. Wang, R. A. Barnes and C. R. McClain, Calibration of SeaWiFS. II. Vicarious Techniques, Appl. Opt. 40, 6701-6718 (2001).

244. R. A. Barnes, R. E. Eplee, Jr., G. M. Schmidt, F. S. Patt and C. R. McClain, The Calibration of SeaWiFS. I. Direct Techniques, Appl. Opt. 40, 6682-6700 (2000). 245. S. W. Brown, B. C. Johnson, M. E. Feinholz, M. A. Yarbrough, S. J. Flora, K. R. Lykke and D. C. Clark, Stray-light Correction in Spectrographs, Metrologia 40, S81-S84 (2003).

246. H. H. Kieffer and R. L. Wildey, Establishing the Moon as a Spectral Radiance Standard, J. Atmos. Oceanic Technol. 13, 360-375 (1996).

247. H. H. Kieffer and J. M. Anderson, Use of the Moon for Spacecraft Calibration Over 350-2500 nm, Proc. SPIE 3498, 325-336 (1998).

248. H. H. Kieffer, T. C. Stone, R. A. Barnes, S. Bender, R. E. Eplee, Jr., J. Mendenhall and L. Ong, On-orbit Radiometric Calibration Over Time and Between Spacecraft Using the Moon, Proc. SPIE 4881, 287-298 (2003).

249. H. H. Kieffer, Photometric Stability of the Lunar Surface, Icarus, 130, 323-327 (1997).

250. R. A. Barnes, R. E. Eplee, Jr., F. S. Patt, H. H. Kieffer, T. C. Stone, G. Meister, J. J. Butler and C. R. McClain, Comparison of SeaWiFS Measurements of the Moon With the U.S. Geological Survey Lunar Model, Appl. Opt. 43, 5838-5854 (2004). 
251. T. C. Stone and H. H. Kieffer, Assessment of Uncertainty in ROLO Lunar Irradiance for On-orbit Calibration, Proc. SPIE 5542, 300-310 (2004).

252. F. Palluconi, H. Tonooka, S. Hook, A. Abtahi, R. Alley, T. Thompson, G. Hoover and S. Zadourian, EOS ASTER Thermal Infrared Band Vicarious Calibration, Proc. SPIE 4540, 255-259 (2001).

253. J. J Butler and R. A.Barnes, The Use of Transfer Radiometers in Validating the Visible to Shortwave Infrared Calibrations of Radiance Sources Used by Instruments in NASA's Earth Observing System, Metrologia 40, S70-S77 (2003). 254. S. W. Brown, B. C. Johnson, H. W. Yoon, J. J. Butler, S. Biggar, P. Spyak, K. Thome, E. Zalewski, M. Helmlinger, C. Bruegge, S. Schiller, G. Fedosejevs, R. Gauthier, S. Tsuchida and S. Machida, Radiometric Comparison of Field Radiometers in Support of the 1997 Lunar Lake Nevada Experiment to Determine Surface Reflectance and Topof-atmosphere Radiance, Remote Sensing of the Environment 77, 257-376 (1997). 255. R. Kannenberg, IR Instrument Comparison Workshop at the Rosenstiel School of Marine and Atmospheric Science (RSMAS), The Earth Observer 10, 51-54 (1998). 256. J. P. Rice, J. J. Butler, B. C. Johnson, P. J. Minnett, T. J. Nightingale, S. J. Hook, A. Abtahi, C. J. Donlon and I. J. Barton, The Miami 2001 Infrared Radiometer Calibration and Intercomparison: 1. Laboratory Characterization of Blackbody Targets, J. Atmos. and Oceanic Technol. 21, 268-283 (2004).

257. I. J. Barton, P. J. Minnett, K. A. Maillet, C. J. Donlon, S. J. Hook, A. T. Jessup and T. J. Nightingale, The Miami 2001 Infrared Radiometer Calibration and Intercomparison: 2. Ship-board Results, J. Atmos. and Oceanic Technol. 21, 258-267 (2004). 258. P. Teillet, G. Fedosejevs and K. J. Thome, Spectral Band Diference Effects on Radiometric Cross-calibration Between Multiple Satellite Sensors in the Landsat Solarreflective Spectral Domain, Proc. SPIE 5570, 307-316 (2004).

259. C. Cao and M. Weinreb, Predicting Simultaneous Nadir Overpasses among Polarorbiting Satellites for the Intersatellite Calibration of Radiometers, J. Atmos. Oceanic Technol. 21, 537-542 (2004).

260. C. Cao and A. Heidinger, Inter-comparison of the Longwave Infrared Channels of MODIS and AVHRR/NOAA-16 Using Simultaneous Nadir Observations at Orbit Intersections, Proc. SPIE 4814, 306-316 (2002).

261. J. Nieke, T. Aoki, T. Tanikawa, H. Motoyoshi, M. Hori and Y.Nakajima, Crosscalibration of Satellite Sensors Over Snow Fields, Proc. SPIE 5151, 406-414 (2003). 262. D. R. Doelling, L. Nguyen and P. Minnis, On the Use of Deep Convective Clouds to Calibrate AVHRR Data, Proc. SPIE 5542, 281-289 (2004).

263. A. K. Heidinger, C. Cao and J. Sullivan, Using Moderate Resolution Imaging spectroradiometer (MODIS) to Calibrate Advanced Very High Resolution Radiometer Reflectance Channels, J. Geophys. Res. 107, 11-1-10 (2002).

264. F. Cabot, O. Hagolle, C. Ruffel and P.Henry, Use of a Remote Sensing Data Repository for In-flight Calibration of Optical Sensors over Terrestrial Targets, Proc. SPIE 3750, 514-523 (1999).

265. C. R. N. Rao, C. Cao and N. Zhang, Inter-calibration of the Moderate Resolution Imaging Spectroradiometer and the Along Track Scanning Radiometer-2, Int. J. Remote Sensing 24, 1913-1924 (2003).

266. P. Minnis, L. Nguyen, D. R. Doelling, D. F. Young, W. F. Miller and D. P. Kratz, Rapid Calibration of Operational and Research Meteorological Satellite Imagers. Part I: 
Evaluation of Research Satellite Visible Channels as References, J. Atmos. Oceanic Technol. 19, 1233-1249 (2002).

267. L. Nguyen, D. R. Doelling, P. Minnis and J. K. Ayers, Rapid Technique to Crosscalibrate Satellite Imager Visible Channels, Proc. SPIE 5542, 227-235 (2004).

268. P. Minnis, L. Nguyen, D. R. Doelling, D.F. Young, W.F. Miller and D.P. Kratz, Rapid Calibration of Operational and Research Meteorological Satellite Imagers. Part II: Comparison of Infrared Channels, J. Atmos. Oceanic Technol. 19, 1250-1266 (2002). 269. P. M. Teillet, J. L. Barker, B. L. Markham, R. R. Irish, G. Fedosejevs and J. C. Storey, Radiometric Cross-calibration of the Landsat-7 ETM+ and Landsat-5 TM Sensors Based on Tandem Data Sets, Remote Sensing of the Environment 78, 39-54 (2001). 270. "Strategic Plan for the U.S. Climate Change Science Program, Climate Change Science Program and Subcommittee on Global Change Research, Washington, D.C., 2003.

271. G. P. Eppledauer, S. W. Brown, T. C. Larason, M. Racz and K. R. Lykke, Realization of a Spectral Radiance Responsivity Scale with a Laser-based Source and $\mathrm{Si}$ Radiance Meters, Metrologia 37, 531-534 (2000).

272. S. W. Brown, B. C. Johnson, S. J. Flora, M. E. Feinholz, R. A. Barnes, Y. S. Kim, K. R. Lykke and D. K. Clark, Stray Light Correction of the Marine Optical Buoy, in "Ocean Optics Protocols for Satellite Ocean Color Validation, Rev. 4, Vol VI: Special Topics in Ocean Optics Protocols and Appendices", NASA TM-2003-211621/Rev. 4Vol. VI, Greenbelt, MD, 2003, pp. 87-124.

273. D. Lizius, Absolute Radiometric Measurements in Space, ORM News 2, 5 (1996). 274. J. Nieke, M. Solbrig, K. H. Sumnich, G. Zimmermann and H. P. Roser, Spaceborne Spectrometer Calibration with LEDs, Proc. SPIE 4135, 384-394 (2000).

275. E.C. Wack and J. E. Baum, Radiometric Error in GOES 8 Imager Data Due to Sensor MTF, Proc. SPIE 3439, 155-154 (1998).

276. S. Qiu, G. Godden, X. Wang and B. Guenther, Satellite-earth Remote Sensor Scatter Effects on Earth Scene Radiometric Accuracy, Metrologia 37, 411-414 (2000).

277. J. L. Mueller, "The First SeaWiFS Intercalibration Round-robin Experiment, SIRREX-1, July 1992”, NASA Tech. Memo 104566, Vol. 14, S.B. Hooker and E.R. Firestone, Eds., NASA Goddard Space Flight Center, Greenbelt, MD.

278. J. L. Mueller, B. C. Johnson, C. L. Cromer, J. W. Cooper, J.T. McLean, S.B. Hooker and T.L. Wesphal, "The Second SeaWiFS Intercalibration Round-robin Experiment, SIRREX-2, June 1993”, NASA Tech. Memo 104566, Vol. 16, S.B. Hooker and E.R. Firestone, Eds., NASA Goddard Space Flight Center, Greenbelt, MD.

279. J. L. Mueller, B. C. Johnson, C. L. Cromer, S. B. Hooker, J. T. McLean and S. F. Biggar, "The Third SeaWiFS Intercalibration Round-robin Experiment, SIRREX-3, September 1994", NASA Tech. Memo 104566, Vol. 34, S.B. Hooker, E.R. Firestone and J.G. Acker, Eds., NASA Goddard Space Flight Center, Greenbelt, MD.

280. B. C. Johnson, H. W. Yoon, S. S. Bruce, P. S. Shaw, A. E. Thompson, S. B. Hooker, R. A. Barnes, R. Eplee, S. Maritorena, and J. L. Muller, "The Fifth SeaWiFS Intercalibration Round-robin Experiment (SIRREX-5) July 1996", NASA Tech. Memo 1999-206892, Vol. 7, S.B. Hooker and E.R. Firestone, Eds., NASA Goddard Space Flight Center, Greenbelt, MD.

281. T. Riley and S. Bailey, "The Sixth SeaWiFS Intercalibration Round-robin Experiment (SIRREX-6) August-December 1997”, NASA Tech. Memo 1998-206878, 
Vol. x, S.B. Hooker and E.R. Firestone, Eds., NASA Goddard Space Flight Center, Greenbelt, MD.

282. S. B. Hooker, S. McLean, J. Sherman, M. Small, G. Lazin, G. Zibordi and J. W. Brown, "The Seventh SeaWiFS Intercalibration Round-robin Experiment (SIRREX-7) March 1999", NASA Tech. Memo 1998-206878, Vol. 17, S.B. Hooker and E.R.

Firestone, Eds., NASA Goddard Space Flight Center, Greenbelt, MD. 283. G. Zibordi, D. D'Alimonte, D. W. van der Linde, J. F. Berthon, S. Hooker, J. L. Mueller and G. Lazin, "The Eighth SeaWiFS Intercalibration Round-robin Experiment (SIRREX-8) September-December 2001", NASA Tech. Memo 2002-206892, Vol. 21, S. B. Hooker and E. R. Firestone, Eds., NASA Goddard Space Flight Center, Greenbelt, MD.

284. J. L. Mueller and R. W. Austin, "Ocean Optics Protocols for SeaWiFS Validation", NASA Tech. Memo 104566, Vol. 5; S.B. Hooker and E.R. Firestone, Eds., NASA Goddard Space Flight Center, Greenbelt, MD. 
Feb 212005

Table 10.1. Accuracies and Stabilities of Satellite Instrument Measurements

Required for the Determination of Listed Earth Geophysical Parameters

\begin{tabular}{|c|c|c|c|}
\hline $\begin{array}{l}\text { Geophysical } \\
\text { Parameters }\end{array}$ & $\begin{array}{c}\text { Satellite Instrument } \\
\text { Type }\end{array}$ & Accuracy & Stability Per Decade \\
\hline Solar Irradiance & Broadband Radiometer & $1.5 \mathrm{~W} / \mathrm{m}^{2}$ & $0.3 \mathrm{~W} / \mathrm{m}^{2}$ \\
\hline Surface Albedo & Visible Radiometer & $5 \%$ & $1 \%$ \\
\hline $\begin{array}{l}\text { Net Solar Radiation: } \\
\text { Top of Atmosphere }\end{array}$ & Broadband Radiometer & $1 \mathrm{~W} / \mathrm{m}^{2}$ & $0.3 \mathrm{~W} / \mathrm{m}^{2}$ \\
\hline $\begin{array}{l}\text { Spectral Thermal } \\
\text { Radiance }\end{array}$ & $\begin{array}{l}\text { Infrared } \\
\text { Spectroradiometer }\end{array}$ & $0.1 \mathrm{~K}$ & $0.04 \mathrm{~K}$ \\
\hline Cloud Base Height & $\begin{array}{l}\text { Visible/Infrared } \\
\text { Radiometer }\end{array}$ & $1 \mathrm{~K}$ & $0.2 \mathrm{~K}$ \\
\hline $\begin{array}{l}\text { Cloud Effective } \\
\text { Particle Size } \\
\text { Distribution }\end{array}$ & $\begin{array}{l}\text { Visible/Infrared } \\
\text { Radiometer }\end{array}$ & $\begin{array}{l}3.7 \mu \mathrm{m}: \text { Water, } 5 \% \\
\text { Ice, } 10 \% \\
1.6 \mu \mathrm{m}: \text { Water, } 2.5 \% \\
\text { Ice, } 5 \%\end{array}$ & $\begin{array}{l}3.7 \mu \mathrm{m}: \text { Water, } 1 \% \\
\text { Ice, } 2 \% \\
1.6 \mu \mathrm{m}: \text { Water, } 0.5 \% \\
\text { Ice, } 1 \%\end{array}$ \\
\hline $\begin{array}{l}\text { Cloud Optical } \\
\text { Thickness }\end{array}$ & Visible Radiometer & $5 \%$ & $1 \%$ \\
\hline $\begin{array}{l}\text { Cloud Top Height, } \\
\text { Pressure and } \\
\text { Temperature }\end{array}$ & Infrared Radiometer & $1 \mathrm{~K}$ & $0.2 \mathrm{~K}$ \\
\hline $\begin{array}{l}\text { Tropospheric } \\
\text { Temperature }\end{array}$ & Infrared Radiometer & $0.5 \mathrm{~K}$ & $0.04 \mathrm{~K}$ \\
\hline $\begin{array}{l}\text { Stratospheric } \\
\text { Temperature }\end{array}$ & Infrared Radiometer & $1 \mathrm{~K}$ & $0.08 \mathrm{~K}$ \\
\hline Water Vapor & Infrared Radiometer & $1 \mathrm{~K}$ & $0.03 \mathrm{~K}$ \\
\hline Total Column Ozone & $\begin{array}{l}\text { Ultraviolet/Visible } \\
\text { Spectrometer }\end{array}$ & $\begin{array}{l}2 \% \text { (spectrally } \\
\text { dependent) } \\
1 \% \text { (spectrally } \\
\text { independent) }\end{array}$ & $0.2 \%$ \\
\hline Stratospheric Ozone & $\begin{array}{l}\text { Ultraviolet/Visible } \\
\text { Spectrometer }\end{array}$ & $3 \%$ & $0.6 \%$ \\
\hline Tropospheric Ozone & $\begin{array}{l}\text { Ultraviolet/Visible } \\
\text { Spectrometer }\end{array}$ & $3 \%$ & $0.1 \%$ \\
\hline Aerosols & $\begin{array}{l}\text { Visible } \\
\text { Radiometer/Polarimeter }\end{array}$ & $\begin{array}{l}\text { Radiometric: } 3 \% \\
\text { Polarimetric: } 0.5 \%\end{array}$ & $\begin{array}{l}\text { Radiometric: } 1 \% \\
\text { Polarimetric: } 0.25 \%\end{array}$ \\
\hline Carbon Dioxide & Infrared Radiometer & $3 \%$ & $\begin{array}{l}\text { Forcing: } 1 \% ; \\
\text { Sources/sinks: } 0.25 \%\end{array}$ \\
\hline Ocean Color & Visible Radiometer & $5 \%$ & $1 \%$ \\
\hline $\begin{array}{l}\text { Sea Surface } \\
\text { Temperature }\end{array}$ & Infrared Radiometer & $0.1 \mathrm{~K}$ & $0.01 \mathrm{~K}$ \\
\hline Sea Ice Area & Visible Radiometer & $12 \%$ & $10 \%$ \\
\hline Snow Cover & Visible Radiometer & $12 \%$ & $10 \%$ \\
\hline Vegetation & Visible Radiometer & $2 \%$ & $0.8 \%$ \\
\hline
\end{tabular}


Feb 212005

Table 10.2. Satellite Instrument Characterization Parameters

\begin{tabular}{|c|c|c|}
\hline Radiometric & Spectral & Spatial \\
\hline Dynamic Range & $\begin{array}{l}\text { Spectral Responsivity } \\
\cdot \text { within band } \\
\text {. out-of-band }\end{array}$ & $\begin{array}{l}\text { Pointing } \\
\cdot \text { accuracy } \\
\cdot \text { knowledge } \\
\end{array}$ \\
\hline Linearity & $\begin{array}{l}\text { Wavelength Stability } \\
\cdot \text { within band } \\
\cdot \text { band-to-band }\end{array}$ & $\begin{array}{l}\text { Spectral Band Registration } \\
\text { - within band } \\
\text { - band-to-band }\end{array}$ \\
\hline Signal to Noise & $\begin{array}{l}\text { Wavelength Accuracy and } \\
\text { Precision }\end{array}$ & $\begin{array}{l}\text { Spatial Responsivity } \\
\cdot \text { within field } \\
\cdot \text { out-of-field } \\
\end{array}$ \\
\hline $\begin{array}{l}\text { Stability } \\
\cdot \text { short-term } \\
\cdot \text { long-term } \\
\end{array}$ & & $\begin{array}{l}\text { Spatial Response Uniformity } \\
\cdot \text { within field } \\
\text {. out-of-field } \\
\end{array}$ \\
\hline $\begin{array}{l}\text { Crosstalk } \\
\cdot \text { optical } \\
\cdot \text { electrical } \\
\end{array}$ & & Modulation Transfer Function \\
\hline Polarization Responsivity & & \\
\hline
\end{tabular}


Table 10.3. Total Solar Irradiance (TSI) Satellite Instruments and Associated Data Records: 1978 to Present

\begin{tabular}{|l|l|c|}
\hline \multicolumn{1}{|c|}{ TSI Instrument } & \multicolumn{1}{|c|}{ Satellite/Platform } & $\begin{array}{c}\text { TSI Data Record } \\
\text { (mm/dd/yy or mm/yy) }\end{array}$ \\
\hline $\begin{array}{l}\text { Earth Radiation Budget (ERB) } \\
\text { Experiment }\end{array}$ & Nimbus-7 & $11 / 16 / 78$ to $12 / 13 / 93$ \\
\hline $\begin{array}{l}\text { Active Cavity Radiometer } \\
\text { Irradiance Monitor I (ACRIM } \\
\text { I) }\end{array}$ & Solar Maximum Mission (SMM) & $2 / 16 / 80$ to $61 / 89$ \\
\hline $\begin{array}{l}\text { Earth Radiation Budget } \\
\text { Experiment (ERBE) }\end{array}$ & $\begin{array}{l}\text { Earth Radiation Budget Satellite } \\
\text { (ERBS) }\end{array}$ & $10 / 25 / 84$ to present \\
\hline $\begin{array}{l}\text { Earth Radiation Budget } \\
\text { Experiment (ERBE) }\end{array}$ & $\begin{array}{l}\text { National Oceanic and } \\
\text { Atmospheric Administration-9 } \\
\text { (NOAA-9) }\end{array}$ & $1 / 23 / 85$ to $12 / 20 / 89$ \\
\hline $\begin{array}{l}\text { Earth Radiation Budget } \\
\text { Experiment (ERBE) }\end{array}$ & $\begin{array}{l}\text { National Oceanic and } \\
\text { Atmospheric Administration-10 } \\
\text { (NOAA-10) }\end{array}$ & $10 / 22 / 86$ to $12 / 1 / 87$ \\
\hline $\begin{array}{l}\text { Active Cavity Radiometer } \\
\text { Irradiance Monitor II (ACRIM } \\
\text { II) }\end{array}$ & $\begin{array}{l}\text { Upper Atmospheric Research } \\
\text { Satellite (UARS) }\end{array}$ & $10 / 5 / 91$ to $8 / 01$ \\
\hline $\begin{array}{l}\text { Solar Variability experiment 2 } \\
\text { (SOVA) }\end{array}$ & $\begin{array}{l}\text { European Retrievable Carrier } \\
\text { (EURECA) }\end{array}$ & $8 / 7 / 92$ to $6 / 93$ \\
\hline Solar Constant (SOLCON) & ATLAS and Hitchhiker & $3 / 24 / 92$ to present \\
\hline $\begin{array}{l}\text { Variability of solar Irradiance } \\
\text { and Gravity Oscillations } \\
\text { (VIRGO) }\end{array}$ & $\begin{array}{l}\text { Solar and Heliospheric } \\
\text { Observatory (SOHO) }\end{array}$ & $12 / 2 / 95$ to present \\
\hline $\begin{array}{l}\text { Active Cavity Radiometer } \\
\text { Irradiance Monitor III } \\
\text { (ACRIM III) }\end{array}$ & $\begin{array}{l}\text { Active Cavity Radiometer } \\
\text { Irradiance Monitor Satellite } \\
\text { (ACRIMSAT) }\end{array}$ & $4 / 5 / 00$ to present \\
\hline $\begin{array}{l}\text { Total Irradiance Monitor } \\
\text { (TIM) }\end{array}$ & $\begin{array}{l}\text { Solar Radiation and Climate } \\
\text { Experiment (SORCE) }\end{array}$ & $2 / 25 / 03$ to present \\
\hline
\end{tabular}

Table 10.4. Four representative solar irradiance spectra

\begin{tabular}{|l|l|l|}
\hline $\begin{array}{c}\text { Solar Irradiance } \\
\text { Spectrum, Year and } \\
\text { Reference }\end{array}$ & \multicolumn{1}{|c|}{$\begin{array}{c}\text { Wavelength Range } \\
(\boldsymbol{\mu m})\end{array}$} & \multicolumn{1}{|c|}{ Spectrum Type } \\
\hline Thekaekara, 1974 [109] & $0.115-400$ & Compilation (measurements) \\
\hline Wehrli, 1985[11] & $0.2-20$ & Compilation (measurements \\
\hline Colina et al., 1996[117] & $0.12-2.5$ & $\begin{array}{l}\text { Compilation (measurements plus } \\
\text { computations) }\end{array}$ \\
\hline Thuillier et al., $2003[124]$ & $0.2-2.4$ & Measurements \\
\hline
\end{tabular}


Feb 212005

Table 10.5. Solar Diffuser Materials and Coatings

\begin{tabular}{|c|c|c|c|}
\hline Diffuser & Type & Satellite Instrument & Reference \\
\hline $\begin{array}{l}\text { Space-grade } \\
\text { Spectralon }\end{array}$ & Reflective & $\begin{array}{l}\text { Moderate Resolution Imaging } \\
\text { Spectroradiometer Terra and Aqua } \\
\text { (MODIS Terra and Aqua) } \\
\text { Multi-angle Imaging SpectroRadiometer } \\
\text { (MISR) } \\
\text { Medium Resolution Imaging } \\
\text { Spectrometer (MERIS) } \\
\text { Advanced Land Imager (ALI) } \\
\text { Modular Optoelectronic Scanner (MOS) } \\
\text { Global Imager (GLI) }\end{array}$ & $\begin{array}{l}139 \\
140 \\
141 \\
\end{array}$ \\
\hline $\begin{array}{l}\text { Roughened } \\
\text { aluminum }\end{array}$ & Reflective & $\begin{array}{l}\text { Total Ozone Mapping Spectrometer } \\
\text { (TOMS) } \\
\text { Global Ozone Monitoring Experiment } 1 \\
\text { and } 2 \text { (GOME 1 \& GOME 2) } \\
\text { Solar Backscatter Ultraviolet and Solar } \\
\text { Backscatter Ultraviolet/2 (SBUV \& } \\
\text { SBUV/2) } \\
\text { Ozone Monitoring Instrument (OMI) } \\
\text { Scanning Imaging Absorption } \\
\text { Spectrometer for Atmospheric } \\
\text { Cartography (SCIAMACHY) }\end{array}$ & $\begin{array}{l}142 \\
143,144 \\
9 \\
145,146 \\
147\end{array}$ \\
\hline YB71 paint & Reflective & $\begin{array}{l}\text { Landsat Enhanced Thematic Mapper Plus } \\
\text { (ETM+) } \\
\text { Sea viewing Wide Field of View Sensor } \\
\text { (SeaWiFS) } \\
\text { Visible and Infrared Scanner (VIRS) } \\
\text { Hyperion }\end{array}$ & $\begin{array}{l}148,149 \\
150 \\
151 \\
152 \\
\end{array}$ \\
\hline $\begin{array}{l}\text { Quartz plate volume } \\
\text { diffuser }\end{array}$ & Reflective & Ozone Monitoring Instrument (OMI) & 145,146 \\
\hline Quartz diffuser & Transmissive & Ozone Monitoring Instrument (OMI) & 147,148 \\
\hline $\begin{array}{l}\text { Mirror Aperture } \\
\text { Mosaic }\end{array}$ & Reflective & $\begin{array}{l}\text { Clouds and the Earth's Radiant Energy } \\
\text { System (CERES) }\end{array}$ & 153,154 \\
\hline Perforated Plate & Transmissive & & 155 \\
\hline
\end{tabular}


Table 10.6. On-board Blackbody Designs for Several Remote Sensing Instruments

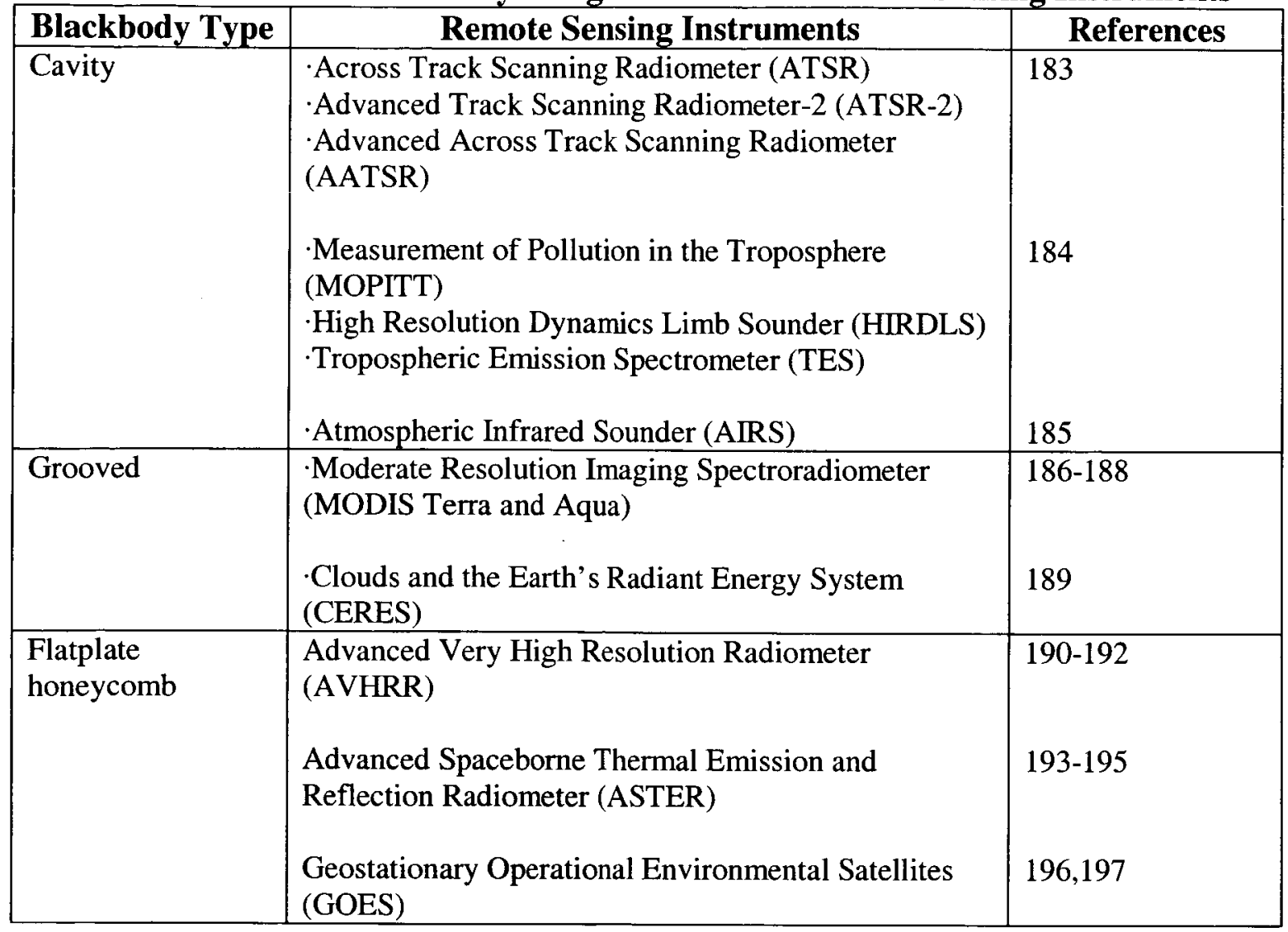


Table 10.7. Sites Used in the Vicarious Calibration of Earth Remote Sensing Instruments

\begin{tabular}{|l|l|l|l|}
\hline \multicolumn{1}{|c|}{ Site } & Site Type & \multicolumn{1}{|c|}{$\begin{array}{l}\text { Vicarious Calibration } \\
\text { Wavelength Region(s) }\end{array}$} & \multicolumn{1}{|c|}{ Reference(s) } \\
\hline Lunar Lake, Nevada & Land & Vis/NIR/SWIR & 208 \\
\hline Railroad Valley, Nevada & Land, Water & Vis/NIR/SWIR/TIR & $209-212$ \\
\hline White Sands, New Mexico & Land & Vis/NIR/SWIR/TIR & 213,214 \\
\hline Edwards AFB, California & Land & Vis/NIR/SWIR/TIR & 215 \\
\hline Ivanpah Playa, California & Land & Vis/NIR/SWIR/TIR & 216,217 \\
\hline $\begin{array}{l}\text { Maricopa Agricultural } \\
\text { Center, Arizona }\end{array}$ & Land & Vis/NIR/SWIR & 218 \\
\hline Lake Tahoe, California & Water & Vis/NIR/SWIR/TIR & 219,220 \\
\hline La Crau, France & Land & Vis/NIR/SWIR & 221,222 \\
\hline $\begin{array}{l}\text { Marine Optical Buoy } \\
\text { Network, Hawaii }\end{array}$ & Water & Vis/NIR & 223 \\
\hline $\begin{array}{l}\text { Newell County Rangeland, } \\
\text { Canada }\end{array}$ & Land & Vis/NIR/SWIR & 224 \\
\hline Barreal Blanco, Argentina & Land & Vis/NIR/SWIR & 217 \\
\hline Salar de Arizaro, Argentina & Land & Vis/NIR/SWIR & 225 \\
\hline $\begin{array}{l}\text { Pima County Fairgrounds, } \\
\text { Arizona }\end{array}$ & Land & Vis/NIR/SWIR & 217 \\
\hline Lake Frome, Australia & Land & Vis/NIR/SWIR & 226 \\
\hline Strzelecki Desert, Australia & Land & Vis/NIR/SWIR & 227 \\
\hline $\begin{array}{l}\text { North Slope ARM Site, } \\
\text { Alaska }\end{array}$ & Land & Vis/NIR/SWIR/TIR & 228 \\
\hline $\begin{array}{l}\text { Southern Great Plains ARM } \\
\text { Site, Oklahoma }\end{array}$ & Land & Vis/NIR/SWIR/TIR & 229 \\
\hline $\begin{array}{l}\text { Tropical Western Pacific } \\
\text { ARM Site }\end{array}$ & Water/Land & Vis/NIR/SWIR/TIR & 230 \\
\hline Salar de Uyuni, Bolivia & Water/Land & Vis/NIR/SWIR & 231 \\
\hline Uardry, Australia & Land & Vis/NIR/SWIR/TIR & 232 \\
\hline Amburla, Australia & Land & Vis/NIR/SWIR/TIR & 232,233 \\
\hline Thangoo, Australia & Water/Land & Vis/NIR/SWIR/TIR & 234 \\
\hline Niobrara, Nebraska & Land & Vis/NIR/SWIR/TIR & 235 \\
\hline Jornada, New Mexico & Land & Vis/NIR/SWIR/TIR & 236 \\
\hline Salton Sea, California & Water/Land & Vis/NIR/SWIR/TIR & 237 \\
\hline $\begin{array}{l}\text { Townsville-Kelso Reef, } \\
\text { Australia }\end{array}$ & Water & TIR & 238 \\
\hline $\begin{array}{l}\text { Perth-Rottnest Island, } \\
\text { Australia }\end{array}$ & Water & TIR & 238 \\
\hline Dunghuang, China & Land & Vis/NIR/SWIR/TIR & 239 \\
\hline
\end{tabular}




\section{Figure captions}

FIG. 10.1. Spectral solar irradiance as a function of wavelength at the top of the Earth's atmosphere (i.e. extraterrestrial) and at an altitude of $2 \mathrm{~km}$ looking through the Earth's atmosphere. A Planck curve for a $5870 \mathrm{~K}$ blackbody, the approximate color temperature of the Sun, is also shown for comparison. The Planck curve is normalized to the irradiance data at $650 \mathrm{~nm}$.

FIG. 10.2. The Earth's energy balance (Kiehl and Trenberth [5]). The left side of the figure depicts the shortwave (i.e. ultraviolet through shortwave infrared) albedo of the Earth, or that fraction of the incident total solar irradiance reflected by the Earth, while the right side depicts longwave emitted processes. The incoming solar radiation of 342 $\mathrm{W} / \mathrm{m}^{2}$ is equal to a solar constant of $1368 \mathrm{~W} / \mathrm{m}^{2}$ divided by a factor of 4 , taking into account the total surface area of an assumed spherical Earth (i.e. $4 \pi r^{2}$ versus $\pi r^{2}$ ). (Figure reproduced with the permission of the American Meteorological Society and the authors.)

FIG. 10.3. Satellite instrument measurements of Total Solar Irradiance (TSI) since 1978. The frequency of sunspots is also plotted in the figure, showing the strong correlation between solar activity and TSI. (Figure courtesy of the Laboratory of Atmospheric and Space Physics (LASP), University of Colorado.) 


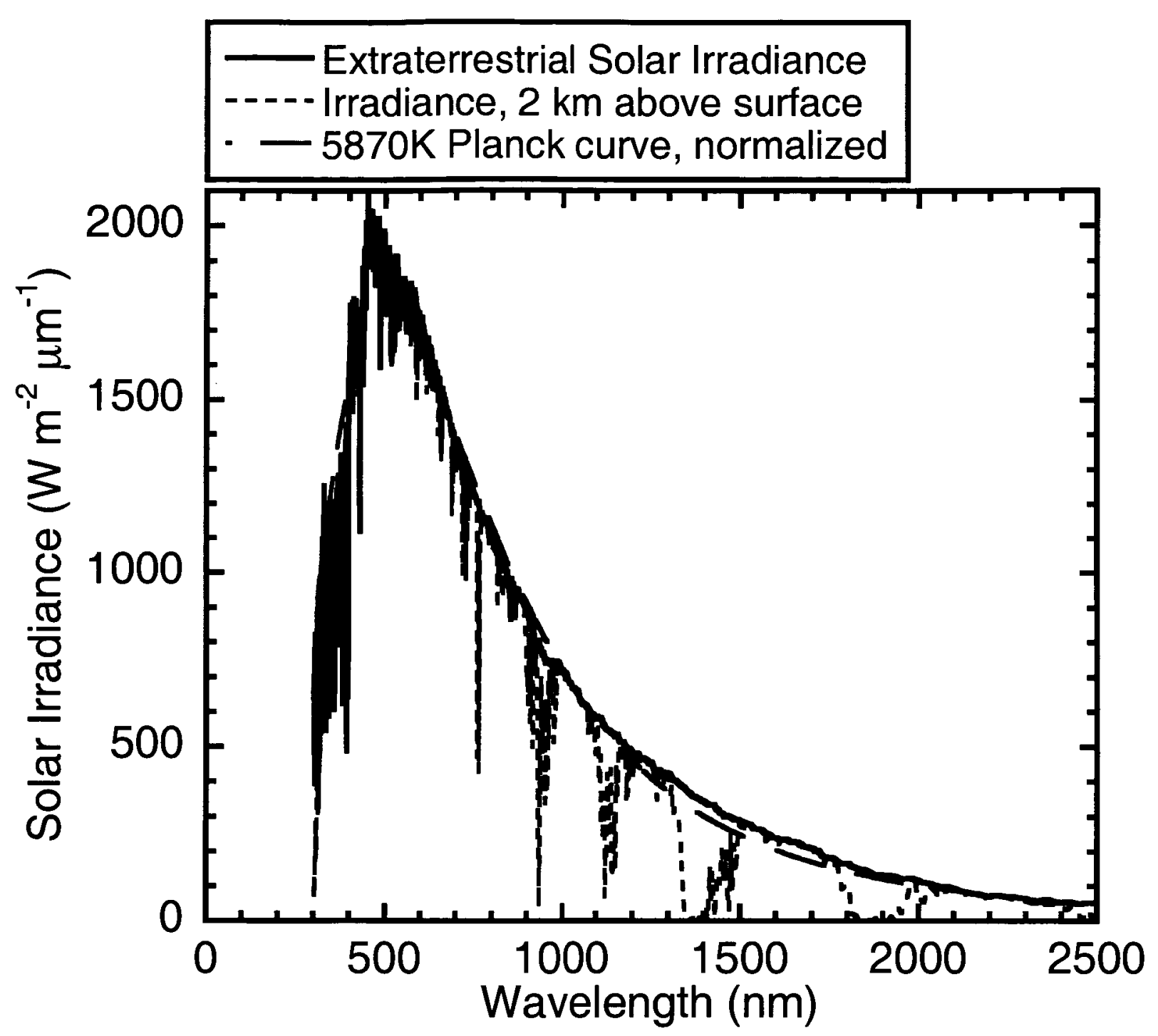

Figure 10.1 


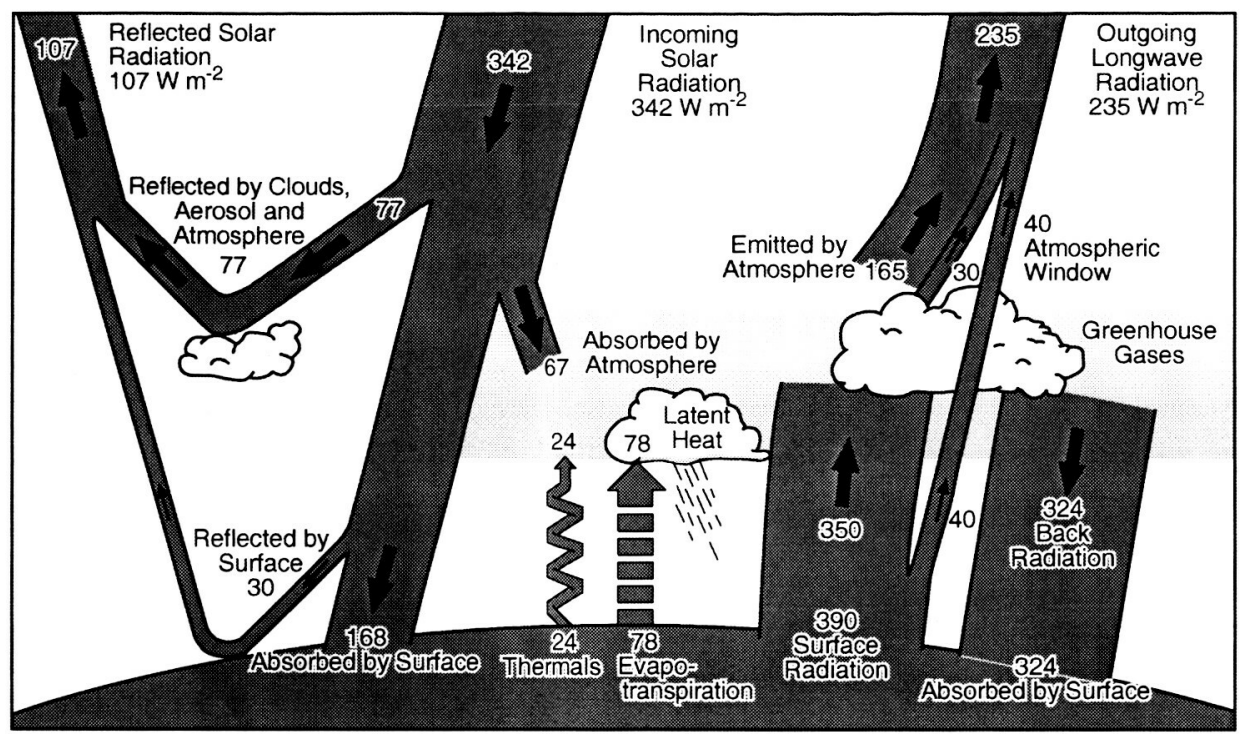

1775-fig 2, 8/95, wg

Figure 10.2 


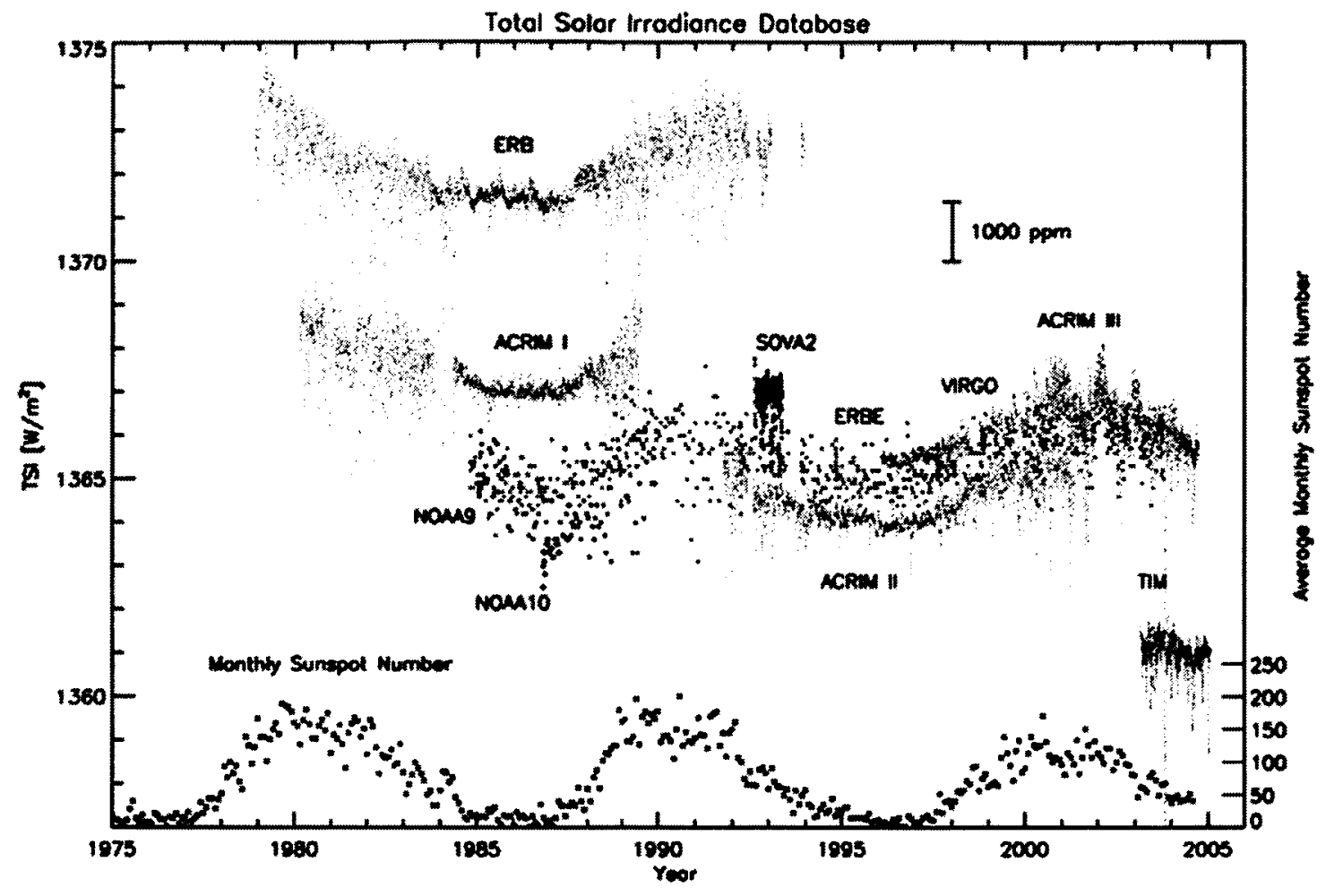

Figure 10.3 


\section{Summary:}

The ability to monitor, understand, and predict short and long term climate and environmental processes is fundamentally related to the quality of the data produced by the remote sensing instruments used to measure those processes. Key to the production of high quality remote sensing data are the careful calibration and characterization of the remote sensing instruments both pre-launch and on-orbit. Calibration can be defined as the process of quantitatively defining an instrument's system response to known, controlled inputs. Characterization can be defined as the set of operations or processes used to quantitatively understand the operation of an instrument. Chapter 10 titled "The Calibration and Characterization of Earth Remote Sensing and Environmental Monitoring Instruments," in the book, The Practice of Optical Radiometry describes current, established approaches in the pre-launch and on-orbit radiometric calibration and spectral characterization of fundamental measurements made by Earth remote sensing and environmental monitoring instruments. Brief descriptions of innovative and state of the art approaches to calibration and characterization are also provided. The examples are confined to optical measurements made in the air ultraviolet through thermal infrared wavelength regions from $190 \mathrm{~nm}$ to $100 \mu \mathrm{m}$. The chapter concludes by identifying a number of challenging areas in the Earth remote sensing field. 